DANILO STEFANI ESPOSTO

\title{
A INFLUÊNCIA DA MASTECTOMIA UNILATERAL NA FUNÇÃO DO SISTEMA ESTOMATOGNÁTICO E NA POSTURA CORPORAL
}

\author{
Versão Corrigida
}

Dissertação apresentada à Faculdade de Medicina de Ribeirão Preto da Universidade de São Paulo para obtenção do título de Mestre em Ciências

Área de Concentração: Fisioterapia

Orientadora: Profa. Dra. Simone Cecilio Hallak Regalo

RIBEIRÃO PRETO 
Autorizo a reprodução e divulgação total ou parcial deste trabalho, por qualquer meio convencional ou eletrônico, para fins de estudo e pesquisa, desde que citada a fonte.

Esposto, Danilo Stefani

A influência da mastectomia unilateral na função do sistema estomatognático e na postura corporal. Ribeirão Preto, 2017. 113 p. : il. ; $30 \mathrm{~cm}$

Dissertação de Mestrado, apresentada à Faculdade de Medicina de Ribeirão Preto da Universidade de São Paulo. Área de concentração: Fisioterapia.

Orientadora: Regalo, Simone Cecilio Hallak.

1. Mastectomia. 2. Músculos da Mastigação. 3. Eletromiografia. 4. Ultrassonografia. 5. Força de Mordida. 6. Postura. 
Nome: ESPOSTO, Danilo Stefani.

Título: A influência da mastectomia unilateral na função do sistema estomatognático e na postura corporal.

Dissertação apresentada à Faculdade de Medicina de Ribeirão Preto da Universidade de São Paulo para obtenção do título de Mestre em Ciências.

Aprovado em:

BANCA EXAMINADORA

Prof.(a) Dr.(a) Instituição:

Julgamento: Assinatura:

Prof.(a) Dr.(a) Instituição:

Julgamento: Assinatura:

Prof.(a) Dr.(a) Instituição:

Julgamento: Assinatura: 

Aos meus pais, Paulo Henrique Esposto e Sandra Helena Stefani Esposto, com gratidão, por proporcionarem todo o carinho e apoio necessário para a execução deste trabalho e tornar este momento realidade.

À Letícia Moraes Souza, com amor, pelo incentivo, paciência e compreensão durante este todo este percurso.

A todas as mulheres que lutam diariamente contra o câncer de mama, em especial à minha tia Maria de Lourdes Silva Esposto (in memoriam), à qual tive a oportunidade de acompanhar de perto as dificuldades e, sobretudo, os momentos de fé, esperança e alegria! 



\section{AGRADECIMENTOS}

A Deus, por conduzir os meus caminhos, momentos, e proporcionar minhas melhores escolhas. Por estar sempre presente em Sua profunda quietude, guiando meus passos e colocando todas essas excelentes pessoas no percurso, às quais tenho o imenso prazer em agradecer...

Aos meus pais, Paulo Henrique Esposto e Sandra Helena Stefani Esposto, pelo amor incondicional e por nunca medirem esforços para me proporcionar o melhor, em especial a educação em todas as suas formas. Obrigado por me apoiarem em todas as decisões, independentemente de quais fossem, por me incentivarem a seguir sempre em frente e jamais desistir.

À Letícia Moraes Souza, meu amor, por incentivar o início desta etapa e estar presente em todos os momentos. Obrigado por compreender os meus períodos de ausência, proporcionar a tranquilidade nas dificuldades, torcer junto, comemorar as conquistas e me ajudar a fazer acontecer.

Ao meu irmão, Bruno Stefani Esposto, pelo convívio, apoio e compreensão, por muitas vezes ter adiado seus compromissos pessoais para que eu pudesse realizar os meus.

À minha madrinha, Neusa Stefani da Silveira, pelo amor e carinho, por estimular e promover todo o suporte para o desenvolvimento deste trabalho.

À Maria de Lourdes Silva Esposto (in memoriam), "Tia Lurdinha”, pela alegria em viver, por entregar em minhas mãos a sua recuperação contra o câncer de mama e por me permitir ajudar em suas limitações. Acompanhar tais dificuldades de perto me estimulou a seguir com este trabalho e, sem sombra de dúvida, auxiliaria ainda mais como participante desta pesquisa. Faltou muito pouco, mas valeu a pena cada momento!

À Profa. Dra. Simone Cecilio Hallak Regalo, pela orientação, ensinamento, por acreditar neste estudo e ajudar a conduzi-lo da melhor forma possível. Obrigado pela disponibilidade, pela oportunidade de desenvolver este estudo e confiar em meu potencial desde o início. 
Ao Prof. Me. Edson Donizetti Verri, razão pela qual conquisto mais esta etapa, por sabiamente conduzir meus caminhos acadêmicos desde a Iniciação Científica e não me deixar parar. Agradeço a amizade, confiança e ajuda em toda a estruturação $e$ desenvolvimento deste projeto.

À Profa. Dra. Marisa Semprini e Profa. Dra. Selma Siéssere, pela prontidão em ajudar, por todas as sugestões, ensinamentos e por proporcionar todos os momentos de convívio e amizade no decorrer deste trabalho.

À Profa. Dra. Elaine Caldeira de Oliveira Guirro, pela disponibilidade em auxiliar o desenvolvimento deste estudo desde o início, contribuindo com sua experiência pessoal e profissional para conduzi-lo pelos melhores caminhos.

À Profa. Dra. Vânia Tie Koga Ferreira, pela prontidão e contribuição no desenvolvimento deste projeto, por compartilhar técnicas, experiências e ensinamentos quando precisei.

Ao Prof. Dr. Marcelo Palinkas, por se mostrar sempre disponível para ajudar, contribuir e adquirir novos conhecimentos. Obrigado por todo o auxílio e capacitação, fundamentais em todas as etapas deste projeto, sem exceção.

Ao Saulo César Vallin Fabrin, pela amizade, parceria nos trabalhos desenvolvidos e por estar sempre presente e disposto a ajudar.

Ao Paulo Batista de Vasconcelos e Luiz Gustavo de Sousa, Especialistas em Laboratório da FORP-USP, e à Clélia Aparecida Celino, Secretária do Departamento de Morfologia, Fisiologia e Patologia Básica da FORP-USP, por todo apoio, capacitação, parceria e dedicação em suas atividades.

Aos amigos e integrantes do Laboratório de Eletromiografia "Prof. Dr. Mathias Vitti", da FORP-USP, por todos os momentos de convivência e aprendizado.

Ao Claretiano Centro Universitário, pela parceria e proporcionar a estrutura para a coleta de dado no Laboratório de Análise Biomecânica do Movimento. 
Ao Programa de Pós-Graduação em Reabilitação e Desempenho Funcional da Faculdade de Medicina de Ribeirão Preto da Universidade de São Paulo, pela oportunidade de aprimorar meus conhecimentos, contribuindo com minha formação científica e profissional.

A todos meus amigos e familiares que, direta ou indiretamente, contribuíram com apoio, palavras de carinho, perseverança e estima.

A todas as participantes desta pesquisa, pela disponibilidade, confiança, e valiosa contribuição. Sem vocês este trabalho não existiria!

À Coordenação de Aperfeiçoamento Pessoal de Nível Superior (CAPES), pelo apoio financeiro imprescindível para o desenvolvimento desta pesquisa científica.
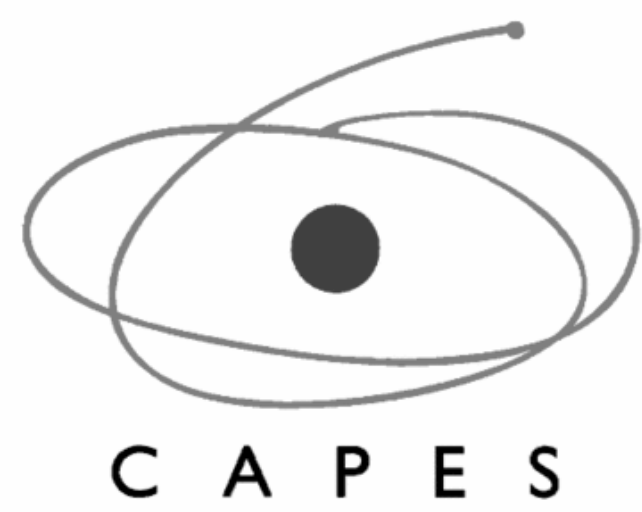

Ao Laboratório de Eletromiografia "Prof. Dr. Mathias Vitti", bem como ao Departamento de Morfologia, Fisiologia e Patologia Básica, da Faculdade de Odontologia de Ribeirão Preto da Universidade de São Paulo, por fornecer o espaço, suporte e equipamentos para realização desta pesquisa. 

“Por vezes sentimos que aquilo que fazemos não é senão uma gota de água no mar. Mas o mar seria menor se lhe faltasse uma gota" 



\section{RESUMO}

\section{ESPOSTO, Danilo Stefani. A influência da mastectomia unilateral na função do sistema}

estomatognático e na postura corporal. 2017. 113 p. Dissertação (Mestrado em Ciências) -

Faculdade de Medicina de Ribeirão Preto, Universidade de São Paulo, Ribeirão Preto, 2017.

O câncer de mama é a neoplasia que mais acomete mulheres no mundo e o mais comum na população feminina brasileira. A mastectomia é um dos procedimentos realizados para o tratamento e pode ocasionar várias alterações físicas e funcionais como linfedema, limitação de amplitude de movimento, neuropraxia, desequilíbrios musculares e alteração postural. $\mathrm{O}$ sistema estomatognático é um complexo sistema que pode ser influenciado na sua função por déficits posturais. O objetivo deste estudo foi analisar a atividade eletromiográfica em diferentes condições posturais da mandíbula, espessura dos músculos temporal direito (TD) e esquerdo (TE) e masseter direito (MD) e esquerdo (ME), bem como a força de mordida molar máxima, a eficiência mastigatória e a postura corporal de mulheres submetidas à mastectomia unilateral. Participaram 32 mulheres que foram distribuídas em dois grupos: GM, grupo mastectomia unilateral $(\mathrm{n}=16)$, idade média de $56,50 \pm 14,50$ anos e $\mathrm{GC}$, grupo controle sem a doença $(n=16)$, idade média de $56,56 \pm 14,15$ anos. Os grupos foram pareados sujeito a sujeito por idade e índice de massa corporal. O eletromiógrafo Trigno (Delsys Inc., Boston, MA, USA), com eletrodos de superficies wireless, foi utilizado para avaliar a atividade mioelétrica em repouso, lateralidade direita e esquerda, protrusão, apertamento dental em contração voluntária máxima com e sem Parafilme $\mathrm{M}^{\circledR}$. A função mastigatória foi avaliada pela eficiência dos ciclos mastigatórios por meio da integral da envoltória linear do sinal eletromiográfico na mastigação habitual e não habitual. A espessura muscular foi mensurada pela imagem obtida do ultrassom Sono Site Titan em repouso e apertamento dental em contração voluntária máxima. Foi utilizado o dinamômetro digital Kratos na análise da força de mordida molar máxima. A postura estática foi mensurada por meio da fotogrametria. Os dados eletromiográficos normalizados, espessura muscular, força de mordida molar máxima e fotogrametria foram tabulados e submetidos à análise estatística (SPSS 21.0; teste $t$ de student, $p \leq 0,05)$. Foi encontrada diferença estatística significante entre o GM e GC na lateralidade direita, para o MD $(p=0,02)$; lateralidade esquerda, para o TE $(p=0,01)$; mastigação com amendoim, para o MD $(p=0,04)$; mastigação com uva-passa, para o ME ( $p$ $=0,04)$; força de mordida molar direita $(p=0,03)$; ângulos do quadrante superior: triângulo de Talles do lado operado $(p=0,03)$ e ângulo esternoclavicular $(p=0,00)$ e ângulos do quadrante inferior: inclinação do pé do lado operado $(p=0,00)$ e não operado $(p=0,03)$ e ângulo tibiotársico do lado operado $(p=0,03)$. Não houve diferença estatística significante entre os GM e GC para espessura muscular e na comparação do lado operado e não operado (em todas as variáveis). Baseado nos resultados obtidos, concluiu-se que o sistema estomatognático e a postura corporal de mulheres submetidas à mastectomia unilateral apresentaram alterações funcionais, com destaque para hiperatividade muscular, redução na eficiência mastigatória, menor força de mordida molar e postura corporal inadequada, quando comparadas com mulheres sem a doença.

Palavras-chave: Mastectomia. Músculos da mastigação. Eletromiografia. Ultrassonografia. Força de mordida. Postura. 



\begin{abstract}
ESPOSTO, Danilo Stefani. The influence of unilateral mastectomy on the stomatognathic system function and the body posture. 2017. 113 p. Dissertation (Master of Science) Faculty of Medicine of Ribeirão Preto, University of São Paulo, Ribeirão Preto, 2017.

Breast cancer is the most common neoplasm of women in the world and the most common in the Brazilian population. Mastectomy is one of the procedures performed for the treatment and can cause several physical and functional changes such as lymphedema, range of motion limitation, neuropraxia, muscular imbalances and postural alteration. The stomatognathic system is a complex system that can be influenced in its function by postural deficits. The objective of this study was to analyze the electromyographic activity in different postural conditions of the mandible, thickness of the right (RT) and left (LT) temporal muscle and right (RM) and left (LM) masseter muscle, but also the maximum molar bite strength, masticatory efficiency and body posture of women undergoing unilateral mastectomy. Thirtytwo women were divided into two groups: $M G$, unilateral mastectomy group $(n=16)$, average

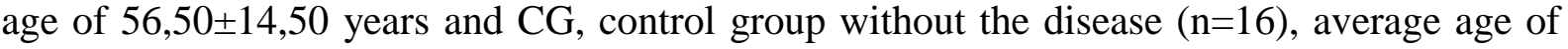
$56,56 \pm 14,15$ years. The groups were matched individual-to-individual by age and body mass index. The Trigno electromyograph (Delsys Inc., Boston, MA, USA) with wireless surface electrodes was used to evaluate myoelectric activity at rest, right and left laterality, protrusion, maximum voluntary contraction of teeth with and without Parafilm $\mathbf{M}^{\circledR}$. The masticatory function was evaluated by the efficiency of the masticatory cycles using the integral of the linear envelope averages of the electromyographic signal in habitual and non-habitual mastication. The muscular thickness was measured by the image obtained from the Sono Site Titan ultrasound at rest and maxillary voluntary contraction. The Kratos digital dynamometer was used to analyze the maximum molar bite force. Static posture was measured using photogrammetry. The normalized electromyographic data, muscle thickness, maximum molar bite force and photogrammetry were tabulated and submitted to statistical analysis (SPSS 21.0; Student t test, $p \leq 0.05)$. A significant statistical difference was found between $\mathrm{MG}$ and CG in right laterality, for RM $(p=0,02)$; left laterality, for LT $(p=0,01)$; chewing with peanuts, for RM $(p=0,04)$; chewing with raisins, for LM $(p=0,04)$; right molar bite force ( $p$ $=0,03)$; upper quadrant angles: Thales triangle operated side $(p=0,03)$ and sternoclavicular joint angle $(p=0,00)$ and lower quadrant angles: foot angle operated $(p=0,00)$ and nonoperated side $(p=0,03)$ and tibiotarsal angle operated side $(p=0,03)$. There was no statistically significant difference between $\mathrm{MG}$ and $\mathrm{CG}$ for muscle thickness and in the comparison of the operated and non-operated side (in all variables). Based on the results obtained, it was concluded that the stomatognathic system and the body posture of women submitted to unilateral mastectomy presented functional alterations, with emphasis on muscular hyperactivity, reduction in masticatory efficiency, lower molar bite force and inadequate body posture when compared to women without the disease.
\end{abstract}

Keywords: Mastectomy. Masticatory muscles. Electromyography. Ultrasonography. Bite force. Posture. 



\section{SUMÁRIO}

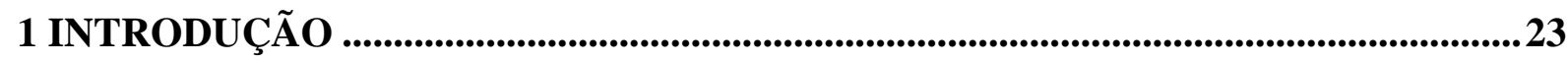

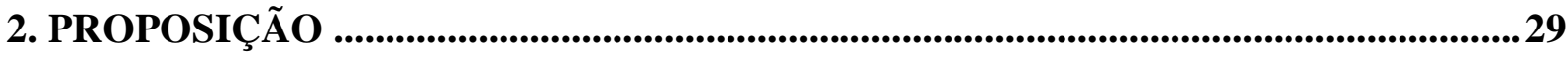

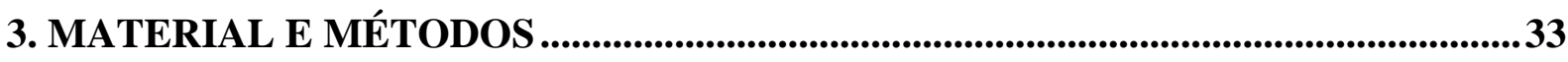

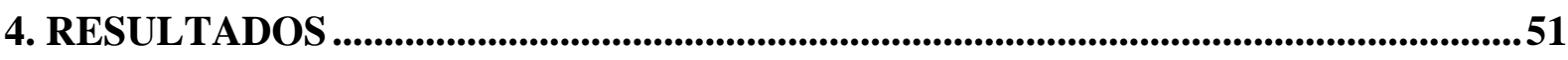

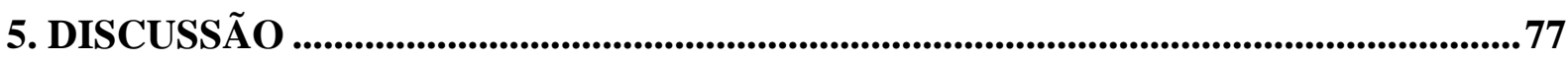

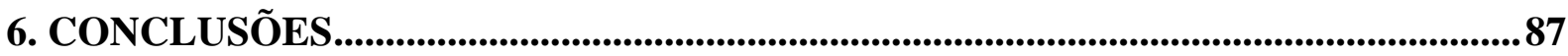

REFERÊNCIAS ...........................................................................................................91

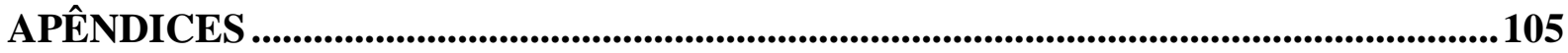

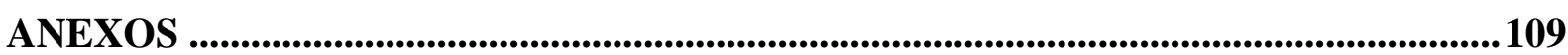






\section{INTRODUÇÃO}

O câncer de mama é a neoplasia que mais acomete as mulheres no cenário mundial e é considerado o mais comum na população feminina brasileira (PORTO et al. 2013; REZENDE et al., 2017).

Estima-se que em 2016 foram diagnosticados 57.960 mil novos casos de câncer de mama feminina no Brasil, com uma estimativa de risco de 56,20 / 100 mil mulheres (INSTITUTO NACIONAL DE CÂNCER JOSÉ ALENCAR GOMES DA SILVA, 2015; ROCHA-BRISCHILIARI et al., 2017). Nos EUA, a incidência estimada de câncer de mama foi em torno de 246.660 mil casos em 2016 (AMERICAN CANCER SOCIETY, 2016; SIEGEL; MILLER; JEMAL, 2016).

As taxas de mortalidade do câncer de mama são elevadas, tanto em países desenvolvidos como em desenvolvimento (BARBOSA et al., 2013; INCA, 2015; RESZKA et al., 2017) possivelmente pelo fato de que a doença ainda é diagnosticada em estágios avançados, apesar de ser considerado um tipo de câncer com prognóstico relativamente bom, com índice de sobrevida de aproximadamente 80\% (DE LIMA VAZQUEZ et al., 2016).

O procedimento cirúrgico é a abordagem mais utilizada para o tratamento do câncer de mama, compreendendo a modalidade conservadora, com preservação da mama, onde se realiza apenas a ressecção do tumor ou do quadrante mamário que contém o carcinoma primário; ou a não conservadora, com a ressecção total da mama, denominada mastectomia (VAN MAAREN MC; POORTMANS P; SIESLING S, 2016; WU et al., 2017; ENGELEN et al., 2017). Adicionalmente à abordagem cirúrgica, pode ser administrada de maneira coadjuvante a quimioterapia, a radioterapia e a hormonioterapia (VERONESI et al., 1986; RETT et al., 2012; CHARGARI; MAGNÉ, 2009).

A mastectomia radical clássica, descrita inicialmente por Halsted, compreendia a retirada total do tecido mamário e dos músculos peitoral maior e menor, além da linfonodectomia axilar completa. Com o avanço de novas técnicas e pesquisas, algumas alterações foram inseridas no procedimento inicial, tornando-o menos agressivo, onde se preserva o músculo peitoral maior ou ambos, sendo assim denominada por mastectomia radical modificada, proposto por Patey, Dyson e Madden (GOUVEIA et al., 2008).

Nos últimos anos, mudanças na abordagem cirúrgica do câncer de mama vêm sendo apresentadas (TIEZI, 2009) e estudos demonstraram que procedimentos cirúrgicos conservadores causam menos impacto na qualidade de vida das pacientes, especialmente na funcionalidade e sintomatologia dolorosa (VEIGA, 2010; JUHL et al., 2017). 
Limitações físicas e funcionais têm sido relatadas em decorrência do tratamento do câncer de mama, como alteração postural, neuropraxia, distúrbios articulares e musculares do ombro e cintura escapular, e déficit de controle postural (BANKOFF; JURADO, 2013; BARBOSA et al., 2013; SUGDEN et al., 1998; MONTEZUMA et al., 2014; GRITSENKO et al., 2015; WIJAYASINGHE et al., 2016). Os procedimentos cirúrgicos de mama provocam ainda alterações sociais e psicológicas, principalmente quando está relacionado com a autoestima (GOUVEIA et al., 2008; CAGLI et al., 2016).

Bregagnol e Dias (2010) demonstraram que no pós-operatório de linfadenectomia em mulheres, ocorreu diminuição significativa na amplitude de flexão e abdução do ombro homolateral à cirurgia. Este fato pode ser decorrente da dor ou aderência cicatricial, edema, comprometimentos na função pulmonar, força dos músculos respiratórios e, ainda, alterações posturais, destacando a importância do cuidado com a postura para se evitar alterações na biomecânica corporal.

Resultados semelhantes foram notados por Haddad et al. (2013) onde constataram que a presença de linfedema pode influenciar na postura e assimetria de movimentos corporais em mulheres pós-mastectomizadas, observando alterações na rotação de cabeça, protrusão de ombro e medidas do triângulo de Talles menores do lado operado, além de elevação da escápula bilateralmente, quando comparadas ao grupo sem linfedema.

Ciesla e Polom (2010) estudaram a postura corporal de 38 mulheres submetidas à mastectomia radical em um sistema tridimensional nos planos frontal, sagital e transverso, previamente ao procedimento cirúrgico e após 6, 12, 18 e 24 meses. Os autores identificaram alterações posturais significativas no grupo estudado, com maior evidência em 18 e 24 meses.

Montezuma et al. (2014) analisaram o controle postural de mulheres submetidas à mastectomia, constatando que as participantes submetidas ao procedimento cirúrgico apresentaram aumento da velocidade e deslocamento do centro de pressão quando comparado ao grupo controle, ocasionando alterações posturais e déficit de equilíbrio corporal.

Serel et al. (2016) analisaram radiografias de tórax póstero-anteriores de 60 mulheres (idade média 56,3 \pm 8,5 anos) antes e após doze meses da mastectomia, observando o ângulo de Cobb e a presença ou ausência de inclinação da linha média no plano coronal do alinhamento da coluna vertebral. Os autores concluíram que ocorreu, a longo prazo, deformação da coluna vertebral de mulheres que foram submetidas à mastectomia unilateral.

Rostkowska et al. (2006) afirmaram que a inclinação do tronco para o lado homolateral à cirurgia, anteriorização da cabeça, elevação da escápula e ombro no lado 
homolateral, rotação pélvica, além de deslocamento do centro de pressão foram as alterações mais frequentementes encontradas em pacientes mastectomizadas.

Cuccia e Caradonna (2009) asseguraram que mudanças na postura corporal podem influenciar a posição mandibular, causando alterações funcionais no sistema estomatognático que é composto por componentes esqueléticos (maxila e mandíbula), arcos dentais, tecidos moles (glândulas salivares e suprimentos vasculares e nervosos), articulação temporomandibular e músculos da mastigação e expressão facial.

Segundo Arellano (2002), as disfunções temporomandibulares podem depender de patologias ascendentes (onde problemas posturais, abaixo do complexo temporomandibular são responsáveis pelo distúrbio) e descendentes (onde a causa do distúrbio é localizada no sistema estomatognático), demonstrando que ambos os sistemas podem estar interligados.

Alterações no quadrante superior corporal podem ocasionar em disfunções do posicionamento anterior da cabeça e hiperextensão sobre o pescoço com retrusão mandibular e, consequentemente, o desenvolvimento de várias disfunções cinéticas e funcionais, afetando a mastigação, deglutição, respiração e fonação (FERREIRA et al., 2012; MUÑOZ-GARCÍA et al., 2016).

Existem métodos que monitoram a musculatura estriada esquelética e entre estes se destaca a eletromiografia de superfície que é um método não invasivo de diagnóstico e de investigação do sistema estomatognático, com a função de observar a resposta à ativação fisiológica dos potenciais de ação das unidades motoras (HERMENS et al., 2000; SUVINEN; KEMPPAINEN, 2007; WOŹNIAK et al., 2013; POLITTI et al., 2016; FUENTES et al., 2016).

A mensuração da espessura muscular, por meio da ultrassonografia de imagem, é um método simples e reprodutível, que permite também acrescentar informações importantes em relação à função muscular (BAKKE et al., 1992; EMSHOFF et al., 2003; BERTRAM et al., 2003; PALINKAS et al., 2010; VASCONCELOS et al., 2015; PALINKAS et al., 2016). Pesquisadores utilizam esta ferramenta confiável, acurada e não invasiva como técnica auxiliar de diagnóstico a fim de se estudar a dinâmica dos músculos da mastigação (BERTRAM et al., 2003; SERRA et al., 2008; PALINKAS et al., 2010). Na literatura nada foi encontrado referente ao estudo da espessura dos músculos da mastigação em mulheres mastectomizadas.

A gnatodinamometria é um método indireto, utilizado para avaliação do sistema mastigatório (SHIAU; WANG, 1993; BORETTI et al., 1995; ORCHARDSON; CADDEN, 1998; TSUGA et al., 1998; DOUGLAS, 1999; OKIYAMA, 2003; KOGAWA et al., 2006; 
TESTA et al., 2016) por meio da força máxima exercida dos primeiros molares permanentes, demonstrando a eficiência do sistema mastigatório (PALINKAS et al., 2010; PITA et al., 2011; PEPATO et al., 2014). Este recurso pode ser fundamental na investigação do desempenho funcional em indivíduos que foram submetidos aos tratamentos cirúrgicos e de reabilitação oral.

A avaliação postural por meio da imagem fotográfica tem sido utilizada por vários pesquisadores e pode fornecer às práticas médicas um meio não invasivo e sem dor para obter medidas espaciais relacionadas ao corpo humano (MITCHELL; NEWTON, 2002; LIMA et al., 2004; CORRÊA; BÉRZIN, 2007; MILANESI et al., 2011; HADDAD et al., 2013; PERES et al., 2017).

Iunes et al. (2005) relataram que a biofotogrametria computadorizada vem sendo utilizada para facilitar o trabalho de profissionais da área da saúde, tendo em vista que tal método consiste em aplicações da fotogrametria no campo da medicina para extrair medidas das formas e dimensões corporais.

Com a evolução das técnicas cirúrgicas e a crescente incidência de neoplasia maligna na mama, se fez necessário verificar as alterações pós-operatórias decorrentes dos procedimentos atuais (BREGAGNOL; DIAS, 2010; PALMA et al., 2016). Dessa forma, destaca-se a importância deste estudo para nortear informações no processo de avaliação e acompanhamento clínico das mulheres mastectomizadas, apresentando caráter esclarecedor para profissionais da saúde com a finalidade de contribuir na análise funcional do corpo humano.

A hipótese deste estudo é que a mastectomia unilateral em mulheres pode apresentar um aumento na atividade eletromiográfica dos músculos mastigatórios, redução da eficiência mastigatória e menor força de mordida molar máxima. 



\section{PROPOSIÇÃO}

A finalidade desta pesquisa foi avaliar mulheres submetidas à mastectomia unilateral comparando com mulheres sem a doença e entre os lados operado e não operado, por meio da:

Atividade eletromiográfica do músculo temporal e masseter (direito e esquerdo) nas condições posturais da mandíbula em repouso, lateralidade direita e esquerda, protrusão e apertamento dental em contração voluntária máxima com e sem Parafilme $\mathrm{M}^{\circledR}$;

> Eficiência mastigatória habitual e não habitual;

$>$ Espessura do músculo temporal e masseter em repouso e contração voluntária máxima;

$>$ Força de mordida molar máxima (direita e esquerda);

> Postura corporal. 




\section{MATERIAL E MÉTODOS}

\subsection{CARACTERIZAÇÃO DA PESQUISA}

O presente estudo teve como objetivo realizar análise morfofuncional dos músculos da mastigação (temporal e masseter) de mulheres submetidas à mastectomia unilateral e sem a doença por meio da avaliação eletromiográfica e ultrassonográfica, além da força de mordida molar máxima e fotogrametria. Os dados foram coletados no Laboratório de Eletromiografia Prof. Dr. Mathias Vitti, do Departamento de Morfologia, Fisiologia e Patologia Básica da Faculdade de Odontologia de Ribeirão Preto (FORP / USP) e no Laboratório de Análise Biomecânica do Movimento do Claretiano Centro Universitário, Batatais (SP). A pesquisa foi aprovada pelo Comitê de Ética em Pesquisa com Seres Humanos (CAAE $n^{\circ}$ 38290714.8.0000.5381) (ANEXO A), sendo que todas as participantes da pesquisa foram informadas sobre os propósitos e etapas do estudo e assinaram o Termo de Consentimento Livre e Esclarecido (APÊNDICE A), de acordo com a Resolução 466/12 e complementar do Conselho Nacional de Saúde.

\subsection{CARACTERÍSTICAS DA POPULAÇÃO E AMOSTRA}

Foram selecionadas 40 mulheres para participar desta pesquisa, sendo 08 excluídas pelos seguintes critérios: alterações ortopédicas prévias de região cervical e membros superiores; alterações cognitivas que comprometessem o entendimento do comando verbal; traumas prévios na região da cabeça e pescoço; mulheres com mamas pequenas (medida inferior a $09 \mathrm{~cm}$ ) ou a presença de linfedema em membros superiores.

O tamanho das mamas foi mensurado pelo índice de Sacchini, que demonstrou as médias da distância entre a margem lateral do esterno e papila mamária e a distância entre o sulco inframamário e papila mamária. Com este tipo de análise, as mamas foram classificadas em pequena (inferiores a $09 \mathrm{~cm}$ ); média (entre 09 e $11 \mathrm{~cm}$ ) ou grande (acima de $11 \mathrm{~cm}$ ) (SACCHINI et al., 1991; FERNANDES et al., 2007).

Para detectar a presença de linfedema foi realizada a medida da circunferência em ambos os membros superiores (TAYLOR et al., 2006), obtendo-se o volume total do membro de acordo com critérios estabelecidos por Sander et al. (2002) pela fórmula demonstrada a seguir, sendo "V" o volume total do segmento, " $\mathrm{n}$ " o número de segmentos, "L" o comprimento de cada segmento e " $\mathrm{C}_{\mathrm{i}}$ " e " $\mathrm{C}_{\mathrm{i}-1}$ " a circunferência de cada segmento i. A 
constatação da presença de linfedema foi considerada quando diferença superior ou igual a 200mL entre os membros fosse identificada (ANDERSEN et al., 2000).

$$
\mathrm{V}=\frac{1}{12 \pi} \sum_{\mathrm{i}=1}^{\mathrm{n}} \mathrm{L}\left(\mathrm{C}_{\mathrm{i}}^{2}+\mathrm{C}_{\mathrm{i}} \mathrm{C}_{\mathrm{i}-1}+\mathrm{C}_{\mathrm{i}-1}^{2}\right)
$$

Para caracterização do nível de atividade física das participantes mastectomizadas foi aplicado o IPAQ - Questionário Internacional de Atividade Física (ANEXO B), versão curta, que avalia a frequência e duração da execução de atividades físicas moderadas, vigorosas ou de caminhada (MATSUDO et al., 2001).

Dados referentes ao procedimento cirúrgico e complementares das participantes mastectomizadas estão descritos na Tabela 1.

Tabela 1 - Dados complementares das mulheres mastectomizadas.

$\begin{aligned} \text { Tempo de cirurgia } & <12 \text { meses: } 2 \\ & >12 \text { meses: } 14\end{aligned}$

$\begin{array}{ll}\text { Lado da cirurgia } & \text { Direito: } 9\end{array}$

Esquerdo: 7

\begin{tabular}{lc}
\hline Uso de prótese & Sim: 14 \\
Não: 2 & Sim: 11 \\
\hline Quimioterapia & Não: 5 \\
\hline Radioterapia & Sim: 9 \\
& Não: 7 \\
\hline Hormonioterapia & Sim: 3 \\
& Não: 13 \\
\hline Nível de atividade física & Insuficientemente ativa: 9 \\
& Ativa: 7 \\
\hline
\end{tabular}

Dessa forma, foram incluídas 32 mulheres com dentição natural, oclusão normal, sem disfunção temporomandibular (RDC/TMD), da comunidade de Ribeirão Preto e região, distribuídas em dois grupos: mulheres que realizaram mastectomia unilateral (GM), idade

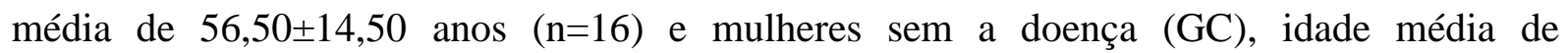


$56,56 \pm 14,15$ anos $(\mathrm{n}=16)$ (Figura 1). Os grupos foram pareados sujeito a sujeito por idade e índice de massa corporal (Tabela 2).

Figura 1 - Fluxograma da distribuição da amostra da pesquisa

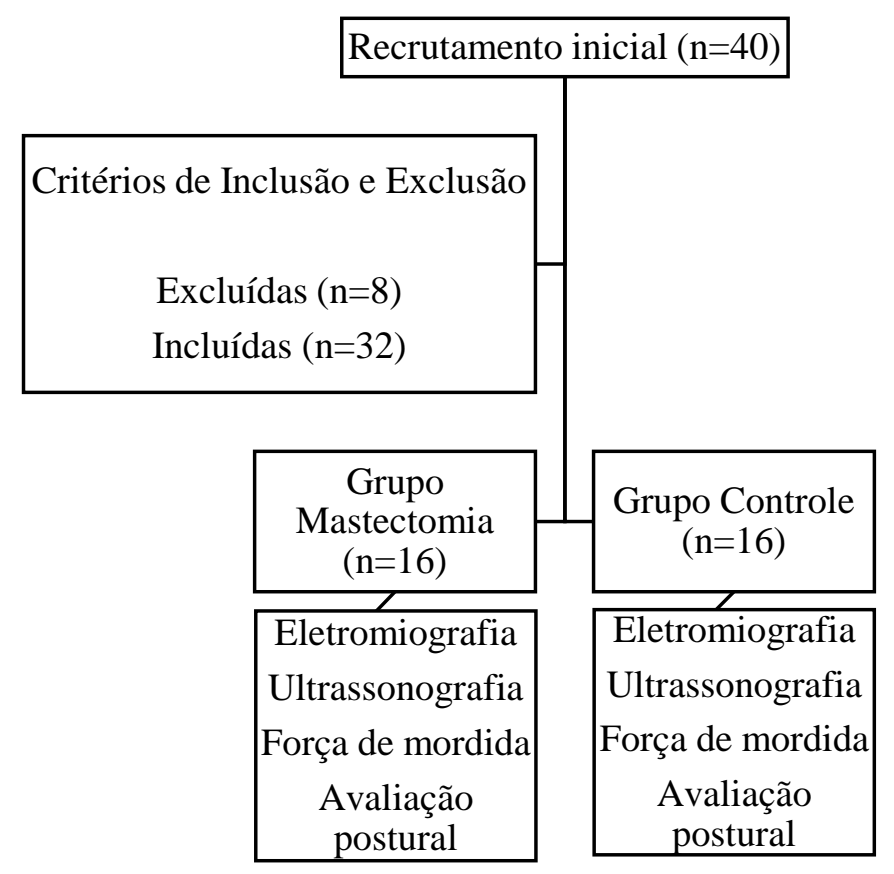

Tabela 2 - Características dos grupos.

\begin{tabular}{ccc}
\hline Variáveis & GM & GC \\
\hline Idade (anos) & $56,50 \pm 14,50$ & $56,56 \pm 14,15$ \\
Peso $(\mathrm{kg})$ & $65,59 \pm 7,53$ & $66,37 \pm 9,54$ \\
Altura $(\mathrm{m})$ & $1,60 \pm 0,06$ & $1,62 \pm 0,042$ \\
IMC $\left(\mathrm{kg} / \mathrm{m}^{2}\right)$ & $25,37 \pm 2,92$ & $25,21 \pm 2,82$ \\
Índice de Sacchini & $15 \mathrm{M} ; 1 \mathrm{G}$ & $15 \mathrm{M} ; 1 \mathrm{G}$
\end{tabular}

GM: grupo mastectomia; GC: grupo controle; M: mamas médias; G: mama grande.

\subsection{SELEÇÃO PARA O RECRUTAMENTO DAS PARTICIPANTES}

As participantes submetidas à mastectomia unilateral foram recrutadas da comunidade de Ribeirão Preto e região por meio de convite aberto à população em mídias impressas e eletrônicas e em centros de saúde especializados em prevenção e tratamento oncológico. Todas foram submetidas às avaliações da atividade eletromiográfica, eficiência mastigatória, 
espessura muscular, força de mordida molar máxima e avaliação postural. Além disso, foi mensurado o tamanho das mamas e realizado perimetria para detecção de linfedema (critérios de exclusão).

Previamente à realização das condutas avaliativas, foram fornecidas todas as informações pertinentes de cada técnica e esclarecidas todas as dúvidas que as participantes apresentassem durante a execução dos procedimentos.

\subsection{INSTRUMENTOS DE COLETA DE DADOS}

\subsubsection{ELETROMIOGRAFIA DE SUPERFÍCIE}

Para coleta dos sinais eletromiográficos foi utilizado o eletromiógrafo Trigno (Delsys Inc., Boston, MA, USA), com eletrodos de superficies wireless, acoplado a um laptop, que possui dezesseis canais para o sistema de controle, armazenamento, processamento e análise de dados (Figura 2). Os eletrodos de superfície wireless apresentam embutido um acelerômetro tri-axial com transmissão de vinte metros; uma bateria recarregável com uma duração mínima de sete horas; largura de banda do sinal EMG $20 \pm 5 \mathrm{~Hz},>40 \mathrm{~dB} / \mathrm{dec}$;

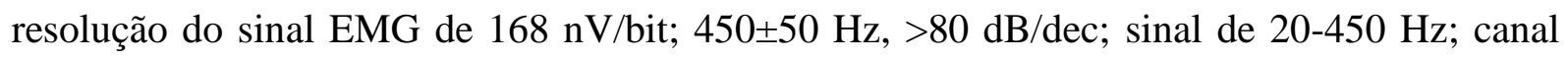
geral <0.75uV; latência <500us; ruído EMG da linha de base de <750 nV RMS; CMRR> 80Db e resolução do sinal EMG de 16-bit.

Figura 2 - (A) Eletromiógrafo Trigno e (B) Eletrodos de superfície wireless.
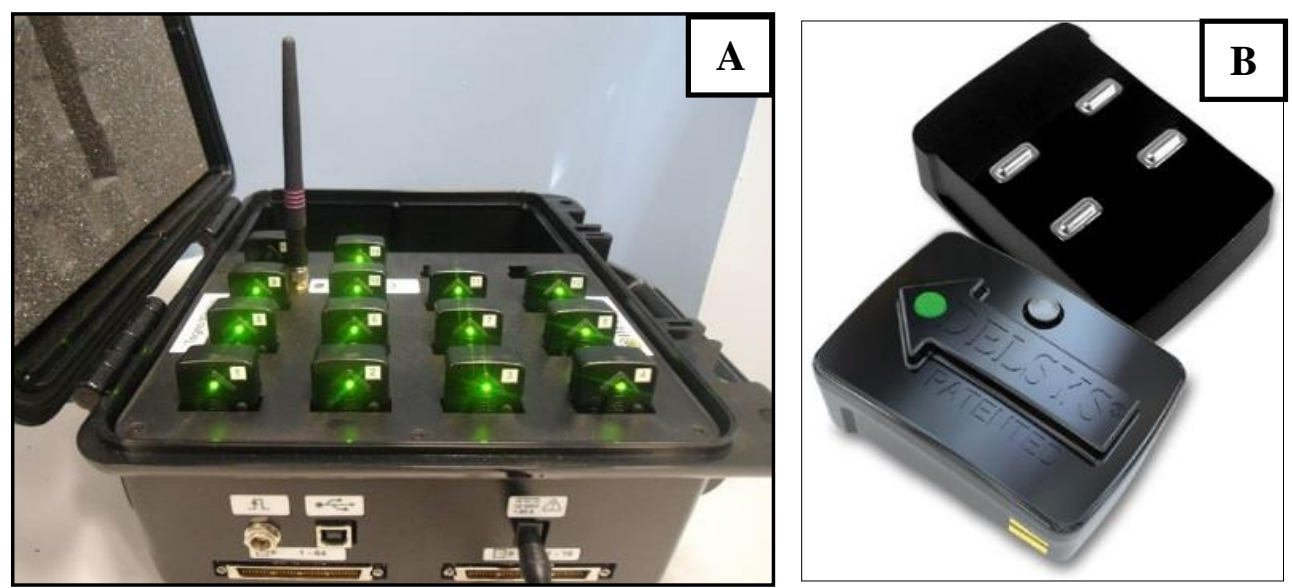

Fonte: (A) Arquivo pessoal; (B) Delsys ${ }^{\circledR}$. 
O posicionamento dos eletrodos wireless sobre os ventres do músculo temporal e masseter (Figura 3) foi identificado por meio da manobra de contração voluntária máxima com a finalidade de localizar o melhor ponto para análise eletromiográfica (CRISWELL, 2010; CRAM; KASMAN; HOLTZ, 2010).

Figura 3 - Posicionamento dos eletrodos na região dos músculos temporal e masseter.

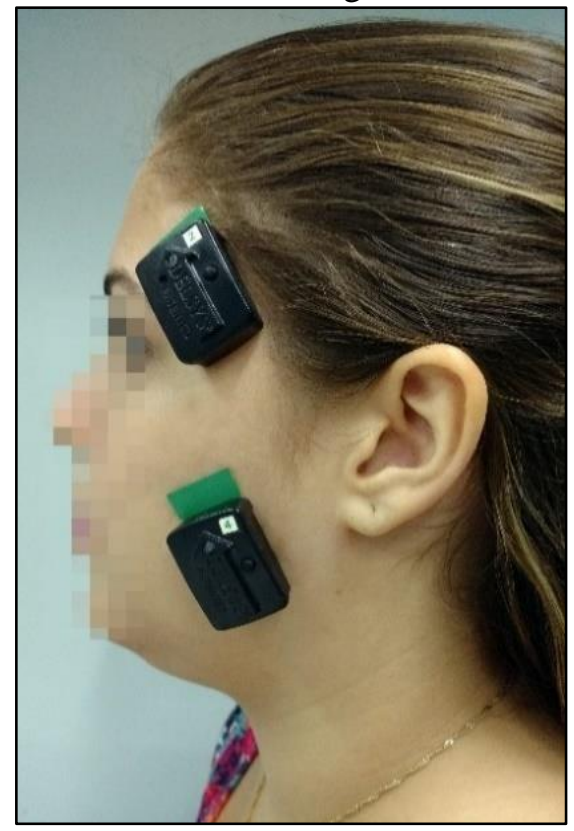

Fonte: Arquivo pessoal

Previamente à colocação dos eletrodos wireless, a pele foi limpa com álcool, eliminando qualquer tipo de resíduos de gordura, maquiagem ou poluição. Durante o registro eletromiográfico foi mantido um ambiente calmo, estando as participantes sentadas em uma cadeira confortável, mantendo os pés apoiados sobre o solo, postura ereta e as mãos apoiadas sobre as coxas. A cabeça foi posicionada de forma ereta, mantendo o plano horizontal de Frankfurt paralelo ao solo. No início da coleta, foi solicitada que a participante permanecesse o mais calma possível, respirando lenta e pausadamente (PALINKAS, 2016).

A avaliação da atividade muscular foi realizada por meio de registros eletromiográficos durante o repouso, condições posturais da mandíbula e mastigação conforme apresentado na Tabela 3. 
Tabela 3 - Protocolo de coleta dos dados eletromiográficos.

MÚSCULO CONDIÇÃO CLÍNICA

ANÁLISE

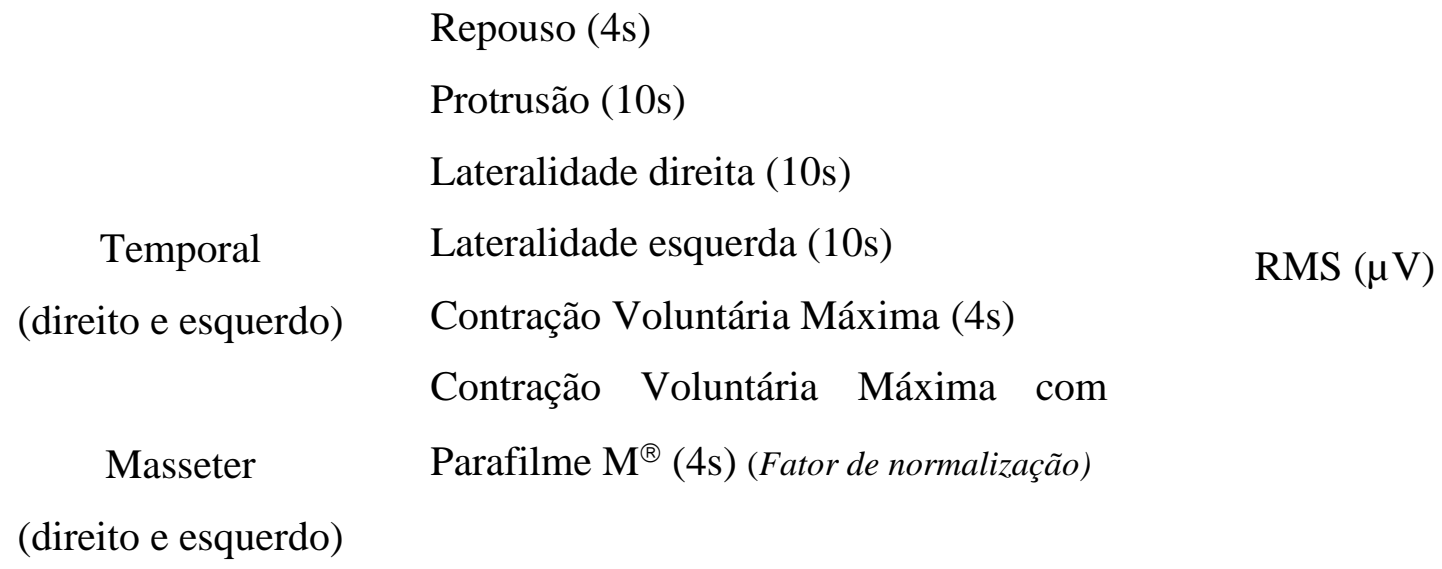

Mastigação de Parafilme $\mathrm{M}^{\circledR}(10 \mathrm{~s})$

Mastigação de Amendoins (10s)

Integral da Envoltória

$(\mu \mathrm{V})$

Mastigação de Uvas-Passas (10s)

Nas avaliações dinâmicas da mandíbula, no que se refere à mastigação habitual e não habitual, foi analisada a eficiência dos ciclos mastigatórios, por meio da integral da envoltória linear do sinal eletromiográfico do músculo temporal e masseter, bilateralmente.

Para a condição de mastigação não habitual foi utilizada uma folha de parafina (Parafilme $\mathbf{M}^{\circledR}$, Pechinery Plastic Packaging, Batavia, IL, USA) e para condição de mastigação habitual foram utilizados dois alimentos testes: $5 \mathrm{~g}$ de amendoim com casca do tipo japonês (Mendorato), simulando um alimento consistente e $5 \mathrm{~g}$ de uvas-passas sem sementes, simulando um alimento macio (Figura 4).

Para fins de padronização, os alimentos pertenciam ao mesmo lote de fabricação ou comercialização e foram armazenados em potes plásticos individualizados com tampa, mantidos em ambiente fresco e arejado. 
Figura 4 - (C) Parafilme $\mathrm{M}^{\circledR}$ para mastigação não habitual; (D) Amendoins para mastigação habitual e (E) Uvas-passas para mastigação habitual de alimento macio.

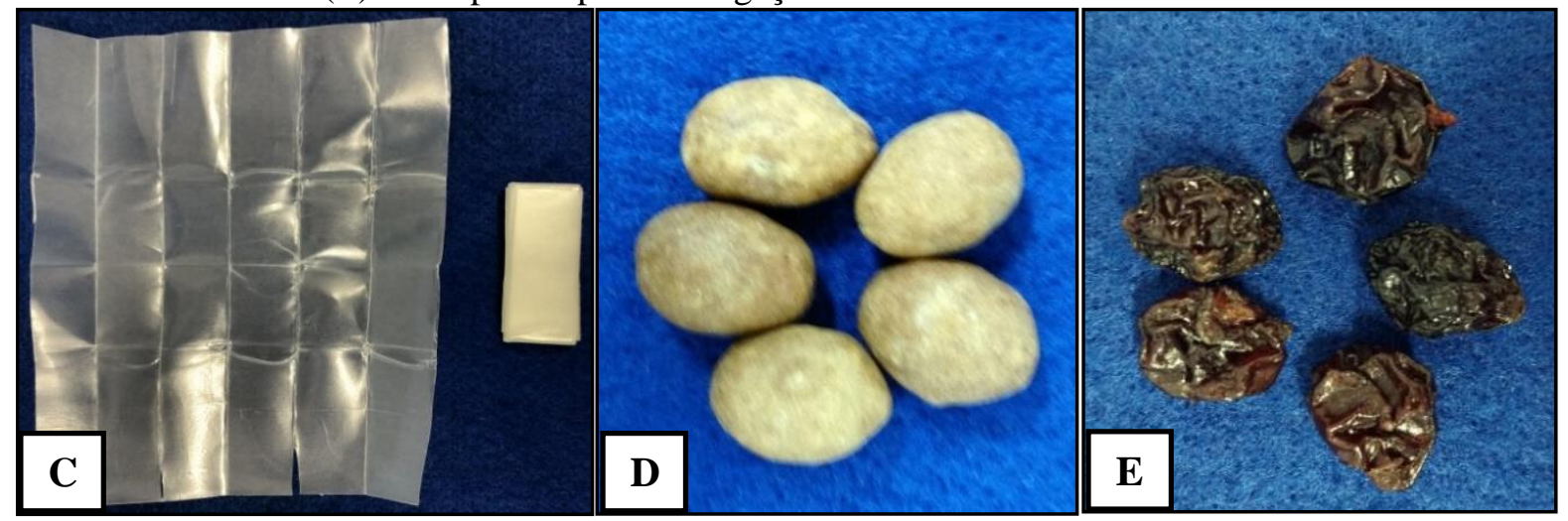

Fonte: Arquivo pessoal

Os sinais eletromiográficos foram processados pelo software Delsys EMGworks Analysis versão 4. Os valores da integral da envoltória dos ciclos mastigatórios em habitual e não habitual foram obtidos eliminando os três ciclos iniciais do processo mastigatório e analisando os cinco ciclos centrais. Os ciclos mastigatórios iniciais foram desprezados, tendo em vista que, no início do processo mastigatório, ocorre considerável variação no padrão de movimentação mandibular (PALINKAS et al., 2013) (Figura 5).

Figura 5 - Sinal eletromiográfico dos ciclos mastigatórios.

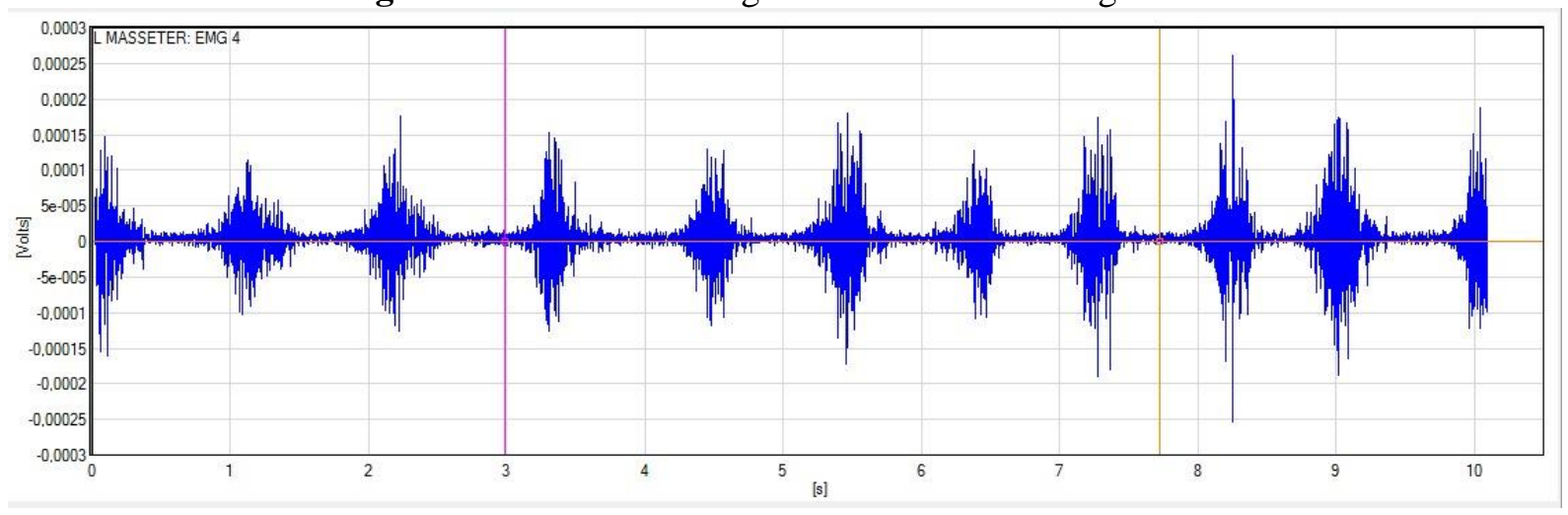

Fonte: Arquivo pessoal 


\subsubsection{ULTRASSONOGRAFIA DE IMAGEM}

O aparelho de ultrassom portátil Sono Site Titan com transdutor linear - L 38 - de 5 a $10 \mathrm{MHz}$ e $38 \mathrm{~mm}$ (Figura 6) foi utilizado para a análise da espessura muscular por meio da aquisição de imagens ultrassonográficas dos músculos temporal e masseter (direito e esquerdo), nas condições de repouso mandibular e apertamento dental em contração voluntária máxima.

Figura 6 - Ultrassom SonoSite Titan com transdutor linear acoplado.

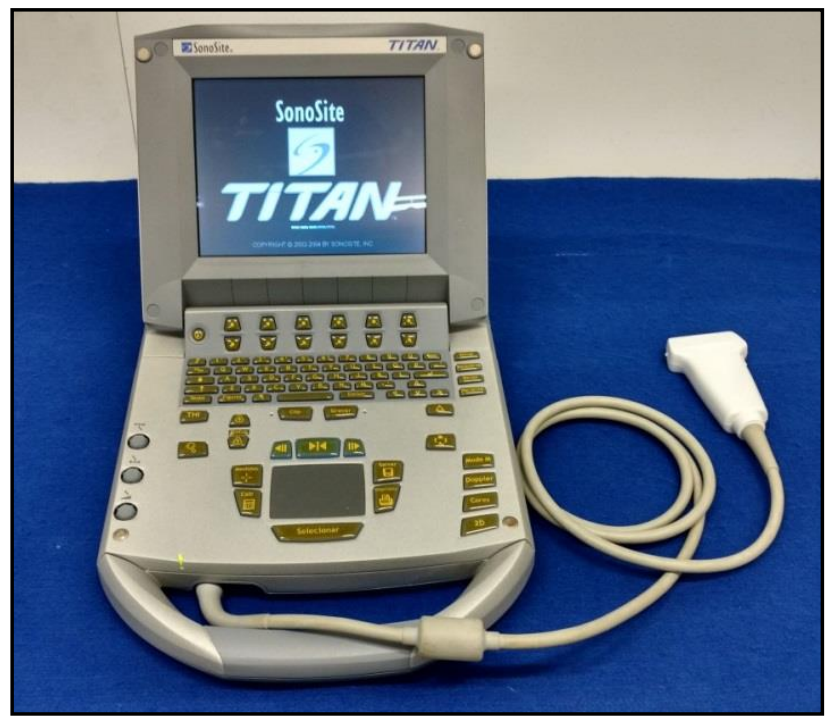

Fonte: Arquivo pessoal

Durante a coleta, manteve-se um ambiente calmo e com luz reduzida, onde as participantes da pesquisa foram posicionadas sentadas em uma cadeira confortável mantendo os pés apoiados sobre o solo, postura ereta e as mãos apoiadas sobre as coxas.

O transdutor linear foi posicionado transversalmente em direção às fibras dos músculos avaliados, acoplado à superfície da pele com um gel eletrocondutor, à base de água.

$\mathrm{Na}$ porção anterior do músculo temporal, o transdutor foi posicionado na região da fossa temporal a cerca de 1,0 a 1,5 cm para trás e para cima do ângulo externo do olho. Para o ventre muscular do músculo masseter, o transdutor linear foi posicionado aproximadamente 1,5 a 2,0 cm acima do ângulo da mandíbula em direção ao arco zigomático (Figura 7). 
Figura 7 - Posicionamento do transdutor linear sobre o músculo temporal (F) e masseter (G).
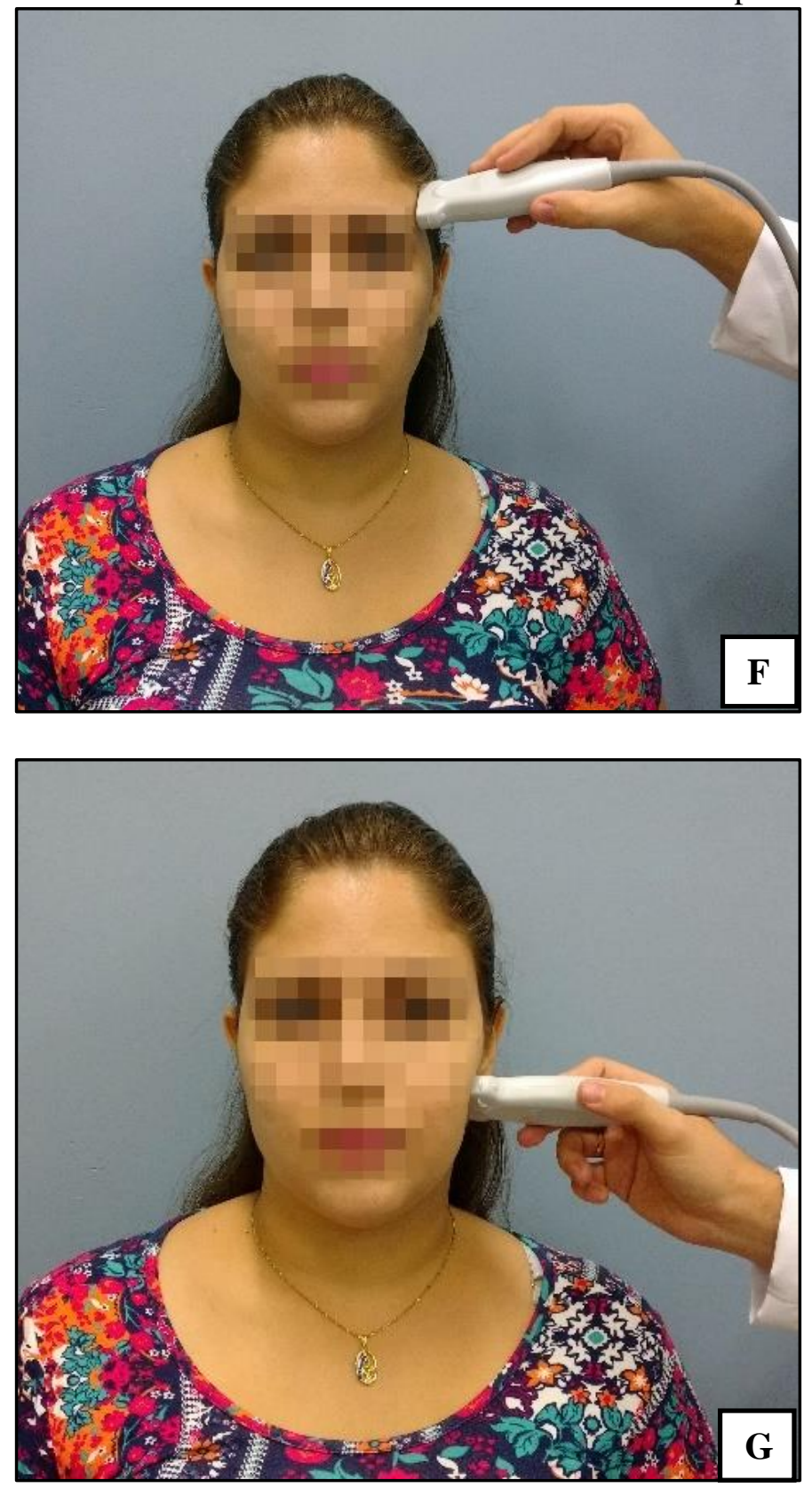

Fonte: Arquivo pessoal

Para cada condição, foram realizados três exames com intervalo de dois minutos entre elas, sendo considerado o valor médio entre as três medidas (em centímetros) para a análise estatística (CASTELO et al., 2007), realizadas diretamente sobre a imagem durante a sua aquisição (Figuras 8 e 9). 
Figura 8 - Imagem ultrassonográfica do músculo temporal obtida durante a condição clínica de repouso $(\mathrm{H})$ e condição clínica de apertamento dental em contração voluntária máxima (I).

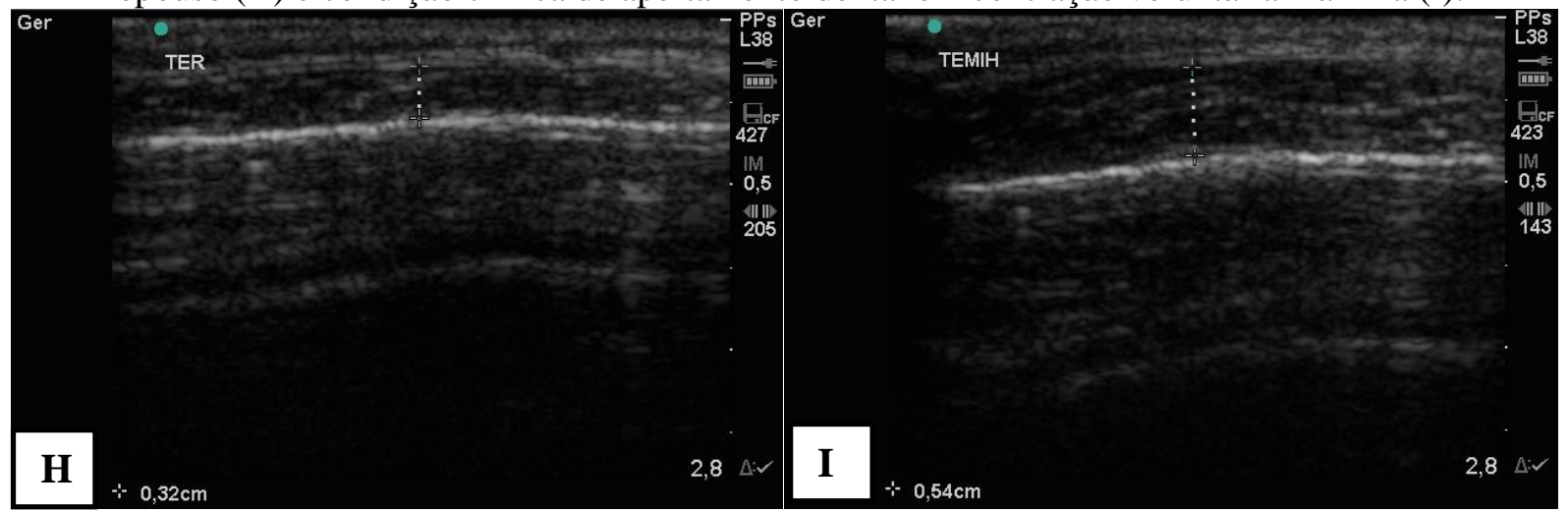

Fonte: Arquivo pessoal

Figura 9 - Imagem ultrassonográfica do músculo masseter obtida durante a condição clínica de repouso $(\mathrm{J})$ e durante a condição clínica de apertamento dental em contração voluntária máxima $(\mathrm{K})$.

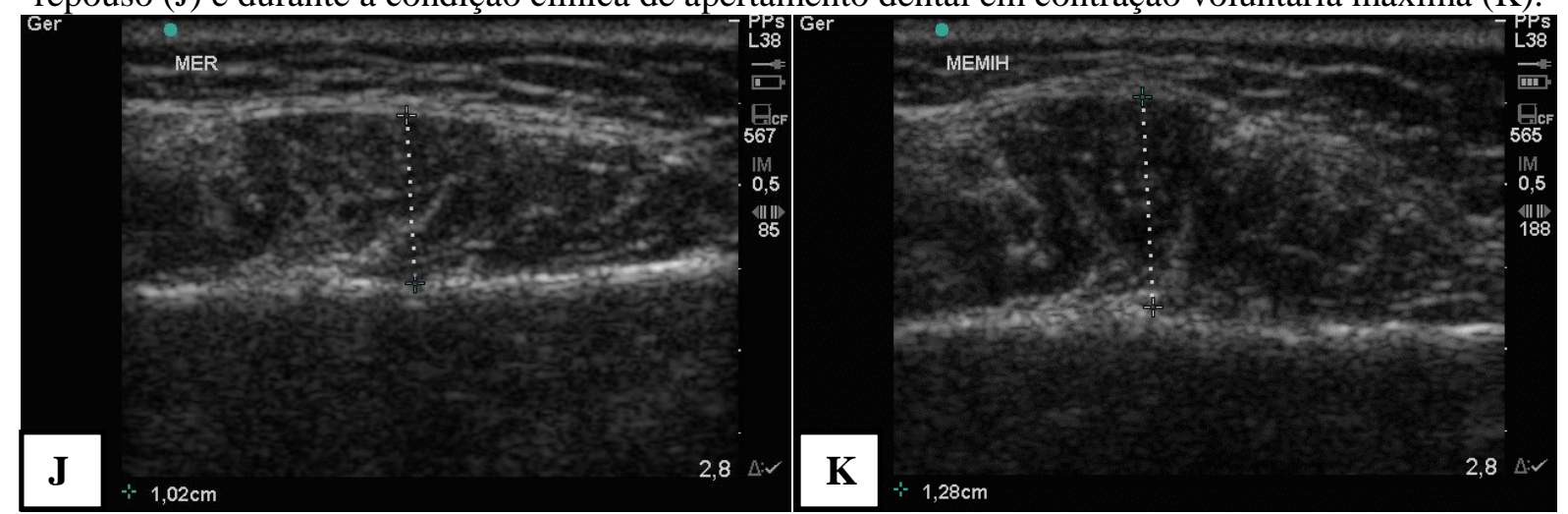

Fonte: Arquivo pessoal

\subsubsection{FORÇA DE MORDIDA MOLAR MÁXIMA}

Foi utilizado o dinamômetro digital modelo IDDK (Kratos, Cotia, SP, Brasil), adaptado para condições bucais e capacidade de até 100 kgf para obtenção dos registros da força de mordida molar máxima (Figura 10).

O aparelho é composto por duas hastes cujas extremidades possuem dois discos de teflon, sobre os quais foi aplicada a força de mordida para registro, com escala em kgf ou N, tecla "set-zero" que permite o controle exato dos valores obtidos, além do registro de "pico", de modo a auxiliar a leitura da força máxima durante a obtenção dos valores. Possui uma célula de carga de precisão elevada e circuito eletrônico que indicam a força, fornecendo medidas precisas e de fácil leitura no seu visor digital. 
Figura 10 - Dinamômetro digital Kratos, modelo IDDK.

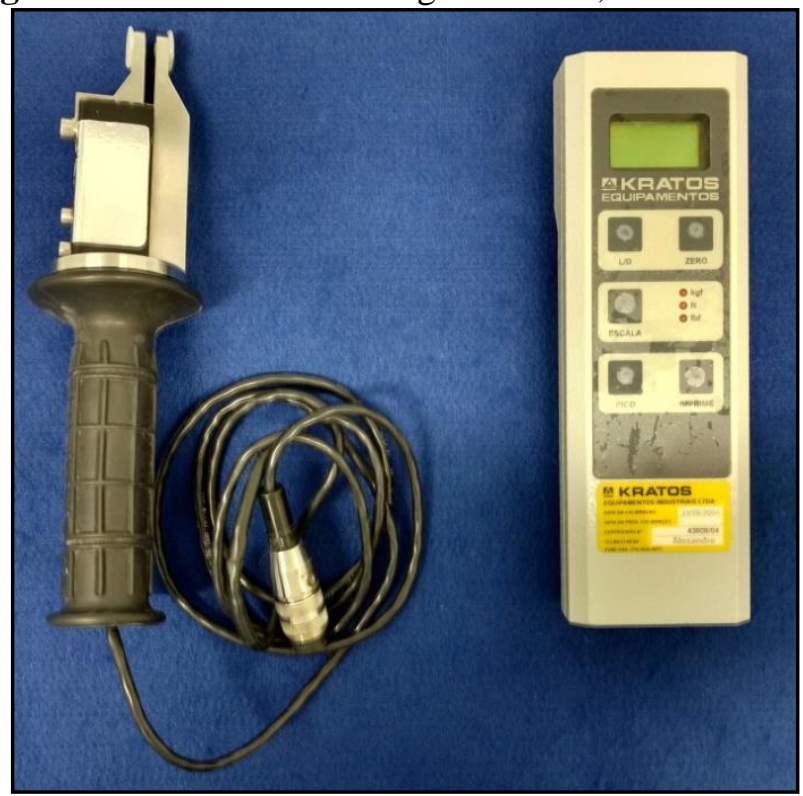

Fonte: Arquivo pessoal

Durante a coleta, as participantes da pesquisa foram posicionadas em uma cadeira confortável mantendo os pés apoiados sobre o solo, postura ereta e as mãos apoiadas sobre as coxas. Por motivo de biossegurança, as hastes do aparelho foram limpas previamente com álcool a cada coleta e protegidas com dedeiras de látex descartáveis (Wariper, SP) e posicionadas na região do primeiro molar permanente (Figura 11) direito e esquerdo, onde se desenvolve a maior força de mordida (REGALO et al., 2008).

Figura 11 - Dinamômetro posicionado na região dos primeiros molares (lado esquerdo).

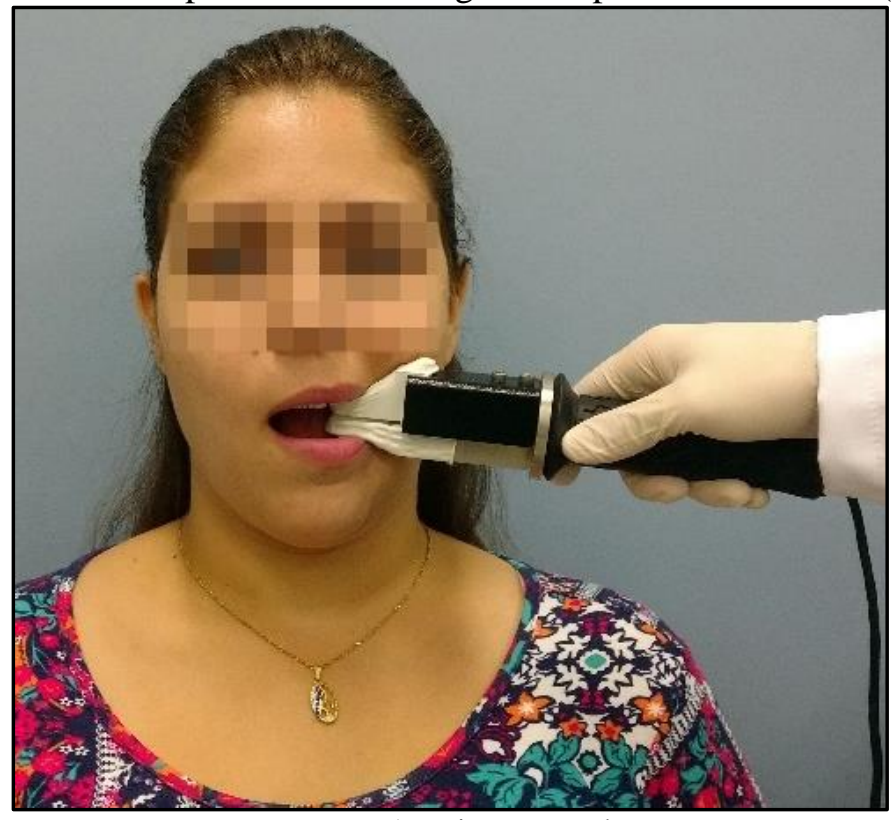

Fonte: Arquivo pessoal 
As participantes apertaram três vezes com força máxima as hastes do dinamômetro, intercalando lado direito e esquerdo, com descanso de dois minutos entre cada registro (BONJARDIM et al., 2009). Foi considerada a maior força de mordida em ambos os lados como método de análise.

\subsubsection{AVALIAÇÃO POSTURAL}

Para análise da postura estática, as participantes da pesquisa foram avaliadas por meio da fotogrametria. O critério de padronização das imagens foi o posicionamento sobre uma plataforma de nivelamento tridimensional à frente de um simetrógrafo com dimensões de 200x100 cm e de $10 \mathrm{~cm}$ de quadrangular (Figura 12), com a participante em trajes de banho. Previamente ao posicionamento, foi realizado um critério de nivelamento parede-solo.

Figura 12 - Posicionamento da participante para aquisição das imagens fotográficas nas vistas anterior (L), lateral direita $(\mathrm{M})$, lateral esquerda $(\mathrm{N})$ e posterior $(\mathrm{O})$.

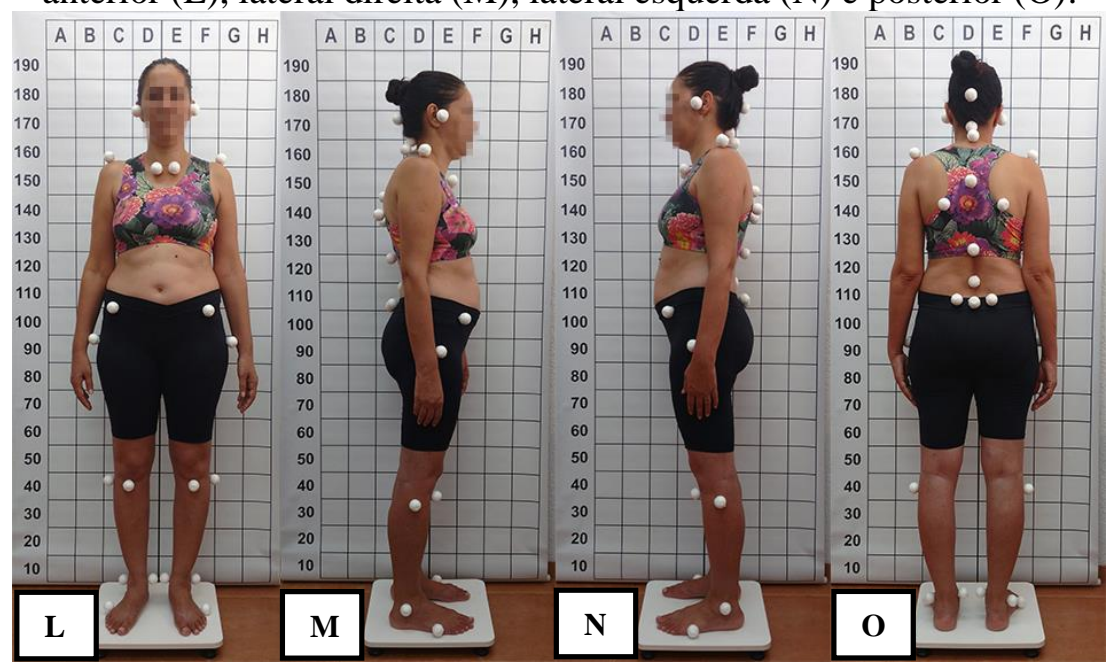

Uma câmera da marca Fujifilm Finepix S2800 HD 14.0 megapixels foi posicionada sobre um tripé a $90 \mathrm{~cm}$ de altura e a uma distância de 2,4 m entre a lente focal da câmera ao centro corporal da participante da pesquisa.

A distância foi demarcada ao solo com uma fita adesiva para padronização de avaliações futuras. Após a padronização biofotogramétrica foi realizado o posicionamento de demarcadores passivos em estruturas corporais específicas.

$\mathrm{Na}$ análise da postura corporal foi utilizado para realizar a demarcação os seguintes pontos referenciais (bilateralmente): trago auricular; articulação acromioclavicular; articulação esternoclavicular; protuberância occipital; espinha ilíaca ântero-superior (EIAS); 
espinha ilíaca póstero-superior; processo espinhoso de C4, C7, T7, T12, L3 e L5; ângulo inferior da escápula; trocânter maior do fêmur; tuberosidade da tíbia; cabeça da fíbula; maléolo lateral; maléolo medial e tuberosidade da diáfise distal do $5^{\circ}$ metatarso, lateralmente (IUNES et al. 2004). A obtenção das imagens foi realizada por um único avaliador, sem zoom e em quatro planos de delimitação: anterior, lateral direito, lateral esquerdo e posterior.

Os eixos angulares (Figura 13) foram analisados conforme descrito por Iunes et al., (2004) pelo software ALCimagem versão 2.1 (Figura 14):

a) AC (ângulo da articulação acromioclavicular), obtido pelo traço das linhas que unem o ponto anatômico demarcado à direita com o da esquerda e uma linha traçada paralelamente ao solo, na horizontal;

b) EC (ângulo da articulação esternoclavicular), obtido pelo traço das linhas que unem o ponto anatômico demarcado à direita com o da esquerda e uma linha traçada paralelamente ao solo, na horizontal;

c) AS (ângulo das espinhas ilíacas ântero-superiores), obtido pelo traço das linhas que unem o ponto anatômico demarcado à direita com o da esquerda e uma linha traçada paralelamente ao solo, na horizontal;

d) $\Delta \mathrm{T}$ (triangulo de Talles): obtido pela intersecção da reta adjacente à cintura com a que passa pelo bordo medial do membro superior;

e) AJ (angulação do joelho), obtido pela intersecção da reta que une a tuberosidade da tíbia e a EIAS à uma reta perpendicular ao solo;

f) IE (ângulo inferior da escápula), obtido pelo traço das linhas que unem o ponto anatômico demarcado à direita com o da esquerda e uma linha traçada paralelamente ao solo, na horizontal;

g) PS (ângulo das espinhas ilíacas póstero-superiores), obtido pelo traço das linhas que unem o ponto anatômico demarcado à direita com o da esquerda e uma linha traçada paralelamente ao solo, na horizontal;

h) IP (ângulo de inclinação do pé), obtido pela intersecção da reta que une o bordo interno do pé ao maléolo medial com uma reta paralela ao solo;

i) PC (protrusão da cabeça), obtido pela intersecção da reta que une o processo espinhoso de $\mathrm{C} 7$ ao tragus da orelha com uma reta paralela ao solo;

j) LC (lordose cervical), obtido pela intersecção da reta que une uma linha horizontal do processo espinhoso de $\mathrm{C} 4$ no fio de prumo à protuberância occipital e a linha que une o processo espinhoso de C7 à linha horizontal do processo espinhoso de C4 no fio de prumo; 
k) CT (cifose torácica), obtido pela intersecção da reta que une uma linha horizontal do processo espinhoso de $\mathrm{T} 7$ no fio de prumo ao processo espinhoso de C7 e a linha que une o processo espinhoso de T12 à linha horizontal do processo espinhoso de T7 no fio de prumo;

1) LL (lordose lombar), obtido pela intersecção da reta que une uma linha horizontal do processo espinhoso de T12 no fio de prumo ao processo espinhoso de T7 e a linha que une o processo espinhoso de L5 à linha horizontal do processo espinhoso de 12 no fio de prumo;

m) FL (flexo de joelho), obtido pela intersecção da linha que une o trocânter maior do fêmur à cabeça da fíbula e a linha da cabeça da fíbula até o maléolo lateral;

n) ATT (ângulo tibiotársico), obtido pela intersecção da linha que une a cabeça da fíbula ao maléolo lateral e a linha do maléolo lateral à tuberosidade da diáfise distal do $5^{\circ}$ metatarso.

Figura 13 - Ilustração dos eixos angulares
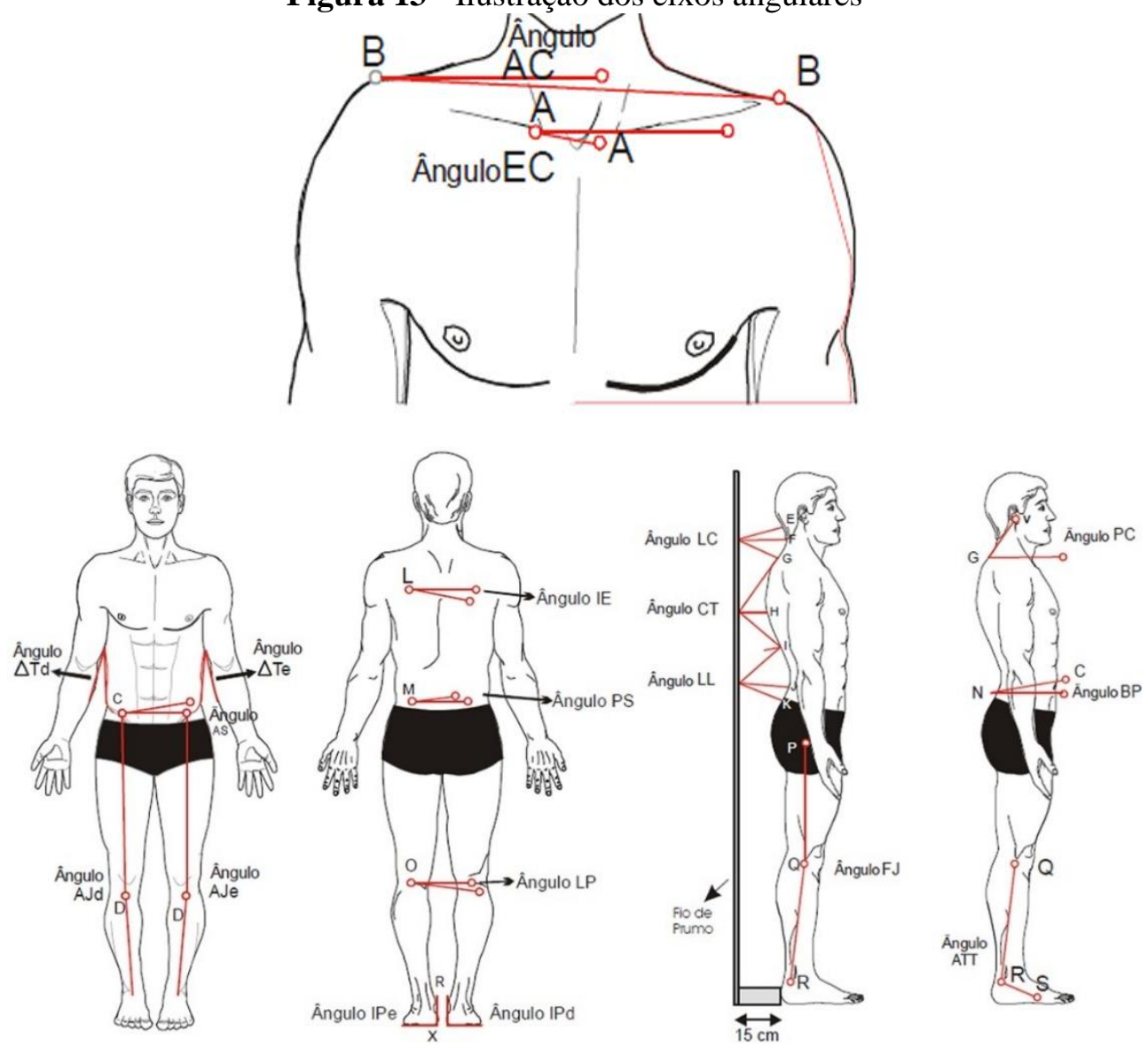

Fonte: Adaptado de "Análise da confiabilidade inter e intra-examinador na avaliação postural pela fotogrametria computadorizada" (IUNES et al., 2004) 
Figura 14 - Cálculo dos valores angulares no software ALCimagem.

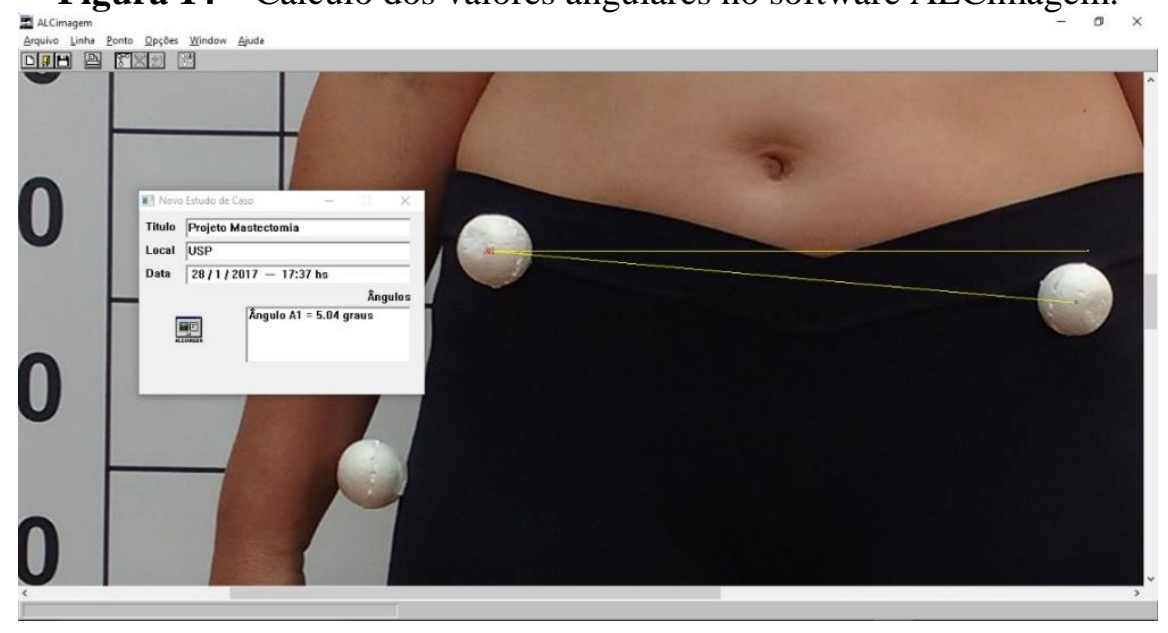

Fonte: Arquivo pessoal

\subsection{ANÁLISE ESTATÍSTICA DOS DADOS}

O sinal eletromiográfico bruto foi utilizado para derivar valores de amplitudes eletromiográficas, obtidos pelo cálculo da raiz quadrada da média (RMS). A função dos ciclos mastigatórios foi verificada por meio da integral da envoltória linear do sinal eletromiográfico normalizado, sendo este valor em microvolts/segundo $(\mu \mathrm{V})$.

Mediante a necessidade de comparações entre diferentes participantes, os valores da RMS e integral da envoltória obtidos durante o apertamento dental em contração voluntária máxima com Parafilme $\mathbf{M}^{\circledR}$, bilateral, foram utilizados para a normalização dos valores da atividade eletromiográfica em repouso, protrusão, lateralidade direita e lateralidade esquerda. Para os valores obtidos na mastigação habitual e não habitual, seguiu-se o mesmo princípio, porém foram utilizados os valores da integral da envoltória durante o apertamento dental em contração voluntária máxima, bilateral, para a normalização dos dados.

Os dados eletromiográficos normalizados, ultrassonográficos, força de mordida molar máxima e postura estática foram submetidos à análise estatística utilizando o software SPSS versão 21.0 para Windows (SPSS Inc.; Chicago, IL, USA). Os resultados foram obtidos por meio da análise descritiva (média e erro padrão) para cada variável. Os valores entre GM e GC foram comparados pelo teste $t$ de student para amostras independentes $(p \leq 0,05)$. A comparação entre os lados operado e não operado foi realizada por meio do teste $t$ pareado. $\mathrm{Na}$ análise postural, a comparação foi realizada pelo lado operado do grupo mastectomia com o lado dominante do grupo controle e o lado não operado do grupo mastectomia com lado não dominante do grupo controle. 




\section{RESULTADOS}

\subsection{ANÁLISE ELETROMIOGRÁFICA - PADRÕES POSTURAIS (RMS)}

\subsubsection{REPOUSO}

$\mathrm{Na}$ análise das médias eletromiográficas normalizadas para condição de repouso mandibular, não houve diferença estatística significante $(p \leq 0,05)$ entre os grupos GM e GC para os músculos temporais e masseteres. GM apresentou maiores médias eletromiográficas para todos os músculos quando comparadas ao GC (Figura 15 e Tabela 4).

Figura 15 - Médias eletromiográficas normalizadas (RMS) na condição de repouso mandibular para o músculo temporal direito (TD), temporal esquerdo (TE), masseter direito (MD) e masseter esquerdo (ME) no grupo mastectomia (GM) e controle sem a doença (GC).

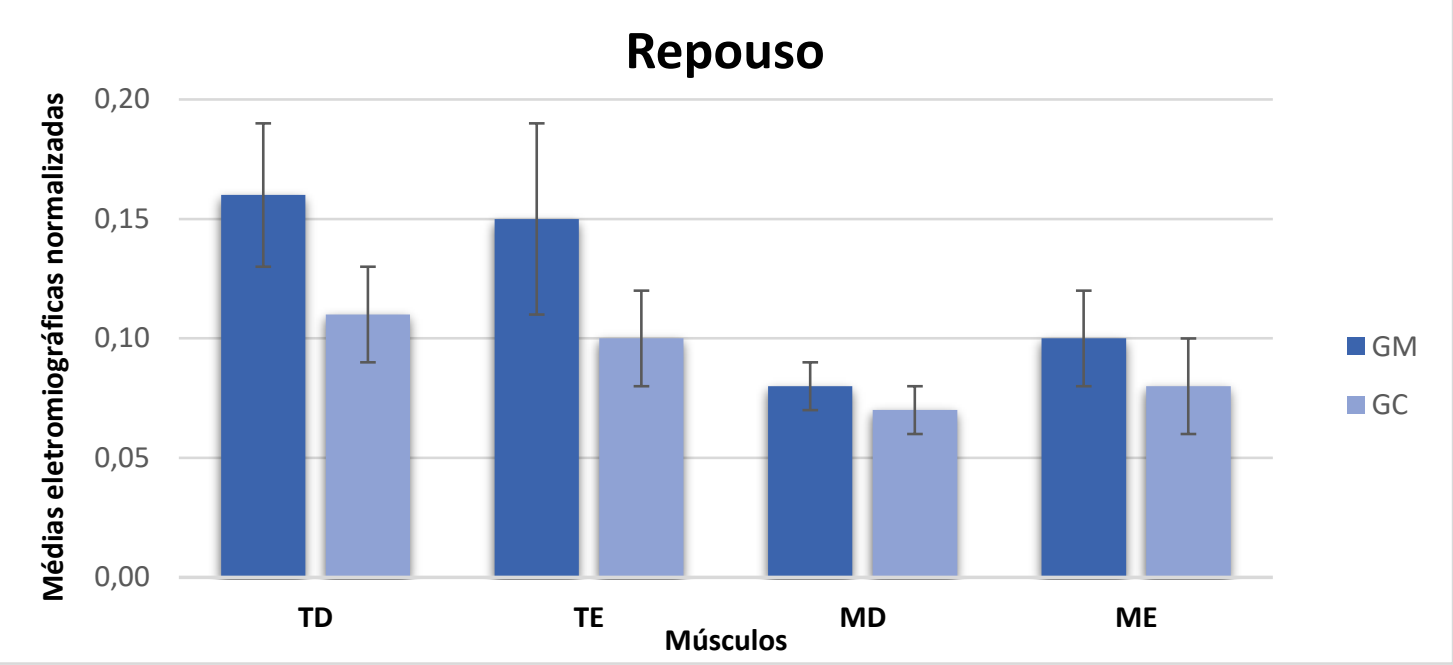

Tabela 4 - Médias eletromiográficas normalizadas $(\mu \mathrm{V})$, erro padrão e valor $p$ na condição de repouso.

\begin{tabular}{ccccc}
\hline Músculos & Grupo & Médias & Erro padrão & Valor $\boldsymbol{d e} \boldsymbol{p}$ \\
\hline \multirow{2}{*}{ TD } & GM & 0,16 & 0,03 & 0,12 \\
& GC & 0,11 & 0,02 & 0,24 \\
TE & GM & 0,15 & 0,04 & 0,51 \\
& GC & 0,10 & 0,02 & \multirow{2}{*}{ MD } \\
\multirow{2}{*}{ ME } & GM & 0,08 & 0,01 & 0,44 \\
& GC & 0,07 & 0,01 & \\
& GM & 0,10 & 0,02 & 0,02 \\
\hline
\end{tabular}

GM: grupo mastectomia; GC: grupo controle; TD: temporal direito; TE: temporal esquerdo; MD: masseter direito; ME: masseter esquerdo. 


\subsubsection{PROTRUSÃO}

Na análise das médias eletromiográficas normalizadas para condição de protrusão, não houve diferença estatística significante $(p \leq 0,05)$ entre os grupos GM e GC para os músculos temporais e masseteres. GM apresentou maiores médias eletromiográficas para todos os músculos quando comparadas ao GC (Figura 16 e Tabela 5).

Figura 16 - Médias eletromiográficas normalizadas (RMS) na condição de protrusão para o músculo temporal direito (TD), temporal esquerdo (TE), masseter direito (MD) e masseter esquerdo (ME) no grupo mastectomia (GM) e controle sem a doença (GC).

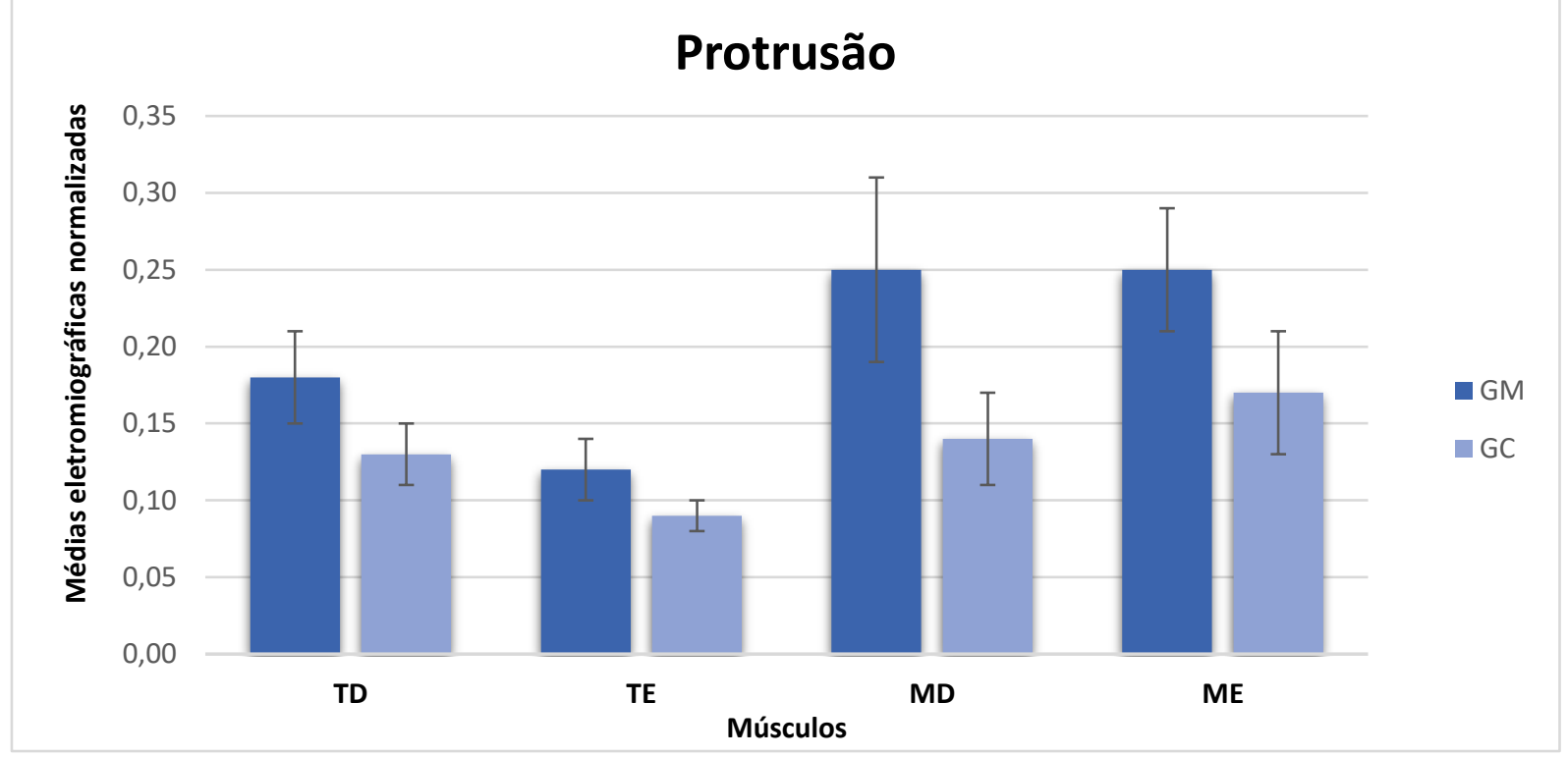

Tabela 5 - Médias eletromiográficas normalizadas $(\mu \mathrm{V})$, erro padrão e valor $p$ na condição de protrusão.

\begin{tabular}{ccccc}
\hline Músculos & Grupo & Médias & Erro padrão & Valor de $\boldsymbol{p}$ \\
\hline \multirow{2}{*}{ TD } & GM & 0,18 & 0,03 & 0,20 \\
& GC & 0,13 & 0,02 & \\
TE & GM & 0,12 & 0,02 & 0,16 \\
& GC & 0,09 & 0,01 & \multirow{2}{*}{ GD } \\
MD & GM & 0,25 & 0,06 & \\
& GC & 0,14 & 0,03 & 0,17 \\
ME & GM & 0,25 & 0,04 & \\
\hline
\end{tabular}

GM: grupo mastectomia; GC: grupo controle; TD: temporal direito; TE: temporal esquerdo; MD: masseter direito; ME: masseter esquerdo. 


\subsubsection{LATERALIDADE DIREITA}

$\mathrm{Na}$ análise das médias eletromiográficas normalizadas para condição de lateralidade direita, houve diferença estatística significante $(p \leq 0,05)$ entre os grupos GM e GC para o músculo masseter direito. GM apresentou maiores médias eletromiográficas para o músculo temporal direito, masseter direito e masseter esquerdo quando comparado ao GC. Os valores mostraram-se semelhantes para o músculo temporal esquerdo (Figura 17 e Tabela 6).

Figura 17 - Médias eletromiográficas normalizadas (RMS) na condição de lateralidade direita para o músculo temporal direito (TD), temporal esquerdo (TE), masseter direito (MD) e masseter esquerdo (ME) no grupo mastectomia (GM) e controle sem a doença (GC).

\section{Lateralidade Direita}

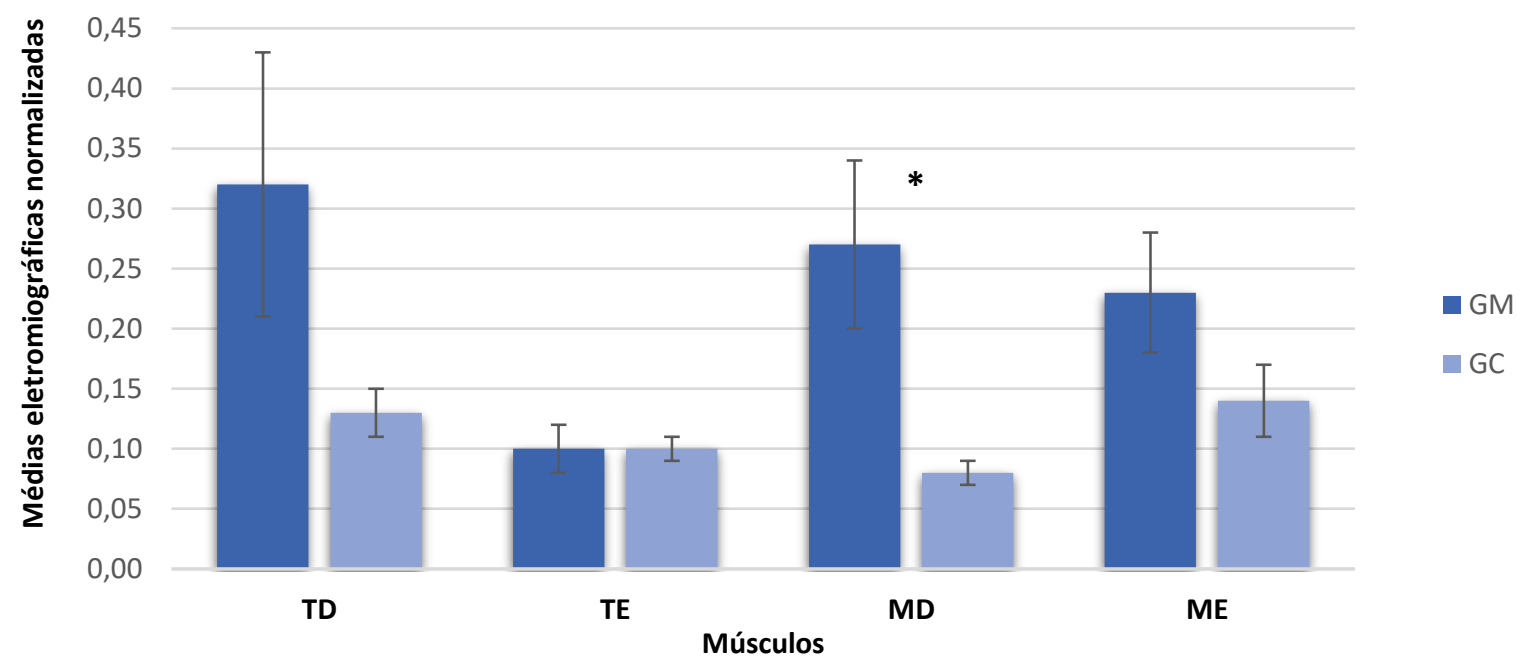

Tabela 6 - Médias eletromiográficas normalizadas $(\mu \mathrm{V})$, erro padrão e valor $p$ na condição de lateralidade direita.

\begin{tabular}{ccccc}
\hline Músculos & Grupo & Médias & Erro padrão & Valor de $\boldsymbol{p}$ \\
\hline \multirow{2}{*}{ TD } & GM & 0,32 & 0,11 & 0,10 \\
& GC & 0,13 & 0,02 & 0,96 \\
TE & GM & 0,10 & 0,02 & \multirow{2}{*}{$0,02^{*}$} \\
& GC & 0,10 & 0,01 & \multirow{2}{*}{ MD } \\
ME & GM & 0,27 & 0,07 & \\
& GC & 0,08 & 0,01 & 0,05 \\
\hline
\end{tabular}

GM: grupo mastectomia; GC: grupo controle; TD: temporal direito; TE: temporal esquerdo; MD: masseter direito; ME: masseter esquerdo; valores significantes $(p \leq 0,05)^{*}$. 


\subsubsection{LATERALIDADE ESQUERDA}

$\mathrm{Na}$ análise das médias eletromiográficas normalizadas para condição de lateralidade esquerda, houve diferença estatística significante $(p \leq 0,05)$ entre os grupos GM e GC para o músculo masseter esquerdo. GM apresentou maiores médias eletromiográficas para todos os músculos quando comparadas ao GC (Figura 18 e Tabela 7).

Figura 18 - Médias eletromiográficas normalizadas (RMS) na condição de lateralidade esquerda para o músculo temporal direito (TD), temporal esquerdo (TE), masseter direito (MD) e masseter esquerdo (ME) no grupo mastectomia (GM) e controle sem a doença (GC).

\section{Lateralidade Esquerda}

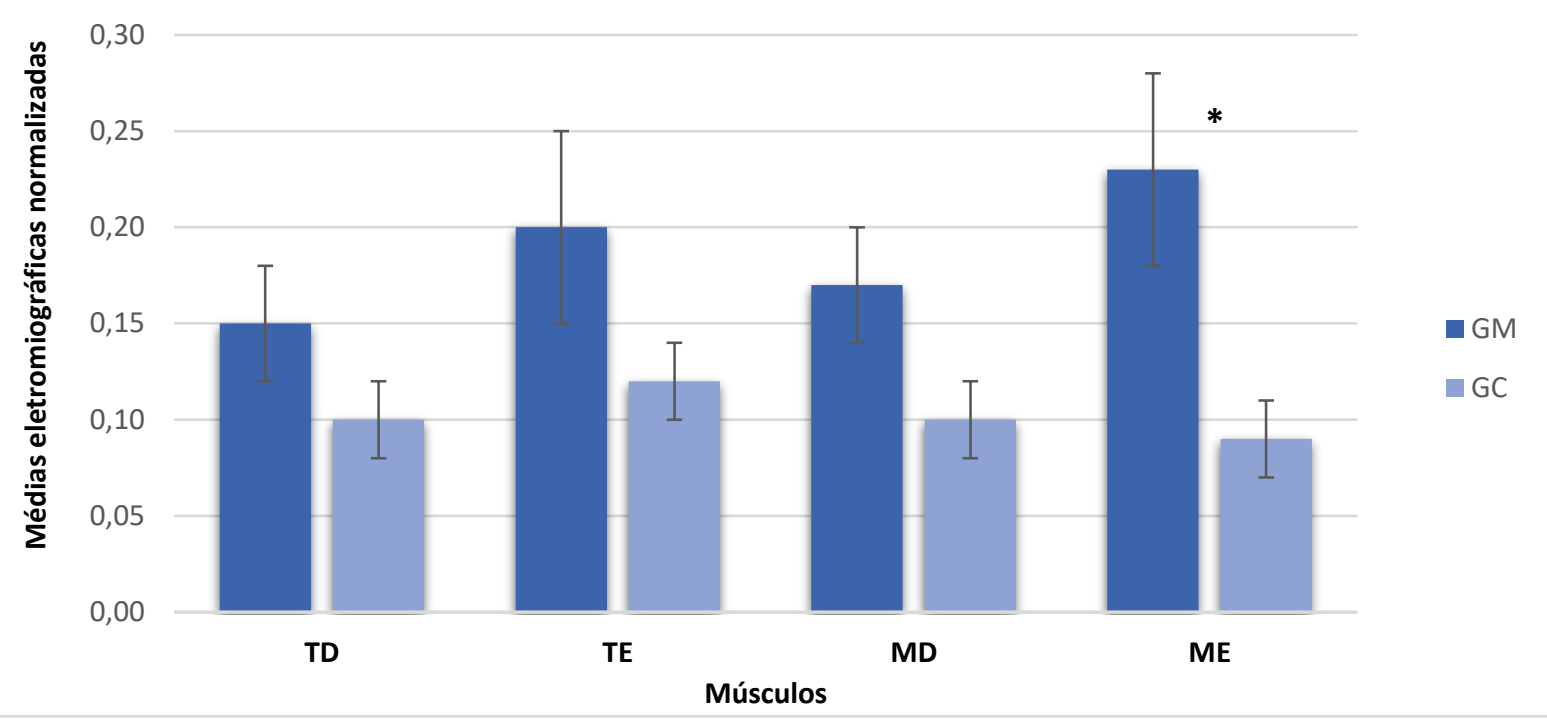

Tabela 7 - Médias eletromiográficas normalizadas $(\mu \mathrm{V})$, erro padrão e valor $p$ na condição de lateralidade esquerda.

\begin{tabular}{ccccc}
\hline Músculos & Grupo & Médias & Erro padrão & Valor de $\boldsymbol{p}$ \\
\hline \multirow{2}{*}{ TD } & GM & 0,15 & 0,03 & 0,11 \\
& GC & 0,10 & 0,02 & 0,14 \\
TE & GM & 0,20 & 0,05 & \multirow{2}{*}{0,07} \\
& GC & 0,12 & 0,02 & \multirow{2}{*}{ MD } \\
\multirow{2}{*}{ ME } & GM & 0,17 & 0,03 & \\
& GC & 0,10 & 0,02 & \\
\hline
\end{tabular}

GM: grupo mastectomia; GC: grupo controle; TD: temporal direito; TE: temporal esquerdo; MD: masseter direito; ME: masseter esquerdo; valores significantes $(p \leq 0,05)^{*}$. 


\subsubsection{CONTRAÇÃO VOLUNTÁRIA MÁXIMA}

$\mathrm{Na}$ análise das médias eletromiográficas normalizadas para condição de contração voluntária máxima, não houve diferença estatística significante $(p \leq 0,05)$ entre os grupos GM e GC para os músculos temporais e masseteres. GM apresentou maiores médias eletromiográficas para o músculo temporal esquerdo e músculo masseter direito e menores médias eletromiográficas para o músculo temporal direito e músculo masseter esquerdo quando comparadas ao GC (Figura 19 e Tabela 8).

Figura 19 - Médias eletromiográficas normalizadas (RMS) na condição contração voluntária máxima para o músculo temporal direito (TD), temporal esquerdo (TE), masseter direito (MD) e masseter esquerdo (ME) no grupo mastectomia (GM) e controle sem a doença (GC).

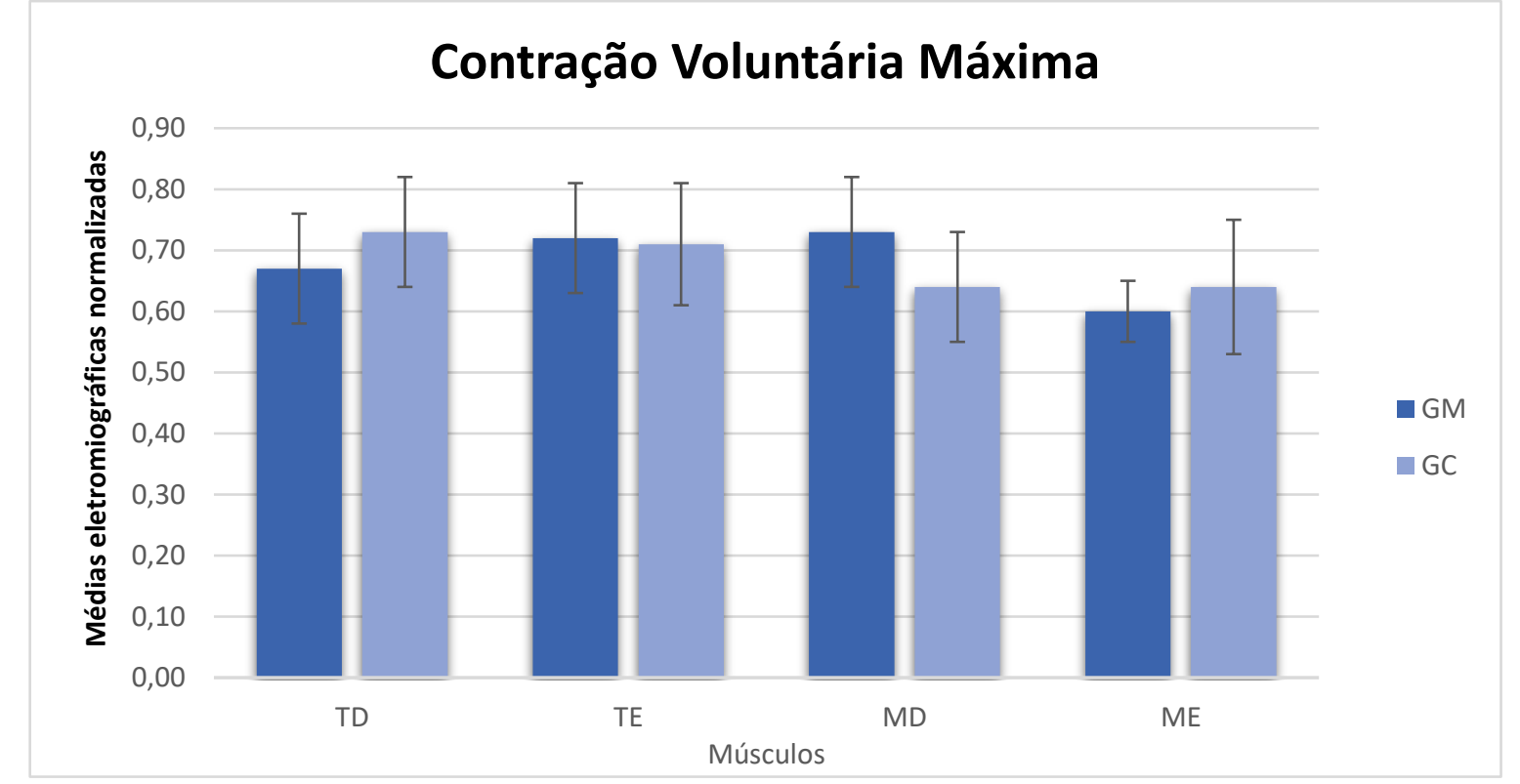

Tabela 8 - Médias eletromiográficas normalizadas $(\mu \mathrm{V})$, erro padrão e valor $p$ na condição de contração voluntária máxima.

\begin{tabular}{ccccc}
\hline Músculos & Grupo & Médias & Erro padrão & Valor de $\boldsymbol{p}$ \\
\hline \multirow{2}{*}{ TD } & GM & 0,67 & 0,09 & 0,67 \\
& GC & 0,73 & 0,09 & 0,95 \\
TE & GM & 0,72 & 0,09 & \\
& GC & 0,71 & 0,10 & 0,50 \\
MD & GM & 0,73 & 0,09 & 0,77 \\
& GC & 0,64 & 0,09 & \\
\hline
\end{tabular}

GM: grupo mastectomia; GC: grupo controle; TD: temporal direito; TE: temporal esquerdo; MD: masseter direito; ME: masseter esquerdo. 


\subsection{ANÁLISE ELETROMIOGRÁFICA - FUNÇÃO MASTIGATÓRIA}

\subsubsection{MASTIGAÇÃO NÃO HABITUAL DE PARAFILME $M^{\circledR}$}

$\mathrm{Na}$ análise das médias eletromiográficas normalizadas para condição de mastigação não habitual de parafilme $\mathbf{M}^{\circledR}$, não houve diferença estatística significante $(p \leq 0,05)$ entre os grupos GM e GC para os músculos temporais e masseteres. GM apresentou maiores médias eletromiográficas para todos os músculos quando comparadas ao GC (Figura 20 e Tabela 9).

Figura 20 - Médias eletromiográficas normalizadas (RMS) na condição de mastigação não habitual de parafilme $\mathrm{M}^{\circledR}$ para o músculo temporal direito (TD), temporal esquerdo (TE), masseter direito (MD) e masseter esquerdo (ME) no grupo mastectomia (GM) e controle sem a doença (GC).

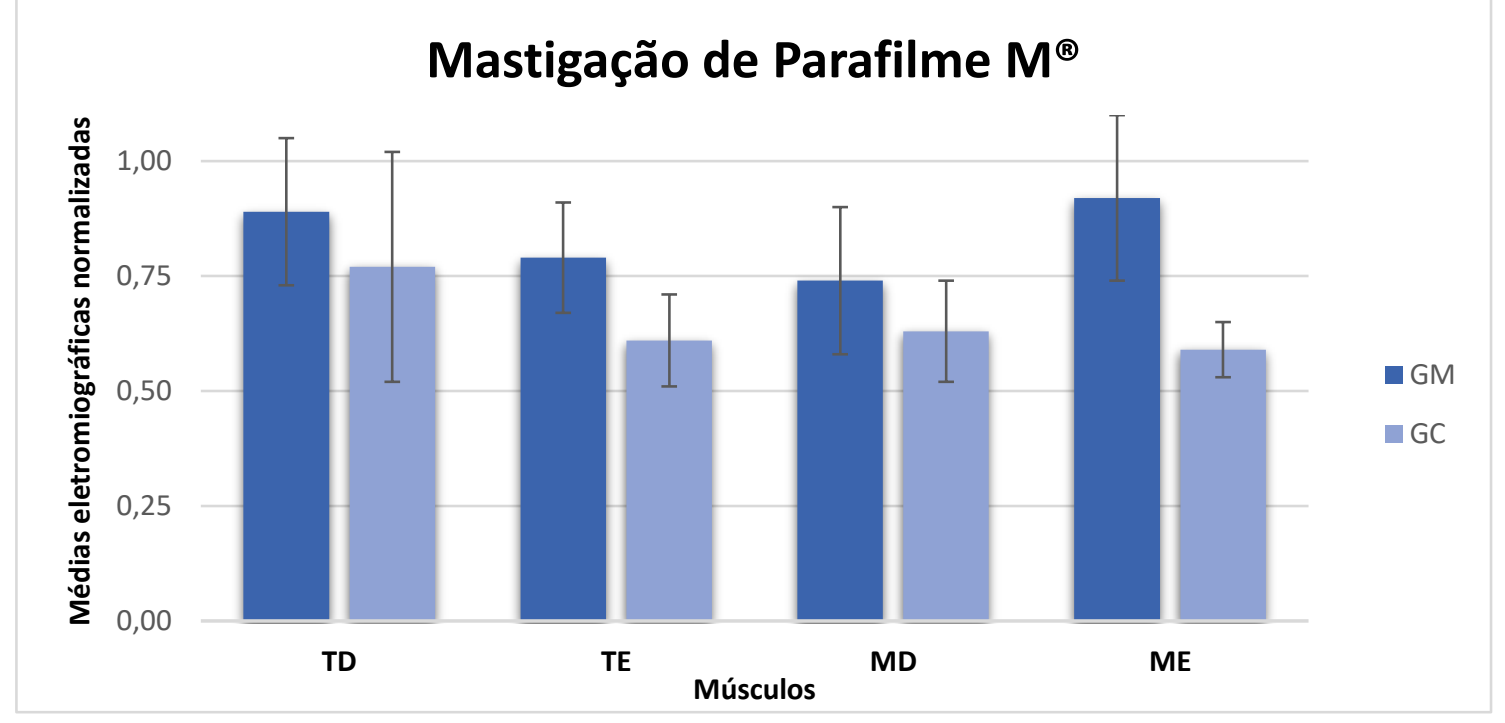

Tabela 9 - Médias eletromiográficas normalizadas $(\mu \mathrm{V})$, erro padrão e valor $p$ na condição de mastigação não habitual de parafilme $\mathbf{M}^{\circledR}$.

\begin{tabular}{ccccc}
\hline Músculos & Grupo & Médias & Erro padrão & Valor de $\boldsymbol{p}$ \\
\hline \multirow{2}{*}{ TD } & GM & 0,89 & 0,16 & 0,69 \\
& GC & 0,77 & 0,25 & 0,25 \\
TE & GM & 0,79 & 0,12 & \\
& GC & 0,61 & 0,10 & 0,57 \\
MD & GM & 0,74 & 0,16 & 0,09 \\
& GC & 0,63 & 0,11 & \\
\hline
\end{tabular}

GM: grupo mastectomia; GC: grupo controle; TD: temporal direito; TE: temporal esquerdo; MD: masseter direito; ME: masseter esquerdo. 


\subsubsection{MASTIGAÇÃO HABITUAL DE AMENDOINS (ALIMENTO CONSISTENTE)}

$\mathrm{Na}$ análise das médias eletromiográficas normalizadas para condição de mastigação não habitual de amendoins, houve diferença estatística significante $(p \leq 0,05)$ entre os grupos GM e GC para o músculo masseter direito. GM apresentou maiores médias eletromiográficas para todos os músculos quando comparadas ao GC (Figura 21 e Tabela 10).

Figura 21 - Médias eletromiográficas normalizadas (RMS) na condição de mastigação não habitual de amendoins para o músculo temporal direito (TD), temporal esquerdo (TE), masseter direito (MD) e masseter esquerdo (ME) no grupo mastectomia (GM) e controle sem a doença (GC).

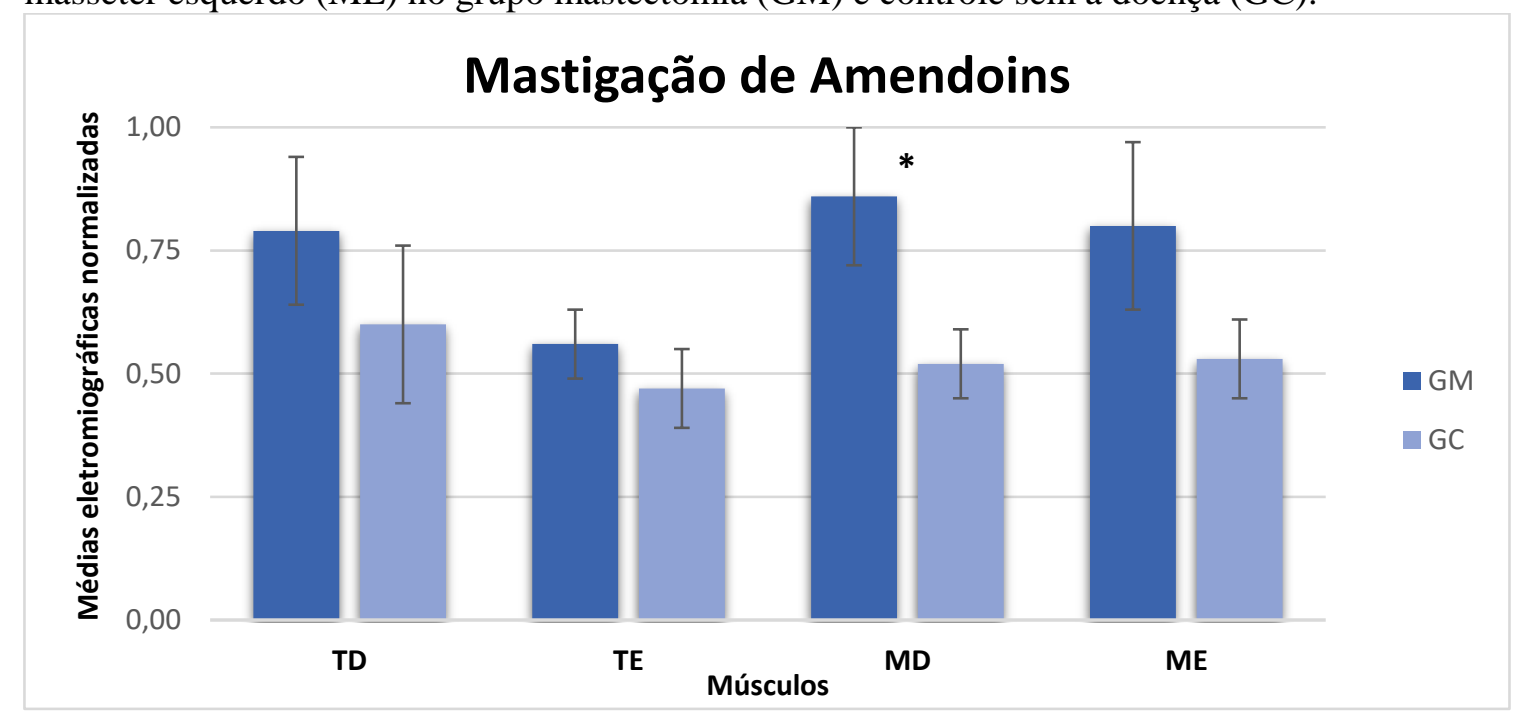

Tabela 10 - Médias eletromiográficas normalizadas $(\mu \mathrm{V})$, erro padrão e valor $\mathrm{p}$ na condição clínica mastigação habitual de amendoins.

\begin{tabular}{ccccc}
\hline Músculos & Grupo & Médias & Erro padrão & Valor de $\boldsymbol{p}$ \\
\hline \multirow{2}{*}{ TD } & GM & 0,79 & 0,15 & 0,39 \\
& GC & 0,60 & 0,16 & 0,42 \\
TE & GM & 0,56 & 0,07 & \\
& GC & 0,47 & 0,08 & $0,04^{*}$ \\
MD & GM & 0,86 & 0,14 & 0,15 \\
& GC & 0,52 & 0,07 & \\
\hline
\end{tabular}

GM: grupo mastectomia; GC: grupo controle; TD: temporal direito; TE: temporal esquerdo; MD: masseter direito; ME: masseter esquerdo; valores significantes $(p \leq 0,05)^{*}$. 


\subsubsection{MASTIGAÇÃO HABITUAL DE UVAS PASSAS (ALIMENTO MACIO)}

$\mathrm{Na}$ análise das médias eletromiográficas normalizadas para condição de mastigação não habitual de uvas passas, houve diferença estatística significante $(p \leq 0,05)$ entre os grupos GM e GC para o músculo masseter esquerdo. GM apresentou maiores médias eletromiográficas para todos os músculos quando comparadas ao GC (Figura 22 e Tabela 11).

Figura 22 - Médias eletromiográficas normalizadas (RMS) na condição de mastigação não habitual de uvas passas para o músculo temporal direito (TD), temporal esquerdo (TE), masseter direito (MD) e masseter esquerdo (ME) no grupo mastectomia (GM) e controle sem a doença (GC).

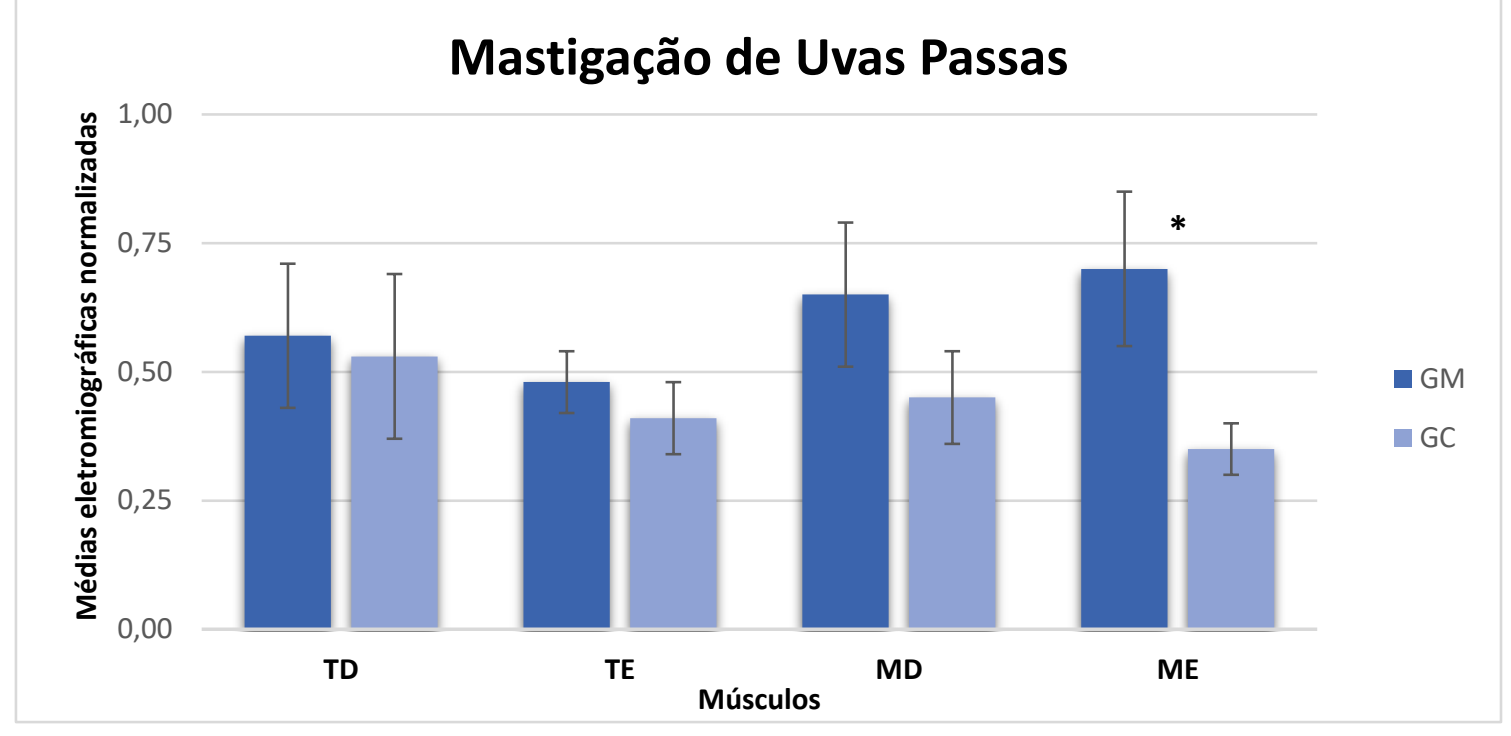

Tabela 11 - Médias eletromiográficas normalizadas $(\mu \mathrm{V})$, erro padrão e valor $p$ na condição de mastigação habitual de uvas-passas.

\begin{tabular}{ccccc}
\hline Músculos & Grupo & Médias & Erro padrão & Valor de $\boldsymbol{p}$ \\
\hline \multirow{2}{*}{ TD } & GM & 0,57 & 0,14 & 0,83 \\
& GC & 0,53 & 0,16 & 0,47 \\
TE & GM & 0,48 & 0,06 & \\
& GC & 0,41 & 0,07 & 0,26 \\
MD & GM & 0,65 & 0,14 & \multirow{2}{*}{$0,03 *$} \\
& GC & 0,45 & 0,09 & \\
\hline
\end{tabular}

GM: grupo mastectomia; GC: grupo controle; TD: temporal direito; TE: temporal esquerdo; MD: masseter direito; ME: masseter esquerdo; valores significantes $(p \leq 0,05)^{*}$. 


\subsection{FORÇA DE MORDIDA MOLAR MÁXIMA}

$\mathrm{Na}$ análise da força de mordida molar máxima direita e esquerda, houve diferença estatística significante $(p \leq 0,05)$ entre os grupos GM e GC para força de mordida molar direita. GM apresentou menores médias de força de mordida molar máxima quando comparadas ao GC (Figura 23 e Tabela 12).

Figura 23 - Médias da força de mordida molar máxima para o grupo mastectomia (GM) e grupo controle (GC), na região do primeiro molar direito e esquerdo, com valores em Kgf.

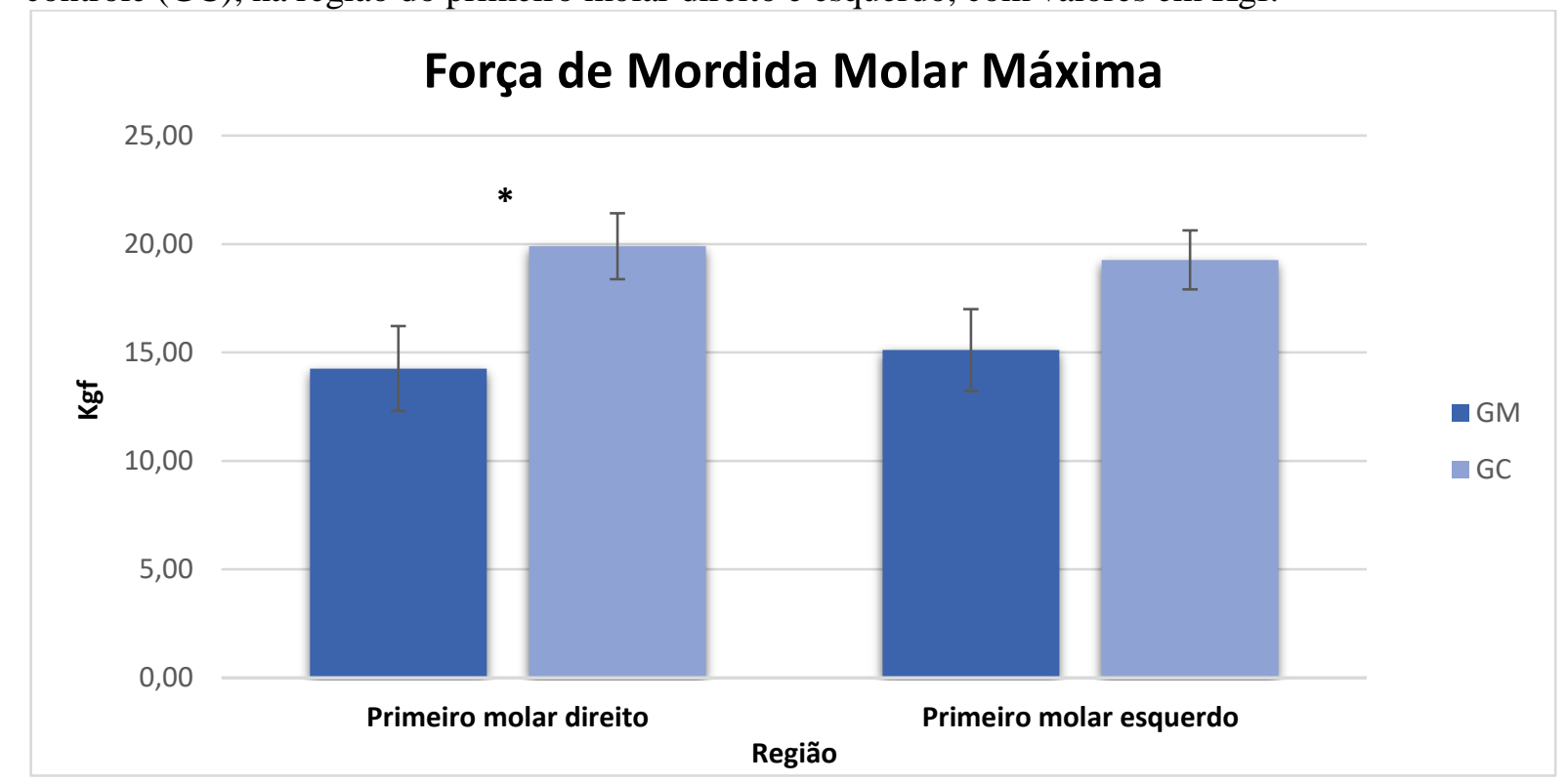

Tabela 12 - Médias (kgf), erro padrão e valor p da força de mordida molar máxima.

\begin{tabular}{ccccc}
\hline $\begin{array}{c}\text { Força de mordida } \\
\text { molar }\end{array}$ & Grupo & Médias & Erro padrão & Valor de $\boldsymbol{p}$ \\
\hline Direita & GM & 14,26 & 1,96 & $0,03^{*}$ \\
& GC & 19,90 & 1,52 & \\
Esquerda & GM & 15,11 & 1,89 & 0,08 \\
& GC & 19,27 & 1,36 & \\
\hline
\end{tabular}

GM: grupo mastectomia; GC: grupo controle; valores significantes $(p \leq 0,05)^{*}$. 


\subsection{ANÁLISE ULTRASSONOGRÁFICA}

\subsubsection{REPOUSO}

$\mathrm{Na}$ análise em repouso da espessura do músculo temporal e masseter, bilateralmente, não foi evidenciado diferença estatística significante $(p \leq 0,05)$ entre o grupo GM e GC. As médias das espessuras musculares foram semelhantes entre os dois grupos (Figura 24 e Tabela $13)$.

Figura 24 - Médias de espessura muscular para condição de repouso para os músculos temporal direito (TD), temporal esquerdo (TE), masseter direito (MD) e masseter esquerdo (ME) no grupo mastectomia (GM) e controle sem a doença (GC).

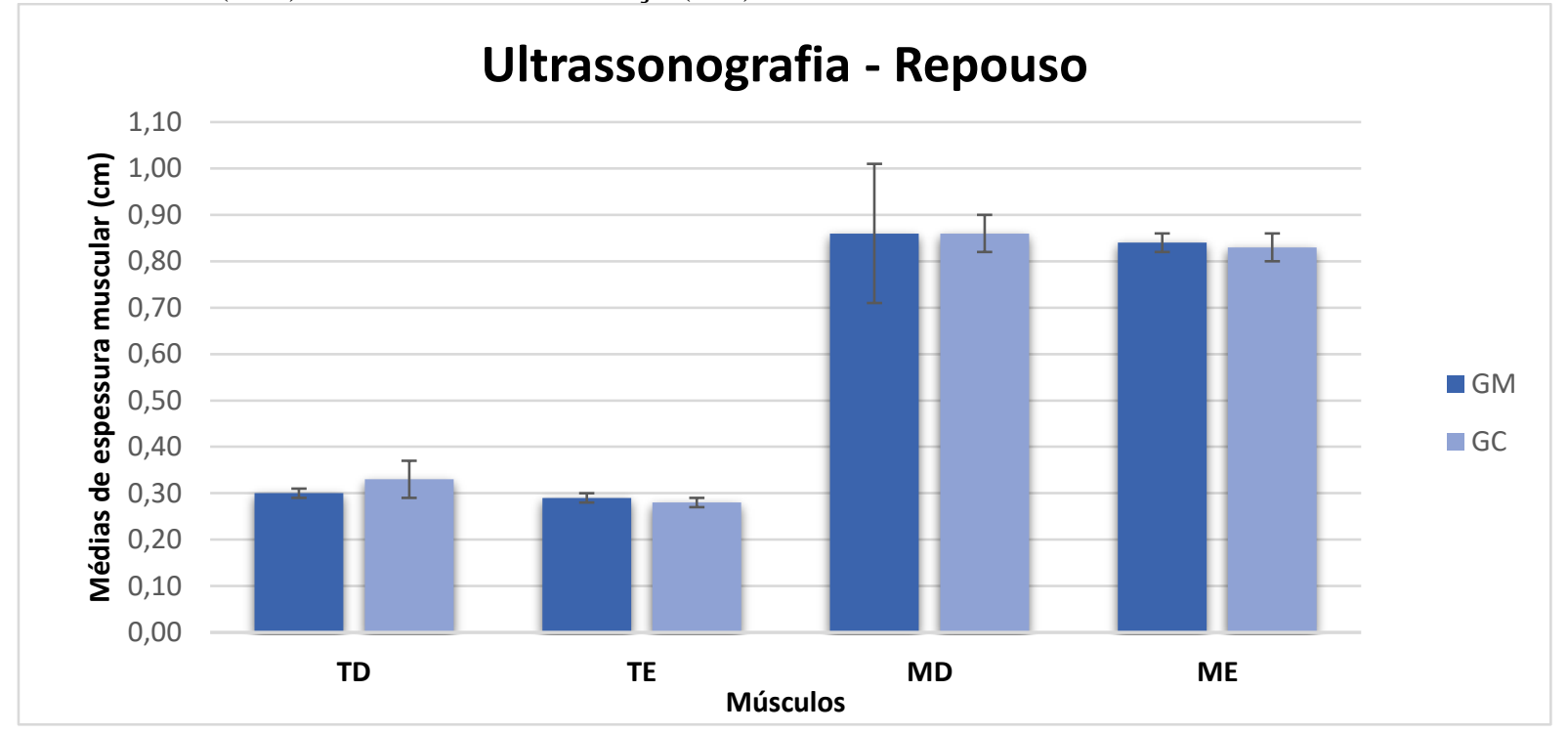

Tabela 13 - Médias, erro padrão e valor $p$ para espessura muscular $(\mathrm{cm})$ na condição de repouso.

\begin{tabular}{ccccc}
\hline Músculos & Grupo & Médias & Erro padrão & Valor de $\boldsymbol{p}$ \\
\hline \multirow{2}{*}{ TD } & GM & 0,30 & 0,01 & 0,56 \\
& GC & 0,33 & 0,04 & 0,44 \\
TE & GM & 0,29 & 0,01 & \\
& GC & 0,28 & 0,01 & 0,92 \\
MD & GM & 0,86 & 0,04 & 0,81 \\
& GC & 0,86 & 0,02 & \\
\hline
\end{tabular}

GM: grupo mastectomia; GC: grupo controle; TD: temporal direito; TE: temporal esquerdo; MD: masseter direito; ME: masseter esquerdo. 


\subsubsection{CONTRAÇÃO VOLUNTÁRIA MÁXIMA}

$\mathrm{Na}$ análise em contração voluntária máxima da espessura do músculo temporal e masseter, bilateralmente, não foi evidenciado diferença estatística significante $(p \leq 0,05)$ entre o grupo GM e GC. As médias das espessuras musculares foram semelhantes entre os dois grupos (Figura 25 e Tabela 14).

Figura 25 - Médias de espessura muscular para condição de contração voluntária máxima para os músculos temporal direito (TD), temporal esquerdo (TE), masseter direito (MD) e masseter esquerdo (ME) no grupo mastectomia (GM) e controle sem a doença (GC).

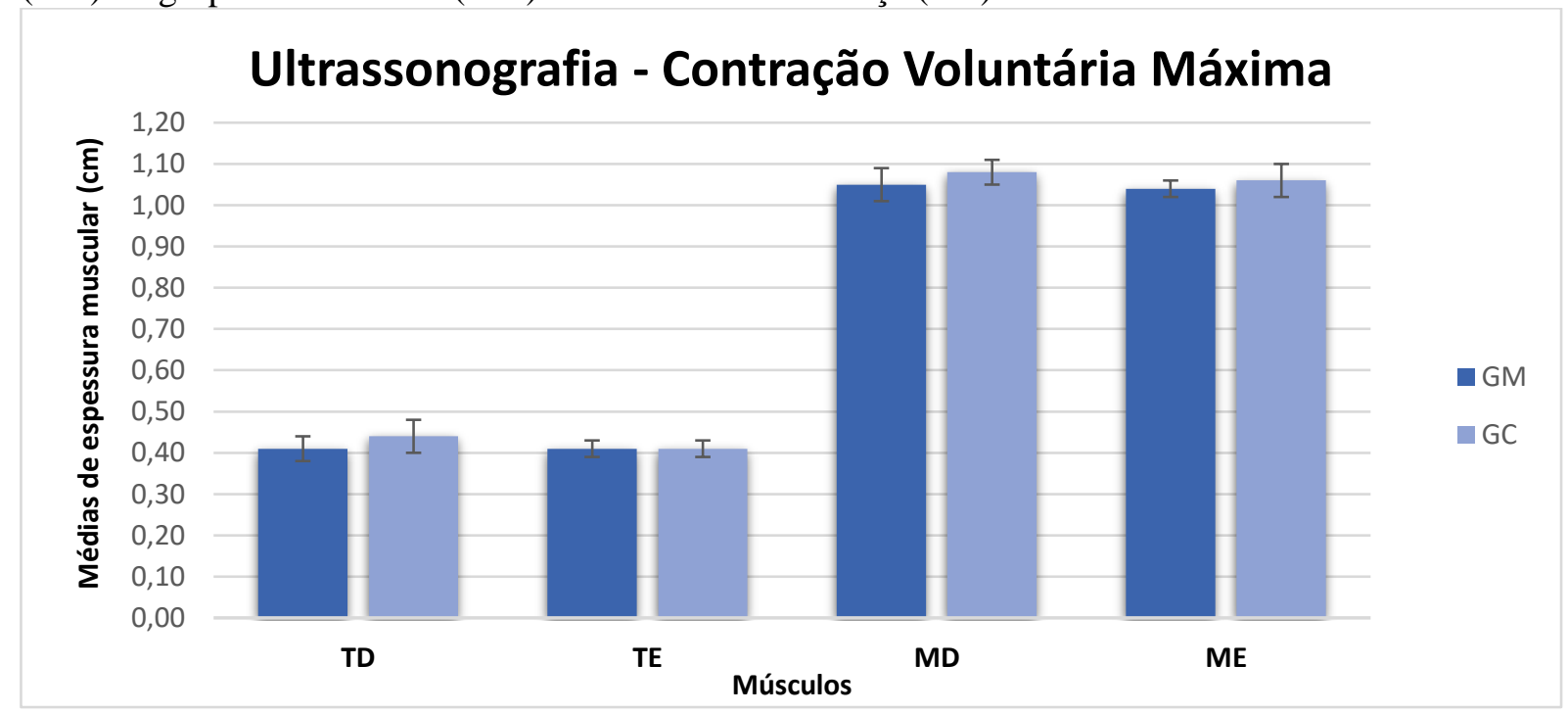

Tabela 14 - Médias, erro padrão e valor $p$ de espessura muscular $(\mathrm{cm})$ na condição de contração voluntária máxima.

\begin{tabular}{ccccc}
\hline Músculos & Grupo & Médias & Erro padrão & Valor de $\boldsymbol{p}$ \\
\hline \multirow{2}{*}{ TD } & GM & 0,41 & 0,03 & 0,50 \\
& GC & 0,44 & 0,04 & 0,82 \\
TE & GM & 0,41 & 0,02 & \\
& GC & 0,41 & 0,02 & 0,51 \\
MD & GM & 1,05 & 0,04 & \multirow{2}{*}{0,50} \\
& GC & 1,08 & 0,03 & \\
\hline
\end{tabular}

GM: grupo mastectomia; GC: grupo controle; TD: temporal direito; TE: temporal esquerdo; MD: masseter direito; ME: masseter esquerdo. 


\subsection{ANÁLISE POSTURAL}

$\mathrm{Na}$ análise postural por meio da biofotogrametria, pode-se observar que o GM apresentou maior assimetria nos ângulos do quadrante superior EC, $\Delta \mathrm{t}$ OP, IE e LC (Tabela 15) quanto nos ângulos do quadrante inferior AS, AJOP, PS, IP OP, IP NOP, FJ NOP e ATT OP (Tabela 16) quando comparada ao GC. Os resultados apresentaram valores significantes para os ângulos EC, IP OP, IP NOP e ATT OP $(p \leq 0,05)$.

Tabela 15 - Médias angulares, erro padrão e valor $p$ da avaliação postural do quadrante superior.

\begin{tabular}{|c|c|c|c|c|}
\hline Ângulos & Grupo & Médias & Erro padrão & Valor de $p$ \\
\hline \multirow{2}{*}{$\mathrm{AC}$} & GM & 1,54 & 0,31 & 0,35 \\
\hline & $\mathrm{GC}$ & 2,01 & 0,39 & \\
\hline \multirow{2}{*}{$\mathrm{EC}$} & GM & 4,09 & 0,38 & $0,00 *$ \\
\hline & GC & 2,50 & 0,30 & \\
\hline \multirow{2}{*}{$\Delta \mathrm{t} \mathrm{OP}$} & GM & 7,36 & 3,22 & $0,03^{*}$ \\
\hline & GC & 15,83 & 1,91 & \\
\hline \multirow{2}{*}{$\Delta \mathrm{t} \mathrm{NOP}$} & GM & 12,31 & 4,05 & 0,39 \\
\hline & GC & 8,56 & 1,43 & \\
\hline \multirow{2}{*}{ IE } & GM & 3,42 & 0,40 & 0,08 \\
\hline & GC & 2,43 & 0,38 & \\
\hline \multirow{2}{*}{$\mathrm{PC}$} & GM & 41,83 & 1,33 & 0,47 \\
\hline & $\mathrm{GC}$ & 43,36 & 1,62 & \\
\hline \multirow{2}{*}{$\mathrm{LC}$} & GM & 38,74 & 2,76 & 0,24 \\
\hline & GC & 34,79 & 1,76 & \\
\hline \multirow{2}{*}{$\mathrm{CT}$} & GM & 100,93 & 2,84 & 0,87 \\
\hline & GC & 101,50 & 2,14 & \\
\hline \multirow{2}{*}{ LL } & GM & 95,28 & 3,31 & 0,76 \\
\hline & GC & 96,66 & 3,11 & \\
\hline
\end{tabular}

GM: grupo mastectomia; GC: grupo controle; AC: ângulo da articulação acromioclavicular; EC: ângulo da articulação esternoclavicular; $\Delta \mathrm{T}$ : triângulo de Talles do lado operado (OP) e não operado (NOP); IE: ângulo inferior da escápula; PC: protrusão da cabeça; LC: lordose cervical; CT: cifose torácica; LL: lordose lombar; valores significantes $(p \leq 0,05)^{*}$. 
Tabela 16 - Médias angulares, erro padrão e valor $p$ da avaliação postural do quadrante inferior.

\begin{tabular}{|c|c|c|c|c|}
\hline Ângulos & Grupo & Médias & Erro padrão & Valor de $p$ \\
\hline \multirow{2}{*}{ AS } & GM & 1,84 & 0,32 & 0,55 \\
\hline & GC & 1,56 & 0,32 & \\
\hline \multirow{2}{*}{ AJ OP } & GM & 180,99 & 1,53 & 0,17 \\
\hline & GC & 178,19 & 1,27 & \\
\hline \multirow{2}{*}{ AJ NOP } & GM & 180,76 & 1,49 & 0,11 \\
\hline & $\mathrm{GC}$ & 183,62 & 0,92 & \\
\hline \multirow{2}{*}{ PS } & GM & 3,13 & 0,41 & 0,16 \\
\hline & GC & 2,36 & 0,33 & \\
\hline \multirow{2}{*}{ IP OP } & GM & 105,40 & 1,42 & $0,00 *$ \\
\hline & $\mathrm{GC}$ & 100,57 & 0,70 & \\
\hline \multirow{2}{*}{ IP NOP } & GM & 102,95 & 1,39 & $0,03 *$ \\
\hline & $\mathrm{GC}$ & 98,99 & 1,00 & \\
\hline \multirow{2}{*}{ FJ OP } & GM & 179,27 & 1,99 & 0,12 \\
\hline & GC & 183,24 & 1,52 & \\
\hline \multirow{2}{*}{ FJ NOP } & GM & 180,94 & 1,76 & 0,10 \\
\hline & GC & 173,24 & 4,13 & \\
\hline \multirow{2}{*}{ ATT OP } & GM & 121,61 & 2,08 & $0,03 *$ \\
\hline & GC & 116,17 & 1,29 & \\
\hline \multirow{2}{*}{ ATT NOP } & GM & 117,92 & 1,74 & 0,86 \\
\hline & $\mathrm{GC}$ & 118,26 & 0,88 & \\
\hline
\end{tabular}

GM: grupo mastectomia; GC: grupo controle; AS: ângulo das espinhas ilíacas ântero-superiores; AJ: angulação do joelho do lado operado (OP) e não operado (NOP); PS: ângulo das espinhas ilíacas póstero-superiores; IP: ângulo de inclinação do pé do lado operado (OP) e não operado (NOP); FL: flexo de joelho do lado operado (OP) e não operado (NOP); ATT: ângulo tíbio társico do lado operado (OP) e não operado (NOP); valores significantes $(p \leq 0,05)^{*}$. 


\subsection{COMPARAÇÕES ENTRE LADO OPERADO E NÃO OPERADO}

\subsubsection{ANÁLISE ELETROMIOGRÁFICA - PADRÕES POSTURAIS (RMS)}

\subsubsection{REPOUSO}

$\mathrm{Na}$ análise das médias eletromiográficas normalizadas (RMS) para o repouso entre o lado operado e não operado, pode-se observar que o lado operado demonstrou menores médias eletromiográficas para todos os músculos analisados quando comparadas ao lado não operado (Figura 26 e Tabela 17). Os resultados não apresentaram diferenças estatísticas significantes $(p \leq 0,05)$.

Figura 26 - Médias eletromiográficas normalizadas (RMS) na condição de repouso, comparando o lado operado (OP) e não operado (NOP) dos músculos temporal e masseter.

\section{Repouso}

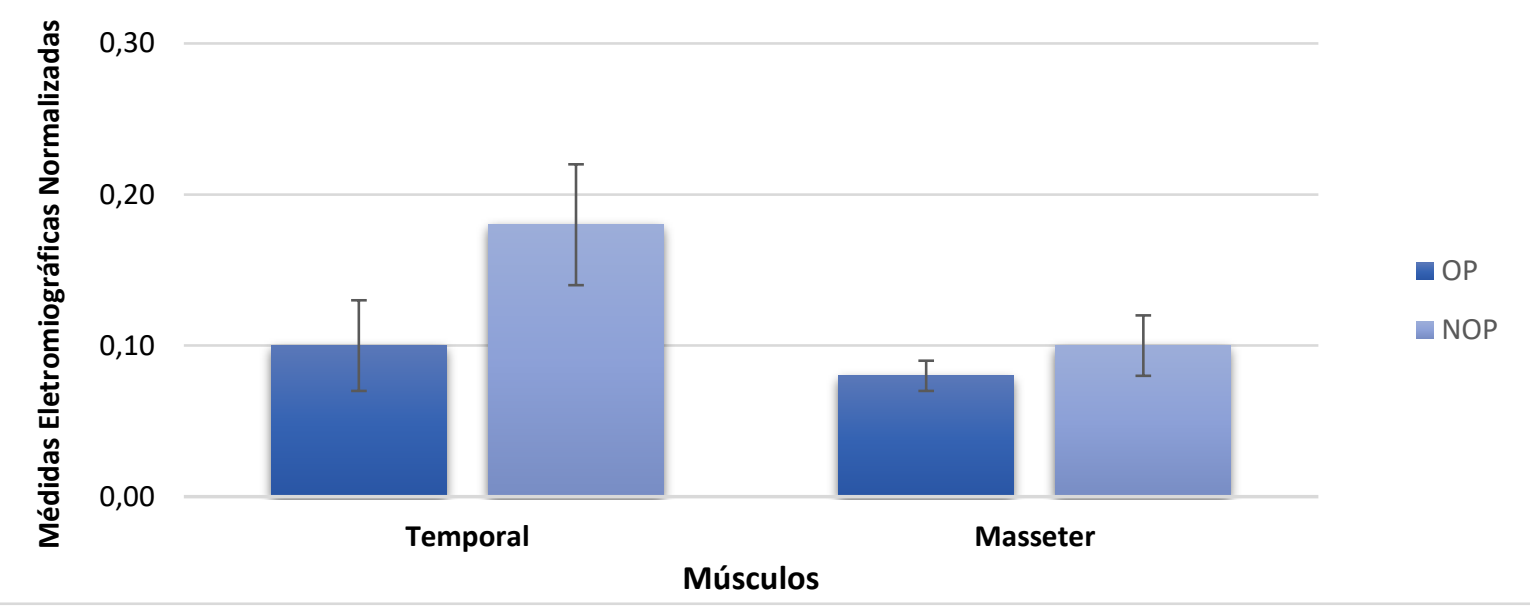

Tabela 17 - Médias eletromiográficas normalizadas $(\mu \mathrm{V})$, erro padrão e valor $\mathrm{p}$ na condição de repouso.

\begin{tabular}{ccccc}
\hline Músculos & Lado & Médias & Erro padrão & valor de $\boldsymbol{p}$ \\
\hline \multirow{2}{*}{ Temporal } & Operado & 0,10 & 0,03 & 0,10 \\
& Não operado & 0,18 & 0,04 & \\
\multirow{2}{*}{ Masseter } & Operado & 0,08 & 0,01 & 0,28 \\
& Não operado & 0,10 & 0,02 & \\
\hline
\end{tabular}




\subsubsection{PROTRUSÃO}

$\mathrm{Na}$ análise das médias eletromiográficas normalizadas (RMS) para a protrusão entre o lado operado e não operado, pode-se observar médias de atividade eletromiográfica semelhantes nos músculos analisados em ambos os lados (Figura 27 e Tabela 18). Os resultados não apresentaram diferenças estatísticas significantes $(p \leq 0,05)$.

Figura 27 - Médias eletromiográficas normalizadas (RMS) na condição de protrusão, comparando o lado operado (OP) e não operado (NOP) dos músculos temporal e masseter.

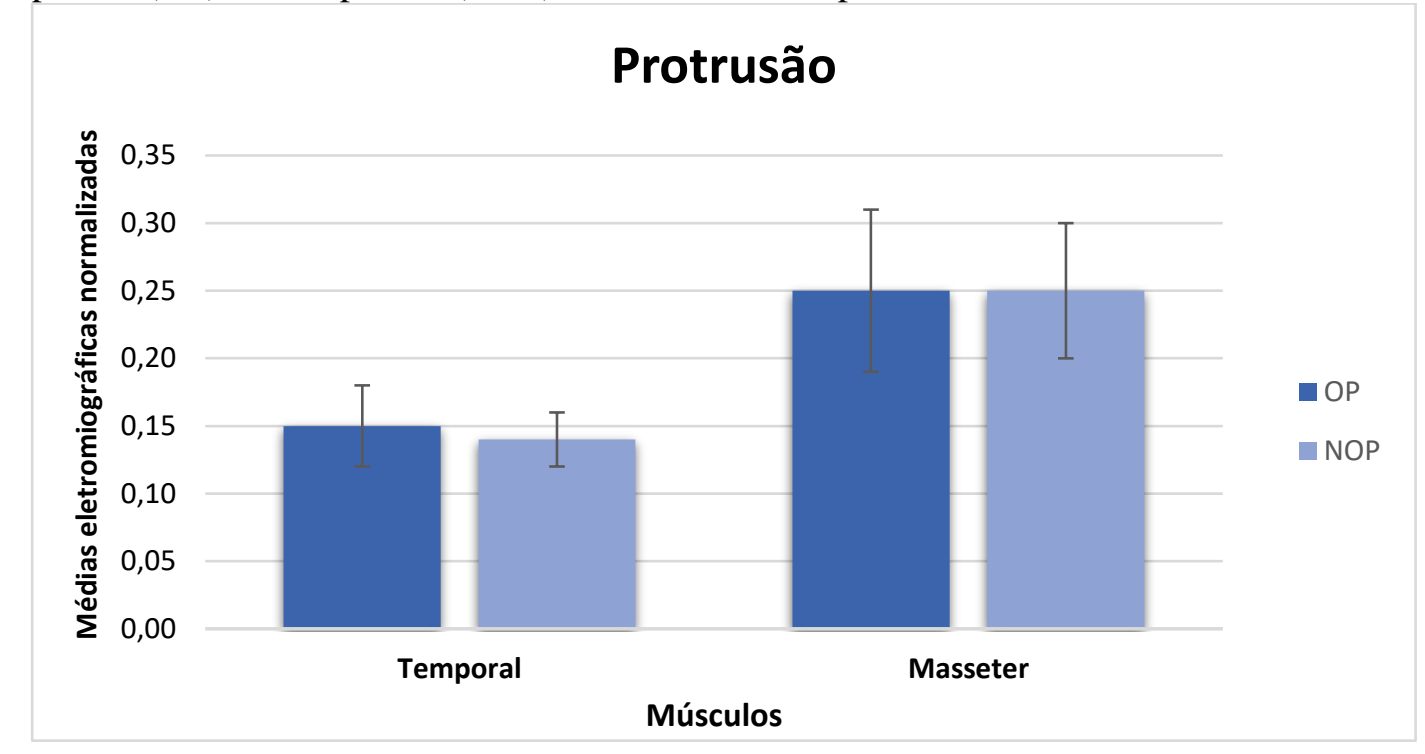

Tabela 18 - Médias eletromiográficas normalizadas $(\mu \mathrm{V})$, erro padrão e valor $p$ na condição de protrusão.

\begin{tabular}{ccccc}
\hline protrusão. & Lado & Médias & Erro padrão & Valor d $\boldsymbol{p}$ \\
\hline \multirow{2}{*}{ Temporal } & Operado & 0,15 & 0,03 & 0,77 \\
& Não operado & 0,14 & 0,02 & \\
\multirow{2}{*}{ Masseter } & Operado & 0,25 & 0,06 & 0,97 \\
& Não operado & 0,25 & 0,05 & \\
\hline
\end{tabular}




\subsubsection{LATERALIDADE DIREITA}

$\mathrm{Na}$ análise das médias eletromiográficas normalizadas (RMS) para a lateralidade direita entre o lado operado e não operado, pode-se observar que o lado operado demonstrou menores médias eletromiográficas para todos os músculos analisados quando comparadas ao lado não operado (Figura 28 e Tabela 19). Os resultados não apresentaram diferenças estatísticas significantes $(p \leq 0,05)$.

Figura 28 - Médias eletromiográficas normalizadas (RMS) na condição de lateralidade direita, comparando os lados operado (OP) e não operado (NOP) dos músculos temporal e masseter.

\section{Lateralidade Direita}

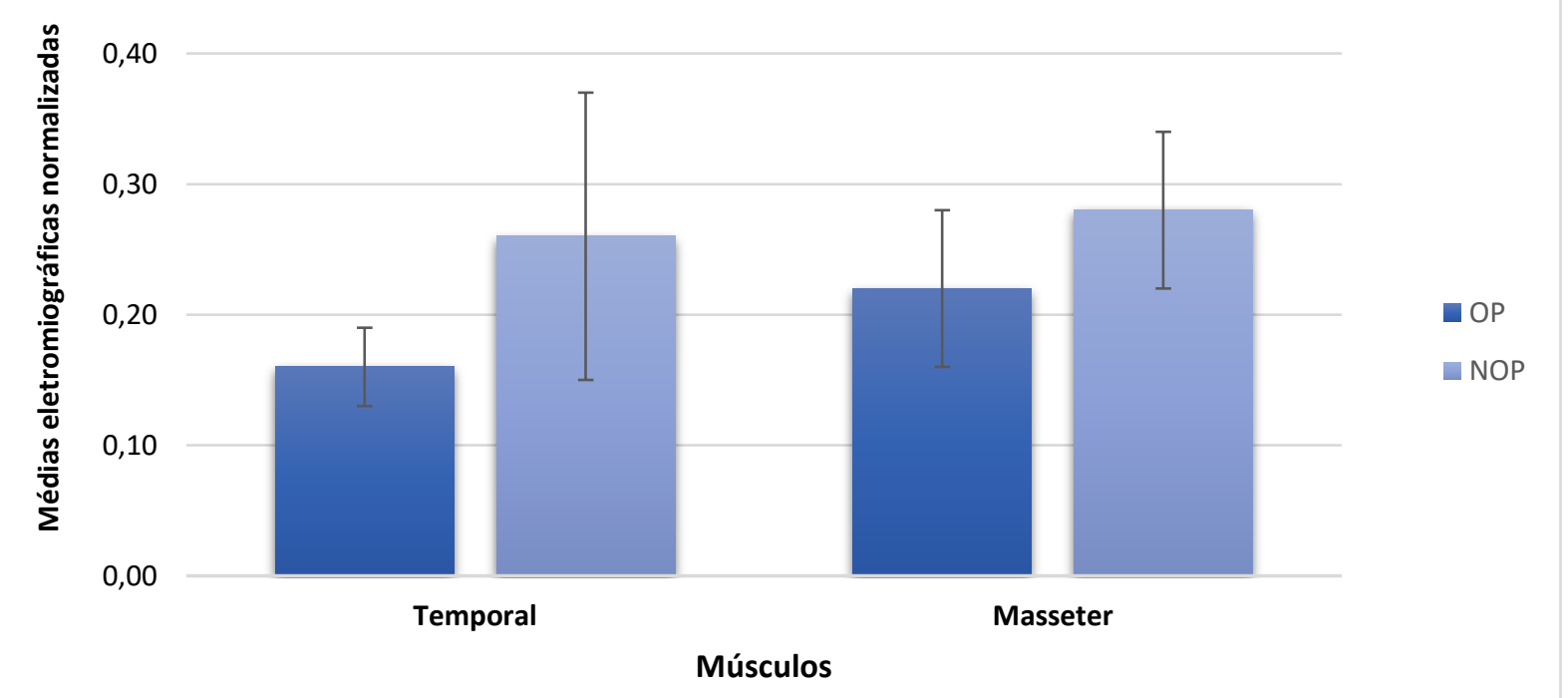

Tabela 19 - Médias eletromiográficas normalizadas $(\mu \mathrm{V})$, erro padrão e valor $p$ na condição de lateralidade direita.

\begin{tabular}{ccccc}
\hline Músculos & Lado & Médias & Erro padrão & Valor de $\boldsymbol{p}$ \\
\hline \multirow{2}{*}{ Temporal } & Operado & 0,16 & 0,03 & 0,40 \\
& Não operado & 0,26 & 0,11 & \\
\multirow{2}{*}{ Masseter } & Operado & 0,22 & 0,06 & 0,46 \\
& Não operado & 0,28 & 0,06 & \\
\hline
\end{tabular}




\subsubsection{LATERALIDADE ESQUERDA}

$\mathrm{Na}$ análise das médias eletromiográficas normalizadas (RMS) para a lateralidade esquerda entre o lado operado e não operado, pode-se observar que o lado operado demonstrou menores médias eletromiográficas para todos os músculos analisados quando comparadas ao lado não operado (Figura 29 e Tabela 20), com diferenças estatísticas significantes para o músculo temporal do lado operado $(p \leq 0,05)$.

Figura 29 - Médias eletromiográficas normalizadas (RMS) na condição de lateralidade esquerda, comparando os lados operado (OP) e não operado (NOP) dos músculos temporal e masseter.

\section{Lateralidade Esquerda}

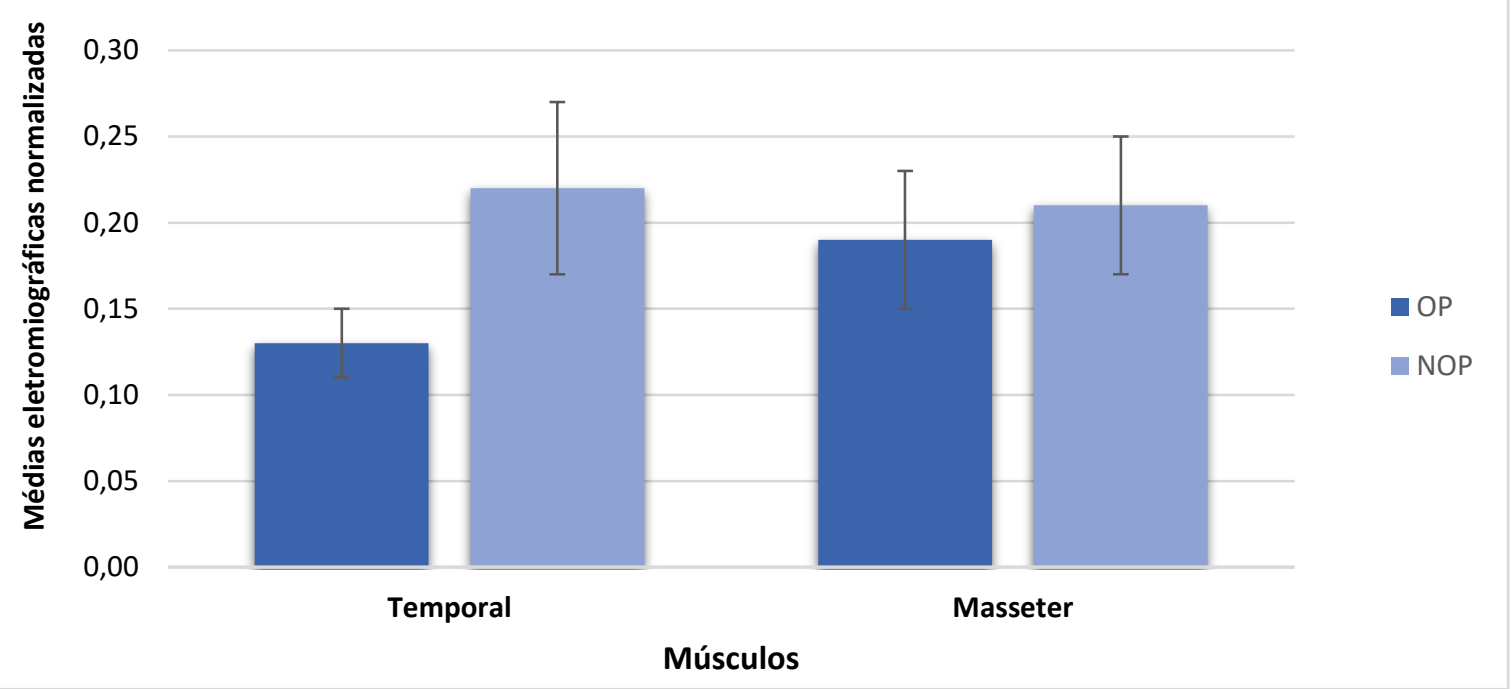

Tabela 20 - Médias eletromiográficas normalizadas $(\mu \mathrm{V})$, erro padrão e valor $p$ na condição de lateralidade esquerda.

\begin{tabular}{ccccc}
\hline Músculos & Lado & Médias & Erro padrão & Valor de $\boldsymbol{p}$ \\
\hline \multirow{2}{*}{ Temporal } & Operado & 0,13 & 0,02 & $0,04^{*}$ \\
& Não operado & 0,22 & 0,05 & \\
\multirow{2}{*}{ Masseter } & Operado & 0,19 & 0,04 & 0,65 \\
& Não operado & 0,21 & 0,04 & \\
\hline
\end{tabular}

Valores significantes $(p \leq 0,05)^{*}$ 


\subsubsection{CONTRAÇÃO VOLUNTÁRIA MÁXIMA}

$\mathrm{Na}$ análise das médias eletromiográficas normalizadas para contração voluntária máxima entre o lado operado e não operado, pode-se observar que o músculo temporal apresentou maiores médias eletromiográficas no lado operado, e o músculo masseter menores médias eletromiográficas no lado operado, quando comparado ao lado não operado (Figura 30 e Tabela 21). Os resultados não apresentaram diferenças estatísticas significantes $(p \leq 0,05)$.

Figura 30 - Médias eletromiográficas normalizadas (RMS) na condição de contração voluntária máxima, comparando o lado operado (OP) e não operado (NOP) dos músculos temporal e masseter.

\section{Contração Voluntária Máxima}

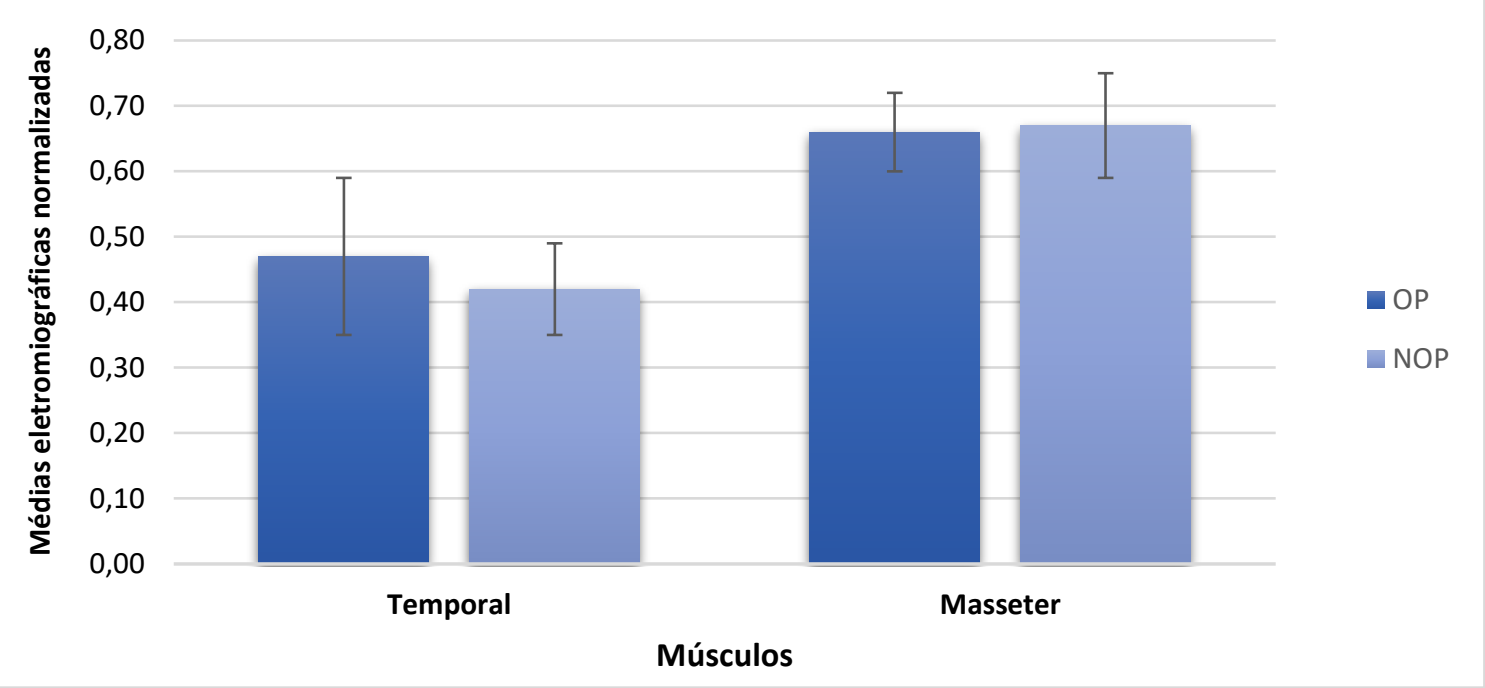

Tabela 21 - Médias eletromiográficas normalizadas $(\mu \mathrm{V})$, erro padrão e valor $p$ na condição de contração voluntária máxima.

\begin{tabular}{ccccc}
\hline Músculos & Lado & Médias & Erro padrão & Valor de $\boldsymbol{p}$ \\
\hline \multirow{2}{*}{ Temporal } & Operado & 0,47 & 0,12 & 0,77 \\
& Não operado & 0,42 & 0,07 & \\
\multirow{2}{*}{ Masseter } & Operado & 0,66 & 0,06 & 0,83 \\
& Não operado & 0,67 & 0,08 & \\
\hline
\end{tabular}




\subsubsection{ANÁLISE ELETROMIOGRÁFICA - FUNÇÃO MASTIGATÓRIA}

\subsubsection{MASTIGAÇÃO NÃO HABITUAL DE PARAFILME M ${ }^{\circledR}$}

$\mathrm{Na}$ análise das médias eletromiográficas normalizadas para condição de mastigação não habitual de Parafilme $\mathbf{M}^{\circledR}$ entre o lado operado e não operado, pode-se observar que o lado operado apresentou maior média de atividade eletromiográfica no músculo temporal quando comparado ao lado não operado, e médias semelhantes para o músculo masseter (Figura 31 e Tabela 22). Os resultados não apresentaram diferenças estatísticas significantes $(p \leq 0,05)$.

Figura 31 - Médias eletromiográficas normalizada $(\mu \mathrm{V})$ na condição de mastigação não habitual de parafilme $\mathrm{M}^{\circledR}$, comparando os lados operado (OP) e não operado (NOP) dos músculos temporal e masseter.

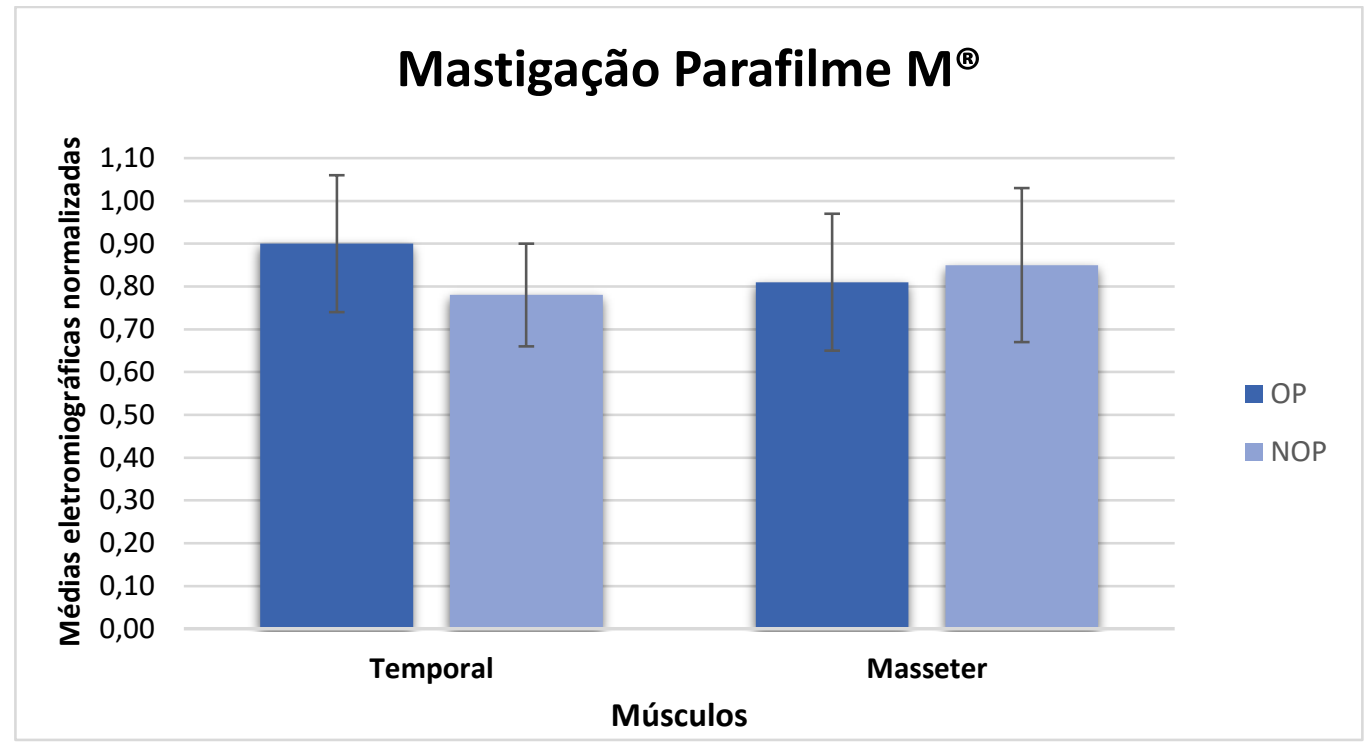

Tabela 22 - Médias eletromiográficas normalizadas $(\mu \mathrm{V})$, erro padrão e valor $p$ na condição de mastigação não habitual de parafilme $\mathbf{M}^{\circledR}$.

\begin{tabular}{ccccc}
\hline Músculos & Lado & Médias & Erro padrão & Valor de $\boldsymbol{p}$ \\
\hline \multirow{2}{*}{ Temporal } & Operado & 0,90 & 0,16 & 0,45 \\
& Não operado & 0,78 & 0,12 & \\
\multirow{2}{*}{ Masseter } & Operado & 0,81 & 0,16 & 0,78 \\
& Não operado & 0,85 & 0,18 & \\
\hline
\end{tabular}




\subsubsection{MASTIGAÇÃO HABITUAL DE AMENDOINS (ALIMENTO CONSISTENTE)}

$\mathrm{Na}$ análise das médias eletromiográficas normalizadas para condição de mastigação habitual de amendoins entre o lado operado e não operado, pode-se observar que o lado operado apresentou maior média de atividade eletromiográfica no músculo temporal quando comparado ao lado não operado, e médias semelhantes para o músculo masseter (Figura 32 e Tabela 23). Os resultados não apresentaram diferenças estatísticas significantes $(p \leq 0,05)$.

Figura 32 - Médias eletromiográficas normalizadas ( (env- $\mu \mathrm{V})$ na condição de mastigação habitual de amendoins, comparando os lados operado (OP) e não operado (NOP) dos músculos temporal e masseter.

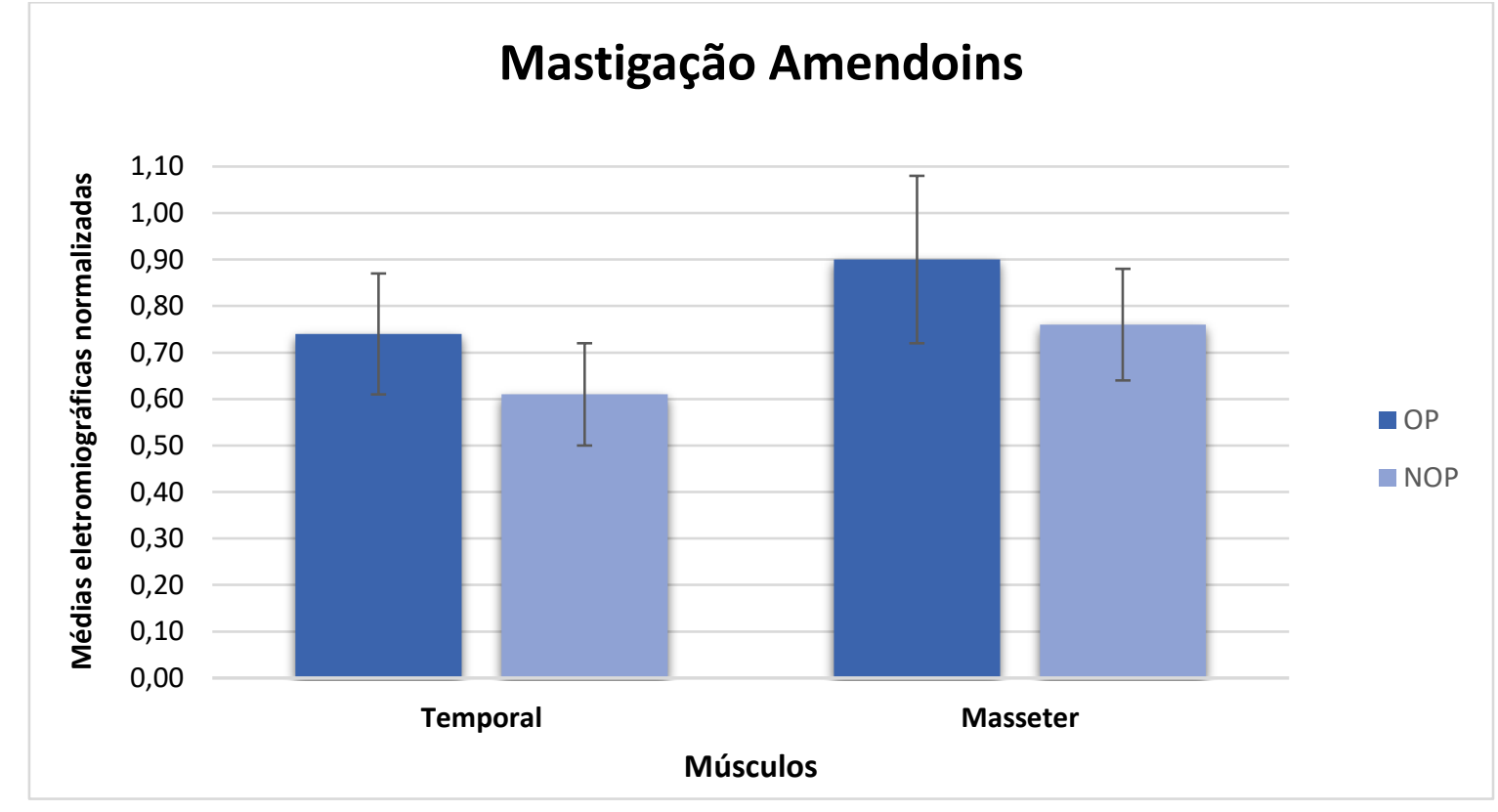

Tabela 23 - Médias eletromiográficas normalizadas $(\mu \mathrm{V})$, erro padrão e valor $\mathrm{p}$ na condição de mastigação habitual de amendoins.

\begin{tabular}{ccccc}
\hline Músculos & Lado & Médias & Erro padrão & Valorde $\boldsymbol{p}$ \\
\hline \multirow{2}{*}{ Temporal } & Operado & 0,74 & 0,13 & 0,39 \\
& Não operado & 0,61 & 0,11 & \\
\multirow{2}{*}{ Masseter } & Operado & 0,90 & 0,18 & 0,23 \\
& Não operado & 0,76 & 0,12 & \\
\hline
\end{tabular}




\subsubsection{MASTIGAÇÃO HABITUAL DE UVAS-PASSAS (ALIMENTO MACIO)}

$\mathrm{Na}$ análise das médias eletromiográficas normalizadas para condição de mastigação habitual de uvas-passas entre o lado operado e não operado, pode-se observar que o lado operado apresentou maiores médias de atividade muscular em todos os músculos analisados quando comparado ao lado não operado (Figura 33 e Tabela 24). Os resultados não apresentaram diferenças estatísticas significantes $(p \leq 0,05)$.

Figura 33 - Médias eletromiográficas normalizadas $(\mu \mathrm{V})$ na condição de mastigação habitual de uvas passas, comparando o lado operado (OP) e não operado (NOP) dos músculos temporal e masseter.

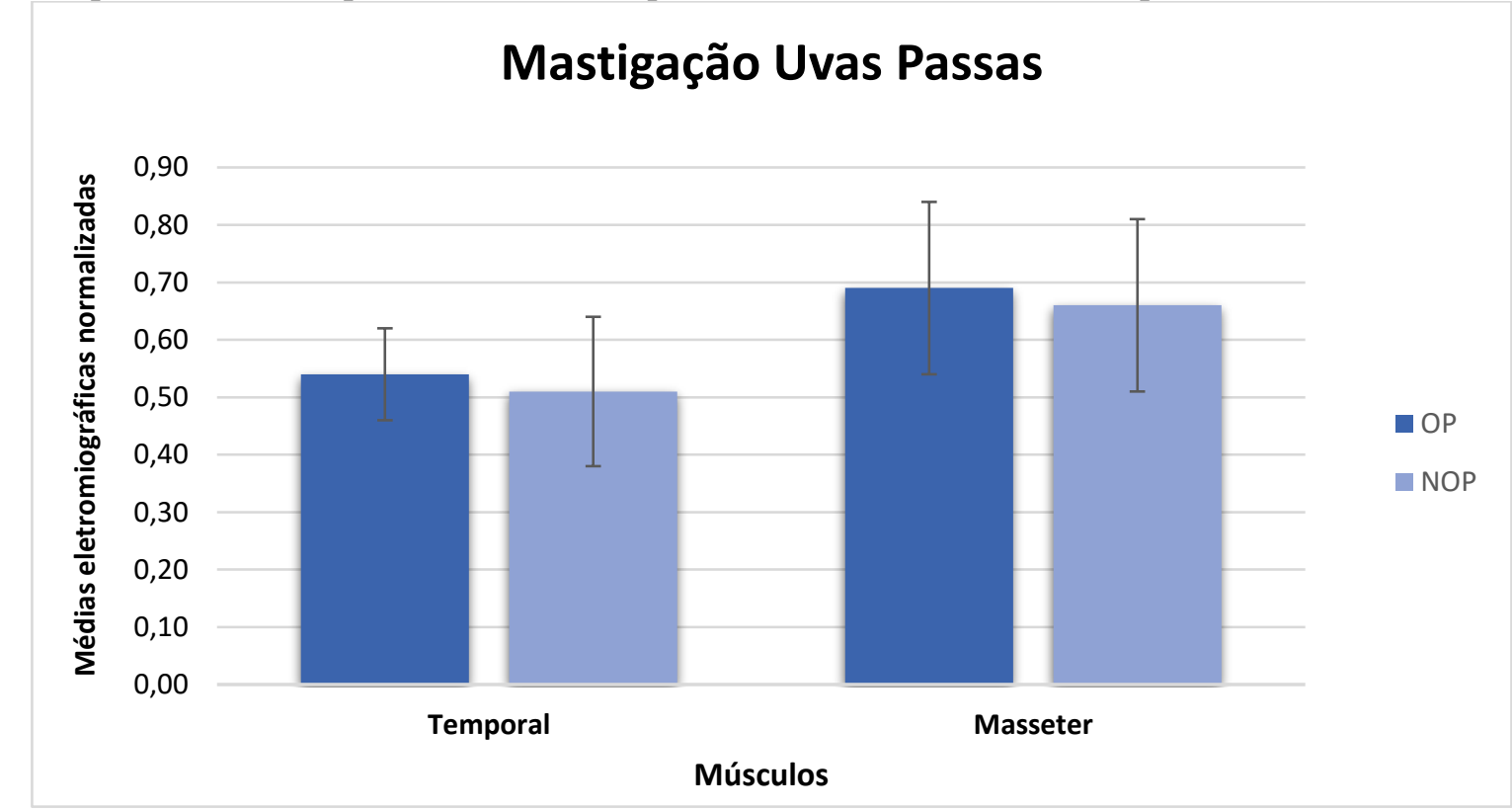

Tabela 24 - Médias eletromiográficas normalizadas $(\mu \mathrm{V})$, erro padrão e valor $p$ na condição de mastigação habitual de uvas-passas.

\begin{tabular}{ccccc}
\hline Músculos & Lado & Médias & Erro padrão & Valor de $\boldsymbol{p}$ \\
\hline \multirow{2}{*}{ Temporal } & Operado & 0,54 & 0,08 & 0,80 \\
& Não operado & 0,51 & 0,13 & \\
\multirow{2}{*}{ Masseter } & Operado & 0,69 & 0,15 & 0,77 \\
& Não operado & 0,66 & 0,15 & \\
\hline
\end{tabular}




\subsubsection{FORÇA DE MORDIDA MOLAR MÁXIMA}

$\mathrm{Na}$ análise da força de mordida molar máxima entre o lado operado e não operado, pode-se observar que o lado operado apresentou menores médias de força de mordida máxima quando comparado ao lado não operado (Figura 34 e Tabela 25). Os resultados não apresentaram valores estatísticos significantes $(p \leq 0,05)$.

Figura 34 - Médias da força de mordida molar máxima (kgf) comparando o lado operado (OP) e não operado (NOP), na região do primeiro molar.

\section{Força de Mordida Molar Máxima}

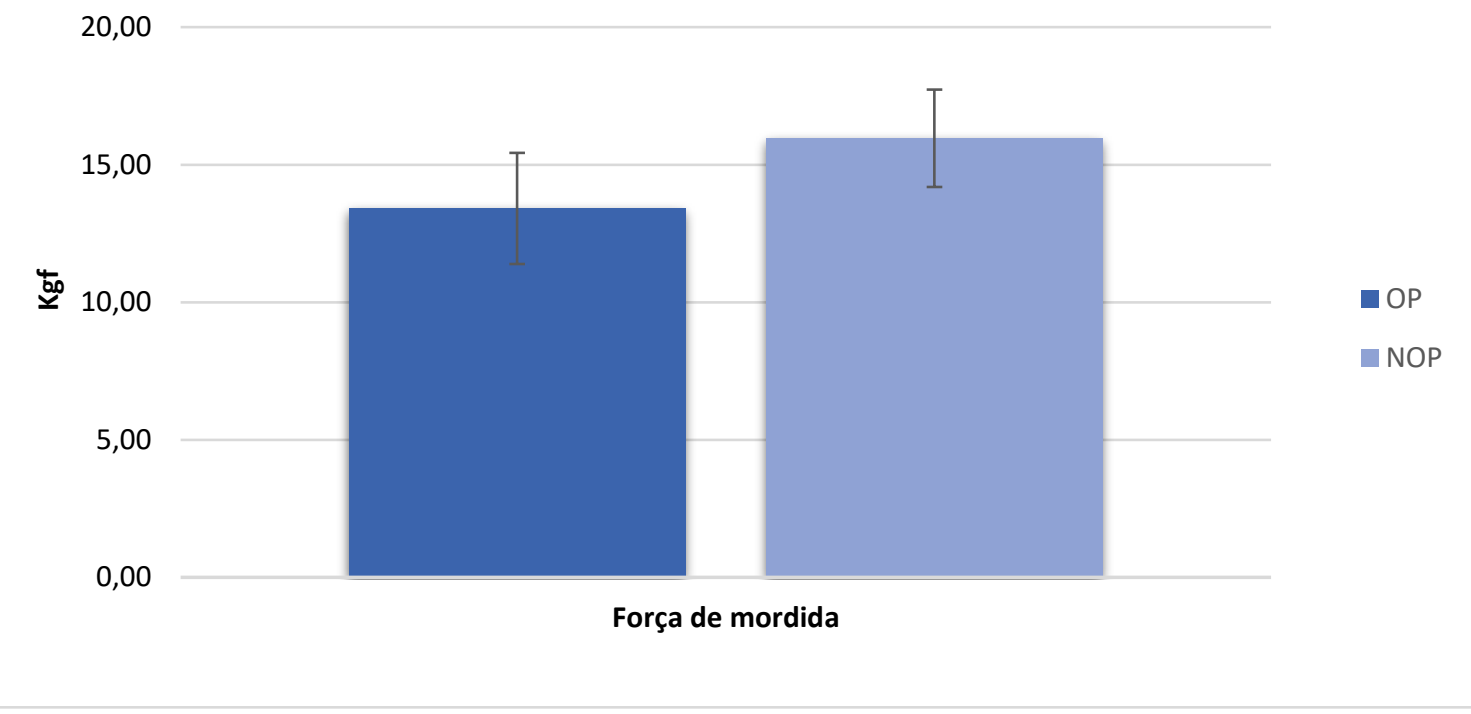

Tabela 25 - Médias, erro padrão e valor $p$ da força de mordida molar máxima (kgf).

\begin{tabular}{ccccc}
\hline Força de Mordida Máxima & Lado & Médias & Erro padrão & Valor de $\boldsymbol{p}$ \\
\hline \multirow{2}{*}{ Região molar } & Operado & 13,41 & 2,02 & 0,06 \\
& Não operado & 15,96 & 1,77 & \\
\hline
\end{tabular}




\subsubsection{ANÁLISE ULTRASSONOGRÁFICA}

\subsubsection{REPOUSO}

$\mathrm{Na}$ análise da ultrassonografia de imagem para a condição de repouso entre o lado operado e não operado, pode-se observar valores semelhantes de médias de espessura para os músculos temporal e masseter em ambos os lados (Figura 35 e Tabela 26). Os resultados não apresentaram valores estatísticos significantes $(p \leq 0,05)$.

Figura 35 - Médias de espessura muscular para condição de repouso, comparando os lados operado (OP) e não operado (NOP) dos músculos temporal e masseter.

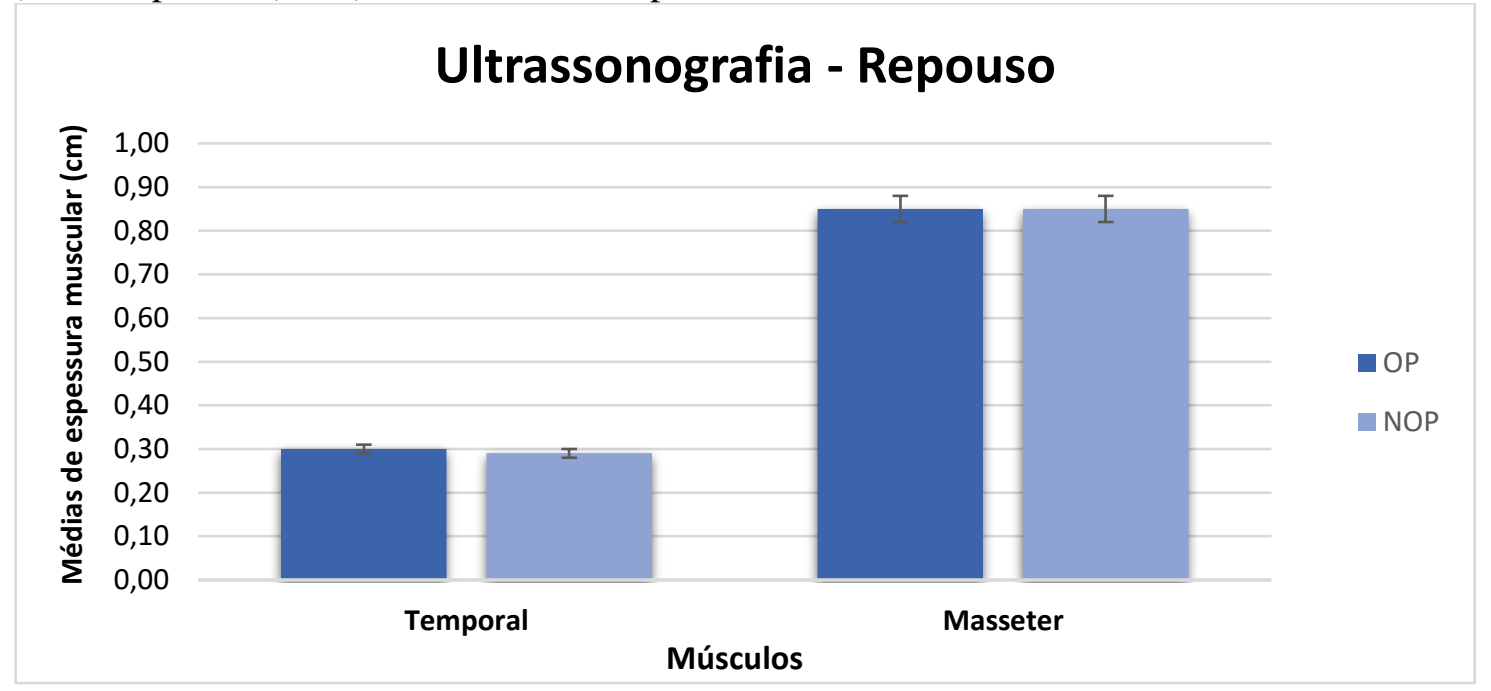

Tabela 26 - Médias, erro padrão e valor $p$ de espessura muscular $(\mathrm{cm})$ na condição clínica de repouso.

\begin{tabular}{ccccc}
\hline Músculos & Lado & Médias & Erro padrão & Valor de $\boldsymbol{p}$ \\
\hline \multirow{2}{*}{ Temporal } & Operado & 0,30 & 0,01 & 0,53 \\
& Não operado & 0,29 & 0,01 & \\
\multirow{2}{*}{ Masseter } & Operado & 0,85 & 0,03 & 0,85 \\
& Não operado & 0,85 & 0,03 & \\
\hline
\end{tabular}




\subsubsection{CONTRAÇÃO VOLUNTÁRIA MÁXIMA}

$\mathrm{Na}$ análise da ultrassonografia de imagem para a condição clínica de contração voluntária máxima entre o lado operado e não operado, pode-se observar valores semelhantes de médias de espessura para os músculos temporal e masseter em ambos os lados (Figura 36 e Tabela 27). Os resultados não apresentaram valores estatísticos significantes $(p \leq 0,05)$.

Figura 36 - Médias de espessura muscular para condição de contração voluntária máxima, comparando o lado operado (OP) e não operado (NOP) dos músculos temporal e masseter.

\section{Ultrassonografia - Contração Voluntária Máxima}

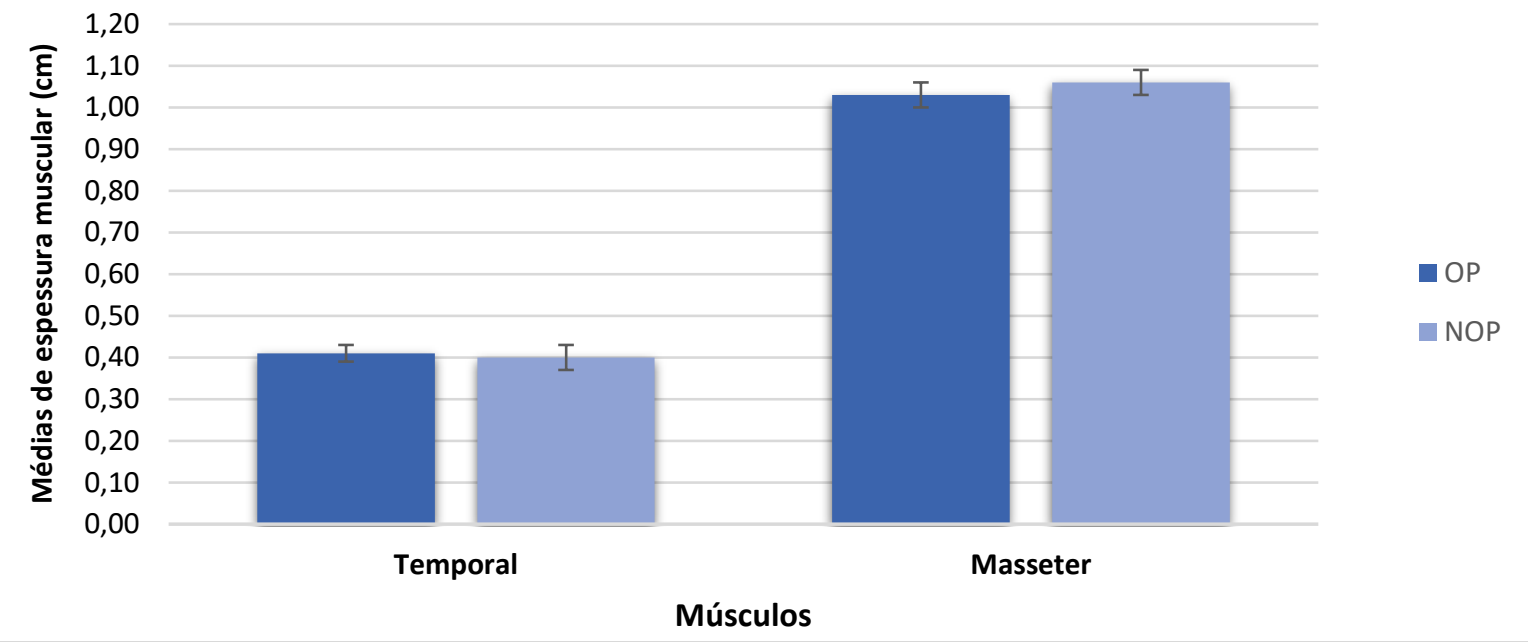

Tabela 27 - Médias, erro padrão e valor $p$ de espessura muscular (ultrassonografia) na condição de contração voluntária máxima.

\begin{tabular}{ccccc}
\hline Músculos & Lado & Médias & Erro padrão & Valor de $\boldsymbol{p}$ \\
\hline \multirow{2}{*}{ Temporal } & Operado & 0,41 & 0,02 & 0,80 \\
& Não operado & 0,40 & 0,03 & \\
\multirow{3}{*}{ Masseter } & Operado & 1,03 & 0,03 & 0,33 \\
& Não operado & 1,06 & 0,03 & \\
\hline
\end{tabular}





\section{DISCUSSÃO}

O câncer de mama é um problema de saúde pública mundial (FERLAY et al., 2009; GONÇALVES et al., 2014; BROWN et al., 2017) que atinge mais o gênero feminino do que o masculino (DAMIANI et al. 2015; GALCERAN et al., 2017; ROBERTSON, et al., 2017), com as maiores taxas de sobrevivência entre todos os tipos de câncer (LOH; MUSA, et al., 2015). Existem várias estratégias para tratamento desta neoplasia, e entre elas se destaca a mastectomia (DE VITA et al., 2107) que, em contrapartida, pode comprometer a função física das mulheres acometidas pela doença (KLASSEN et al., 2016; ZHANG, et al., 2017).

Mesmo sendo reabilitadas após a mastectomia, muitas mulheres apresentam complicações que dificultam a função corporal e principalmente da musculatura estriada esquelética (YANG et al., 2016), promovendo espasmos na musculatura cervical, sensibilidade alterada na musculatura da cintura escapular, comprometendo a mobilidade e postura corporal (LAYEEQUE et al., 2004; FERNÁNDEZ-LAO et al., 2012; SHAMLEY et al., 2012; BANKOFF; JURADO, 2013; MONTEZUMA et al, 2014; SHAMLEY; LASCURAIN-AGUIRREBEÑA; OSKROCH, 2014; HOJAN et al., 2016).

A manutenção da postura corporal equilibrada é uma função extremamente complexa que depende da interação do sistema neural, por meio de estruturas exteroceptivas e proprioceptivas, e do sistema musculoesquelético (FARRELL et al., 2014).

A musculatura do pescoço é fundamental para a manutenção do equilíbrio cervical e dos músculos do sistema estomatognático, onde uma intervenção em qualquer nível pode resultar em alterações funcionais deste sistema (BOUDREAU; FALLA, 2014). Dessa forma, mudanças na postura da cabeça são responsáveis por ocasionar modificações na atividade dos músculos mastigatórios (STRINI et al., 2009).

O sistema estomatognático é extremamente complexo e apresenta funções fisiológicas bem determinadas, que exigem requisição do componente motor mandibular, associado a movimentos de diversas estruturas, por exemplo, eventos motores da face e pescoço. Todas estas funções ocorrem a partir do comando do sistema nervoso central e sofrem influência de inputs periféricos, de modo a obter um desempenho correto de tais funções (DOUGLAS; AVOGLIO; OLIVEIRA et al., 2010; CARVALHO-OLIVEIRA et al., 2016). Caso algum distúrbio venha acometer os componentes motores do sistema estomatognático, o organismo utilizará processos adaptativos para manter a eficiência funcional do sistema, de modo a não permitir a ocorrência de falhas, que poderão ser manifestadas por sinais e ou sintomas de disfunções (DOUGLAS; AVOGLIO; OLIVEIRA et al., 2010; PALINKAS et al., 2016). 
Assim, o estudo dos mecanismos de desenvolvimento e das funções deste complexo sistema poderá proporcionar parâmetros úteis para se reconhecer os desvios de normalidade (CASTELO et al., 2010; SPAGNOL et al., 2016).

Estudos prévios demonstraram que os tratamentos coadjuvantes para o manejo das neoplasias podem ocasionar vários efeitos deletérios aos seus usuários, inclusive sobre a saúde bucal, como periodontite, mucosite oral, perda de dentes, osteonecrose da mandíbula, alterações na fala, deglutição e mastigação afetando, negativamente, a qualidade de vida (KOLOKYTHAS, 2010; AMÓDIO et al., 2014; VILLAFUERTE, 2014; WONG, 2014; BARKOKEBAS et al., 2015; OMOLEHINWA; AKINTOYE 2016), tornando a avaliação funcional dos componentes dessa região de fundamental importância. Portanto, o objetivo deste estudo inédito foi quantificar a atividade neuromuscular dos músculos temporais e masseteres observando se a mastectomia unilateral poderia influenciar na função do sistema estomatognático. Foram utilizadas metodologias reconhecidas internacionalmente com a finalidade de demonstrar subsídios concretos de como a musculatura mastigatória se comporta após tratamento cirúrgico, mostrando a relevância deste estudo para comunidade científica.

Durante as análises eletromiográficas das atividades clínicas propostas para este estudo, observou-se que o padrão de comportamento de ativação das fibras musculares do grupo mastectomia (GM) apresentou diversas alterações quando comparado ao grupo controle (GC).

A análise dos dados desta pesquisa permitiu evidenciar que, na posição de repouso dos músculos temporais e masseteres (direitos e esquerdos), ocorreu atividade mioelétrica para ambos os grupos. No entanto, para as mulheres do GM, a atividade eletromiográfica foi maior.

A musculatura mastigatória, cervical e torácica apresentam relações anatômicas bem definidas, com funções interdependentes (HWANG et al., 2016) e, segundo alguns autores, após o tratamento invasivo na região torácica, toda manutenção postural pode ficar prejudicada promovendo desequilíbrio das forças musculares correlacionadas (HOJAN et al., 2016), o que desestabiliza o posicionamento mandibular, promovendo alteração funcional das fibras dos músculos mastigatórios e consequentemente, hiperatividade muscular, associada a disfunções do sistema estomatognático (PALINKAS et al., 2016).

Durante a condição de protrusão, o padrão de ativação muscular mostrou que os músculos temporais estão mais ativos que os músculos masseteres em ambos os grupos (GM e GC). Foi observado que o GM apresentou hiperatividade muscular quando comparado com o GC. Esses resultados são concordes com o padrão descrito pela literatura, onde os músculos 
temporais são mais ativos que os músculos masseteres (CECILIO et al., 2010, PALINKAS et al., 2016).

Movimentos excursivos da mandíbula são influenciados pela posição da cabeça, impulsos periféricos e situações emocionais (DOUGLAS et al., 2010). Após a mastectomia unilateral, percebem-se morbidades funcionais, destacando as alterações posturais que afetam o sistema estomatognático, principalmente a cinemática mandibular, promovendo alterações funcionais (GONZALEZ.; MANNS, et al., 1996; GILLIES et al., 2003; ROGGIA et al., 2016).

Verificou-se que na condição clínica de lateralidade direita e esquerda, a ativação do músculo masseter não acompanhou o padrão neuroanatômico descrito na literatura, em ambas as condições clínicas, demonstrando que a maior atividade contralateral muscular durante a função não foi encontrada nos resultados deste estudo (CECILIO et al., 2010, PALINKAS et al., 2016). Observou-se também que nos movimentos excursivos da mandíbula, a atividade eletromiográfica normalizada do músculo temporal e masseter foi menor no GM quando comparada ao GC. Mulheres submetidas ao tratamento de câncer de mama apresentam quadro de tensão muscular, sensação de fadiga, e depressão (CAMPBELL-ENNS; WOODGATE, 2015), que podem interferir no comprometimento da função mastigatória, causando alteração funcional (DANTE et al., 2014), entretanto, estas variáveis não foram avaliadas neste estudo.

$\mathrm{Na}$ condição de apertamento dental em contração voluntária máxima, o músculo masseter esquerdo e temporal direito mostraram menor atividade eletromiográfica no GM em comparação ao GC. O procedimento cirúrgico realizado nas mulheres com câncer de mama foi a mastectomia unilateral e provavelmente o equilíbrio corporal, mesmo com a reconstrução mamária, que devolve o volume e o contorno da mama, não é reestabelecido totalmente, promovendo alterações no equilíbrio, desestabilizando o movimento de posição estática (MOCHIZUKI et al., 2003). Neste estudo, 87,5\% das mulheres submetidas à mastectomia unilateral realizaram reconstrução mamária com prótese de silicone, mantendo a similaridade da mama contralateral de acordo com o Índice proposto por Sacchini et al. (1991), índice este que foi mensurado neste estudo, o que nos permitiu a constatação e inclusão de quinze participantes com mamas médias e uma participante com mama grande.

Em nosso estudo, a atividade elétrica do músculo temporal e masseter durante o apertamento dental em contração voluntária máxima com Parafilme $\mathrm{M}^{\circledR}$ foi utilizada para normalizar os dados, sendo esse procedimento recomendado, com a finalidade de reduzir as diferenças entre os registros de diferentes indivíduos, de forma a tornar a interpretação dos 
dados reprodutível na comparação científica (HERMENS et al., 1999; MAPELLI et al., 2016).

A capacidade funcional mastigatória é totalmente dinâmica e pode demonstrar as adaptações ou alterações funcionais das estruturas anatomo-fisiológicas do corpo humano (MARCELLO-MACHADO et al., 2016; CARVALHO et al., 2016), explicando, por exemplo, as variações nas características da eficiência mastigatória observadas entre indivíduos saudáveis e com alterações funcionais (PIANCINO et al., 2005).

Entre as atividades dinâmicas analisadas na literatura, a mais frequente é da mastigação, sendo considerada atividade fisiológica com funções específicas e de grande importância para o sistema estomatognático (PALINKAS et al., 2013; CAZAL et al., 2015). Devido ampla variabilidade dos movimentos associados a esta atividade, a avaliação mastigatória é complexa e aborda alguns parâmetros tais como a duração, o número de ciclos e seu desempenho, dependendo das forças desenvolvidas e da consistência dos alimentos (WOŹNIAK et al., 2013).

Uma metodologia cinesiológica, utilizada pela comunidade científica, que tem como objetivo avaliar e determinar o desempenho mastigatório, mostrando quando e como um músculo é ativado, é a integral da envoltória do sinal eletromiográfico (SIÉSSERE et al., 2009; BORGES et al., 2013). Este cálculo matemático analisa os períodos de contrações isométricas pela atividade elétrica muscular durante a formação dos ciclos mastigatórios e determina a coordenação de diferentes músculos envolvidos no movimento, demonstrando possíveis alterações no desempenho mastigatório (PALINKAS et al., 2010; PEPATO et al., 2013).

Neste estudo, o processo mastigatório foi avaliado pela utilização de alimentos testes como o amendoim, representando o alimento consistente, uva-passa reproduzindo o alimento macio e o Parafilm $\mathrm{M}^{\circledR}$ como material inerte. $\mathrm{O}$ uso do material inerte teve a função de demonstrar o movimento em charneira dos registros dinâmicos, de curta excursão de abertura bucal, solicitado para reduzir efeitos da mudança de comprimento muscular (DE LUCA, 1997; PALINKAS et al., 2013). Foi observado que na mastigação habitual (amendoim e uvapassa) e não habitual (Parafilme $\mathrm{M}^{\circledR}$ ) que o GM apresentou maior atividade eletromiográfica normalizada quando comparada ao GC. Quando se constata hiperatividade muscular em ações dinâmicas de indivíduos que sofreram alterações no organismo, percebe-se que as fibras musculares se comportam de maneira diferente onde ocorre maior recrutamento para manter o mesmo desempenho, quando na comparação com sistema saudável (PALINKAS et al., 2013). 
Esta hipótese pode explicar os resultados menos eficientes do desempenho mastigatório em mulheres mastectomizadas.

Os parâmetros relacionados com a espessura dos músculos temporais e masseteres em mulheres que foram submetidas à mastectomia unilateral não foram estudados até o presente momento desta pesquisa. Tal situação justifica a relevância desta variável para comunidade científica, colaborando no conhecimento de possíveis alterações morfológicas que servirão para profissionais da área ciência médica e odontológica (KILIARIDIS; GEORGIAKAKI; KATSAROS, 2003).

Foi utilizado, neste estudo, o exame de ultrassonografia de imagem com a finalidade de aferir a espessura com precisão e dinamismo, observando a secção transversal dos músculos temporais e masseteres (CASTELO et al., 2007; PALINKAS et al., 2010; TIRCOVELURI et al., 2013; PALINKAS et al., 2016). Os dados demonstraram que não houve diferenças consideráveis entre GM e GC tanto na condição de repouso mandibular quanto em contração voluntária máxima. Apesar de uma aparente deficiência na função dos músculos da mastigação de mulheres mastectomizadas, não houve alteração nas medidas de espessura muscular mastigatória quando comparadas com os dados coletados de mulheres sem a doença.

Dante et al. (2014) estudaram os efeitos da radioterapia em indivíduos com câncer de cabeça e pescoço, constatando que a radiação poderia afetar o sistema estomatognático. Neste estudo, os pesquisadores observaram aumento da atividade eletromiográfica nas condições posturais de mandíbula e maiores medidas de espessura muscular quando comparado ao grupo controle.

Em relação à gnatodinamometria, considerado um instrumento auxiliar no diagnóstico de alterações no sistema estomatognático por ser indicador do estado funcional, proporcionando elementos confiáveis para análise da função e atividade mastigatória, por meio da variável força de mordida molar (PALINKAS et al., 2010; SILVA et al., 2017), podemos dizer que foi um método indispensável para demostrar que o desempenho funcional mastigatório em mulheres mastectomizadas unilateral é menor em comparação com as mulheres sem a doença porque ocorreu redução na força de mordida molar máxima.

Klassen et al. (2016) avaliaram a força muscular de 255 mulheres com câncer de mama em diferentes tratamentos adjuvantes e compararam também os dados com indivíduos saudáveis. Os autores concluíram que mulheres com câncer de mama apresentaram menor força muscular e disfunções articulares após o tratamento da doença. 
Não foram encontrados relatos na literatura referentes à avaliação funcional dos músculos da mastigação em mulheres submetidas à mastectomia unilateral. Entretanto, são escassos estudos que explorem possíveis alterações funcionais causadas pelos procedimentos cirúrgicos nas regiões adjacentes à mama e as consequências que os distúrbios psicológicos podem causar no sistema estomatognático. Assim, estudos como este são necessários pois contribuem para melhor tratamento pós-mastectomia com terapias alternativas, consequentemente melhorando as atividades de vida diária e a qualidade de vida destas pacientes.

É importante ressaltar que qualquer aumento na atividade elétrica do músculo masseter e temporal quando relacionado com o sistema estomatognático saudável pode ser indício de disfunção muscular (RANCAN et al.,2009; SIÉSSERE et al., 2009). As mudanças na postura da cabeça são responsáveis por ocasionar alterações na atividade dos músculos mastigatórios (STRINI et al., 2009). Um posicionamento anterior da cabeça leva à hiperextensão sobre o pescoço, com retrusão da mandíbula, podendo causar desconforto e alteração funcional (ARELLANO, 2002). Mulheres submetidas a mastectomia apresentam mudanças posturais da cabeça e pescoço (HOJAN et al., 2016).

Assimetrias posturais foram confirmadas neste estudo, onde foi possível observar assimetria dos valores angulares da articulação esternoclavicular; triângulo de Talles, ângulo inferior da escápula; espinhas ilíacas ântero-superiores e póstero-superiores; angulação do joelho e flexo de joelho; inclinação do pé e ângulo tibiotársico, demonstrando alteração postural global. Tal análise foi realizada por meio da fototogrametria, recurso que apresenta confiabilidade intra e interexaminadores (IUNES et al., 2005), e que tem sido utilizado em estudos de diferentes áreas da saúde (LIMA et al., 2004; CORRÊA; BÉRZIN, 2007; MILANESI et al., 2011; HADDAD et al., 2013; PERES et al., 2017). O protocolo base adotado em nossa metodologia foi descrito por Iunes et al., (2009), que consideraram que a medida do ângulo EC é simétrica quando o valor angular resultante for igual a zero. Neste estudo, o GM e GC apresentaram assimetria no referido ângulo, porém observa-se maior assimetria no GM comparada ao $\mathrm{GC}$, com diferença estatística significante $(\mathrm{p}=0,00)$.

O triângulo de Talles é considerado simétrico se a comparação entre os lados analisados se demonstre semelhantes (IUNES et al., 2009). Nós encontramos assimetria em ambos os lados analisados, sendo que a medida do lado operado das mulheres mastectomizadas apresentou-se menor quando comparada ao grupo controle, com diferença significante $(p=0,03)$. 
Para o ângulo de inclinação do pé, Iunes et al., (2009) consideram valores dentro da normalidade quando for igual a $90^{\circ}$. Baseados nos dados da literatura, encontramos valores discrepantes entre os ângulos e grupos analisados, com diferença significante para os lados operado $(p=0,00)$ e não operado $(p=0,03)$ do GM comparado ao GC. Foi observado ainda, diferença estatística significante para o ângulo tibiotársico do lado operado $(p=0,03)$ de mulheres mastectomizadas unilateral comparadas a mulheres sem a doença, apesar dos valores de normalidade não terem sido descritos no protocolo utilizado.

Embora existam diferentes métodos de avaliação do controle e postura corporal descritos na literatura atual envolvendo mulheres mastectomizadas (CIESLA; POLOM, 2010; MALICKA et al., 2010; MONTEZUMA et al., 2014; SEREL et al., 2016; PERES et al., 2017), nossos resultados também encontraram, de modo geral, alterações da simetria corporal desde grupo em estudo tanto no quadrante superior quanto no quadrante inferior.

$\mathrm{Na}$ análise do lado operado e não operado do nosso grupo caso podemos afirmar que nas condições de repouso mandibular, lateralidade direita e esquerda, protrusão e apertamento dental em contração voluntária máxima, o lado operado apresentou menor atividade eletromiográfica normalizada. Nas condições dinâmicas que englobam a mastigação habitual e não habitual observou-se semelhança entre os dados obtidos. Esta comparação específica permitiu determinar que o lado operado apresentasse menores valores de força de mordida, embora sem diferença significante.

$\mathrm{Na}$ literatura não existem relatos científicos que consideraram os aspectos estáticos e dinâmicos da musculatura da mastigação em mulheres submetidas à mastectomia unilateral, por meio da avaliação eletromiográfica, desempenho mastigatório, espessura muscular, força de mordida molar máxima e análise postural, o que torna difícil discutir e comparar os resultados verificados nesse estudo. Pesquisas que tem o intuito de avaliar este público alvo com a finalidade de detalhar as alterações morfofuncionais do sistema estomatognático após o tratamento do câncer e da cirurgia tem seu mérito científico e social, mostrando o impacto negativo que a doença e o seu tratamento podem promover nas funções do aparelho mastigatório, auxiliando os profissionais da área da saúde no momento de realizar propostas de reabilitações orais e tratamentos terapêuticos, porque, baseados nos resultados obtidos nesse estudo, o sistema muscular mastigatório e padrão postural destas mulheres poderão estar comprometidos, fragilizados e com prejuízo funcional. 




\section{CONCLUSÕES}

Baseados nos resultados obtidos nesta pesquisa pode-se concluir que as mulheres submetidas à mastectomia unilateral em comparação com o grupo controle sem a doença apresentaram:

Maiores médias de atividade eletromiográfica nas condições posturais da mandíbula;

$>$ Menor eficiência na mastigação habitual e não habitual;

$>$ Menor força de mordida molar máxima;

$>$ Médias de espessuras musculares mastigatórias semelhantes com o grupo controle sem a doença na condição clínica de repouso e de contração voluntária máxima;

Alterações posturais tanto no quadrante superior quanto no quadrante inferior. 



\section{REFERÊNCIAS}





\section{REFERÊNCIAS}

1. AMERICAN CANCER SOCIETY. Cancer facts \& figures 2016. Atlanta: American Cancer Society; 2016.

2. AMÓDIO, J. et al. Oral health after breast cancer treatment in postmenopausal women. Clinics (Sao Paulo), v. 69, n. 10, p. 706-708. 2014.

3. ANDERSEN, L.; HOJRIS, I.; ERLANDSEN, M.; ANDERSEN, J. Treatment of breastcancer-related lymphedema with or without manual lymphatic drainage: a randomized study. Acta Oncologica, v. 39, n. 3, p. 399-405. 2000.

4. ARELLANO, J.C.V. Relações entre postura corporal e sistema estomatognático. Jornal Brasileiro de Oclusão, ATM e Dor Orofacial, v.2, n. 6, p.155-164. 2002.

5. BAKKE, M.; TUXEN, A.; VILMANN, P.; JENSEN, B.R.; VILMANN, A.; TOFT, M. Ultrasound image of human masseter muscle related to bite force, electromyography, facial morphology, and occlusal factors. Scand J Dent Res, v. 100, p. 164-171. 1992.

6. BALLENBERGER, $\mathrm{N}$. et al. Influence of different upper cervical positions on electromyography activity of the masticatory muscles. J Manipulative Physiol Ther, v. 35, n. 4, p. 308-318. 2012

7. BANKOFF, A.D.P.; JURADO, S.R. Electromyographic study of shoulder and acromioclavicular joint muscles in women who underwent unilateral breast surgery of the types mastectomy and quadrantectomy. Health, v.5, n. 11, p.1866-1871. 2013.

8. BARBOSA, J.A.N.; AMORIM, M.H.C.; ZANDONADE, E.; DELAPRANE, M.L. Avaliação da postura corporal em mulheres com câncer de mama. Rev. Bras. Ginecol. Obstet, v.35, n. 5, p. 215-220. 2013.

9. BARKOKEBAS, A. et al. Impact of oral mucositis on oral-health-related quality of life of patients diagnosed with câncer. J Oral Pathol Med, v. 44, n. 9, p. 746-51. 2015.

10. BAS, B.; YILMAZ, N.; GÖKCE, E.; AKAN, H. Diagnostic value of ultrasonography in temporomandibular disorders. Journal of oral and maxillofacial surgery, v. 69, n. 5, p. 1304-1310, 2011.

11. BERTRAM, S.; BRANDLMAIER, I.; RUDISCH, A.; BODNER, G.; EMSHOFF, R. Cross-sectional characteristics of the masseter muscle: an ultrasonographic study. International journal of oral and maxillofacial surgery, v.32, n.1, p.64-68, 2003.

12. BONJARDIM, L.R. et al. Association between symptoms of temporomandibular disorders and gender, morphological occlusion, and psychological factors in a group of university students. Indian J Dent Res, v. 20, n. 2, p. 190-194. 2009.

13. BORETTI, G.; BICKEL, M.; GEERING, A.H. A review of masticatory ability and efficiency. The Journal of Prosthetic Dentistry, v. 74, n. 4, p. 400-403. 1995. 
14. BORGES, T.F.; REGALO, S.C.; TABA, M.JR.; SIÉSSERE, S.; MESTRINER, W. JR.; SEMPRINI, M. Changes in masticatory performance and quality of life in individuals with chronic periodontitis. J Periodontol, v. 84, n. 3, p. 325-331. 2013.

15. BREGANOL, R.K.; DIAS, A.S. Alterações funcionais em mulheres submetidas à cirurgia de mama com linfadenectomia axilar total. Revista Brasileira de Cancerologia, v. 56, n. 1, p.25-33. 2010.

16. BROWN, E.R. et al. Development of multi-disciplinary breast cancer care in Southern Malawi. Eur J Cancer Care, v. 26, n. 1. 2017.

17. BOUDREAU, S.A.; FALLA, D. Chronic neck pain alters muscle activation patterns to sudden movements. Exp Brain Res, v. 232, n. 6, p. 2011-2020. 2014.

18. CAGLI, B. et al. Ten years experience with breast reconstruction after salvage mastectomy in previously irradiated patients: analysis of outcomes, satisfaction and wellbeing. Eur Rev Med Pharmacol Sci, v. 20, n. 22, p. 4635-4641. 2016.

19. CAMPBELL-ENNS, H.; WOODGATE, R. The psychosocial experiences of women with breast cancer across the lifespan: a systematic review protocol. JBI Database System Rev Implement Rep, v. 13, n. 1, p. 112-121. 2015.

20. CARVAlHO, P.M.; CASTElO, P.M.; CARPENTER, G.H.; GAVIÃO, M.B. Masticatory function, taste, and salivary flow in young healthy adults. J Oral Sci, v. 58, n. 3, p. 391-399. 2016.

21. CARVAlHO-OliVEIRA, M.; SAlles, C.; TERSE, R.; JÚNIOR, O. A. Association between severe asthma and changes in the stomatognathic system. J Bras Pneumol, v. 42, n. 6, p. 423-428. 2016.

22. CASTELO, P.M.; GAVIÃO, M.B.; PEREIRA, L.J.; BONJARDIM, L.R. Masticatory muscle thickness, bite force, and occlusal contacts in young children with unilateral posterior crossbite. Eur J Orthod, v. 29, n.2, p.149-156. 2007.

23. CASTELO, P.M.; PEREIRA, L.J.; BONJARDIM, L.R.; GAVIÃO, M.B.D. Changes in bite force, masticatory muscle thickness, and facial morphology between primary and mixed dentition in preschool children with normal occlusion. Annals of Anatomy, v. 192, p. 23-26. 2010.

24. CAZAL, M.S.; DA SILVA, A.M.; GALO, R.; JUNIOR, W.M.; DA SILVA, M.A. Comparison of dynamic electromyographic analysis of masticatory capsules with materials of different textures. Cranio, v. 34, n. 2, p. 105-111. 2016.

25. CECÍLIO, F.A.; REGALO, S.C.; PALINKAS, M.; ISSA, J.P.; SIÉSSERE, S.; HALLAK, J.E.; MACHADO-DE-SOUSA, J.P.; SEMPRINI, M. Ageing and surface EMG activity patterns of masticatory muscles. J Oral Rehabil, v. 37, n. 4, p. 248-255. 2010.

26. CHARGARI, C.; MAGNÉ, N. Concurrent hormone and radiation therapy in patients with breast cancer: how does chemotherapy affect treatment? - authors' reply. The Lancet Oncology, v. 10, n. 5, p. 445-446. 2009. 
27. CIESLA, L.; POLOM, K. The effect of immediate breast reconstruction with Becker 25 prosthesis on the preservation of proper body posture in patients after mastectomy. EJSO, v. 36. p.625-631. 2010.

28. CORRÊA, E.C.R.; BÉRZIN, F. Efficacy of physical therapy on cervical muscle activity and on body posture in school-age mouth breathing children. International Journal of Pediatric Otorhinolaryngology, v. 71, n. 10, p. 1527-1535. 2007.

29. CRAM, J.R.; KASMAN, G.S.; HOLTZ, J. Introduction to Surface Electromyography. Ed. Gaithersburg. Maryland: Aspen Publication ®. 1998.Criswell E. Cram's Introduction to Surface Electromyography. Jones \& Bartlett Learning, 2a ed., p.412, 2010.

30. CRISWELL, E. Cram's Introduction to Surface Electromyography. Jones \& Bartlett Learning, $2^{\mathrm{a}}$ ed.; 412p. 2010.

31. CUCCIA, A.; CARADONNA, C. The relationship between the stomatognathic system and body posture. Clinics, v. 64, n.1, p. 61-66. 2009.

32. DAMIANI, G.; BASSO, D.; ACAMPORA, A.; BIANCHI, C. B.N.A.; SILVESTRINI, G.; FRISICALE, E. M.; SASSI, F.; RICCIARDI, W. The impact of level of education on adherence to breast and cervical cancer screening: Evidence from a systematic review and meta-analysis. Preventive Medicine, v. 81, p. 281-289. 2015.

33. DANTE, A.M.M. et al. Effect of radiation on the performance of the stomatognathic system - a pilot study. Dentistry, Oral Disorders \& Therapy, v. 2, n. 3, p. 1-5. 2014.

34. DE LIMA VAZQUEZ, F. et al. Retrospective analysis of breast cancer prognosis among young and older women in a Brazilian cohort of 738 patients, 1985-2002. Oncology Letters, v. 12, n. 6, p. 4911-4924. 2016.

35. DE LUCA, C.J. The use of surface electromyography in biomechanics. J Appl Biomech, v. 13, p.135-163, 1997.

36. DE VITA, R.; ZOCCALI, G.; BUCCHERI, E.M.; COSTANTINI, M.; BOTTI, C.; POZZI, M. Outcome evaluation after 2023 nipple-sparing mastectomies: our experience. Plast reconstr surg, v. 139, n. 2, p. 335e-347.

37. DOUGLAS, C.R. Fisiologia aplicada às ciências da saúde. São Paulo: Robe Editorial, $7^{\mathrm{a}}$ ed, 1999. 1338p.

38. DOUGLAS, C.R.; AVOGLIO, J.L.V.; OLIVEIRA, H. Stomatognathic adaptive motor syndrome is the correct diagnosis for temporomandibular disorders. Medical Hypotheses, v. 74, P. 710-718. 2010.

39. EMSHOFF, R.; EMSHOFF, I.; RUDISCH, A.; BERTRAM, S. Reliability and temporal variation of masseter muscle thickness measurements utilizing ultrasonography. Journal of oral rehabilitation, v.30, n.12, p.1168-1172, 2003. 
40. ENGELEN, M.P. et al. Presence of early stage cancer does not impair the early protein metabolic response to major surgery. J Cachexia Sarcopenia Muscle. 2017. [Epub ahead of print]. doi: 10.1002/jcsm.12173.

41. FARRELL， B.J.; BULGAKOVA， M.A.; BELOOZEROVA， I.N.; SIROTA， M.G.; PRILUTSKY, B.I. Body stability and muscle and motor cortex activity during walking with wide stance. J Neurophysiol, v. 112, n. 3, p. 504-524. 2014.

42. FERLAY, J.; HÉRY, C.; AUTIER, P.; SANKARANARAYANAN, R. Global Burden of Breast Cancer,s. In: Li, Ch. (ed.): Breast Cancer Epidemiology, Springer, New York, p. 1-19. 2010.

43. FERNANDES, P.M. et. al. Back pain: assessment in breast hypertrophy patients. Acta Ortop Bras, v. 15, n. 4, p. 227-230. 2007.

44. FERNÁNDEZ-LAO， C.; CANTARERO-VILLANUEVA， I.; FERNÁNDEZ-DE-LASPEÑAS, C.; DEL-MORAL-ÁVILA, R.; MENJÓN-BELTRÁN, S.; ARROYOMORALES, M.J. Development of active myofascial trigger points in neck and shoulder musculature is similar after lumpectomy or mastectomy surgery for breast cancer. Bodyw Mov Ther, v. 16, n. 2, p. 183-190. 2012.

45. FERREIRA, B. et al. Analysis of the stomatognathic system after anterior cruciate ligamentplasty. Open Journal of Stomatology, v. 2, p.88-96. 2012.

46. FUENTES, A.D.; SFORZA, C.; MIRALlES, R.; FERREIRA, C.L.; MAPELLI, A.; LODETTI, G.; MARTIN, C. Assessment of electromyographic activity in patients with temporomandibular disorders and natural mediotrusive occlusal contact during chewing and tooth grinding. Cranio, v. 22, p. 1-10. 2016.

47. GALCERAN, J. et al. Cancer incidence in Spain. Clin Transl Oncol. 2017.

48. GILLIES, G.T.; CHRISTY, D.W.; STENGER, J.M.; BROADDUS, W.C. Equilibrium and non-equilibrium dynamics of the cranio-mandibular complex and cervical spine. J Med Eng Technol, v. 27, n. 1, p. 32-40. 2003.

49. GONÇAlveS, L. L. C.; G. L. TRAVASSOS; A. M. de AlMEIDA; A. M. D’Á N. GUIMARÃES; C. F. L. GOIS. Barriers in health care to breast cancer: perception of women. Rev Esc Enferm USP, v. 48, n. 3, p. 394-400. 2014.

50. GONZALEZ, H.E.; MANNS, A. Forward head posture: its structural and functional influence on the stomatognathic system. A conceptual study. Cranio, v. 14, n. 1, p. 71-80. 1996.

51. GOUVEIA, P.F.; GONZALEZ, E.O.; GRER, P.A.; FERNANDES, C.A.; LIMA, M.C. Avaliação da amplitude de movimento e força da cintura escapular em pacientes de pósoperatório tardio de mastectomia radical modificada. Fisioterapia e Pesquisa, v.15, n. 2, p.172-176. 2008. 
52. GRITSENKO, V. et al. Feasibility of using low-cost motion capture for automated screening of shoulder motion limitation after breast cancer surgery. PLoS One, v. 10, n. 6. 2015.

53. HADDAD, C.A.; SAAD, M.; PEREZ M.C.; MIRANDA JÚNIOR, F. Assessment of posture and joint movements of the upper limbs of patients after mastectomy and lymphadenectomy. Einstein, v. 11, n. 4, p. 426-434. 2013.

54. HERMENS, J.H. European Recommendations for Surface Electromyography: Results of the SENIAM project. 1999.

55. HERMENS, H.J.; FRERIKS, B.; DISSELHORST-KLUG, C.; RAU, G. Development of recommendations for sEMG sensors and sensor placement procedures. J Electromyogr Kinesiol, v. 10, p. 361-374. 2000.

56. HOJAN, K.; MANIKOWSKA, F.; CHEN, B.P.; LIN, C.C. The influence of an external breast prosthesis on the posture of women after mastectomy. J Back Musculoskelet Rehabil. V. 29, n. 2, p. 337-342. 2016.

57. HWANG, K.; KIM, J.Y.; LIM, J.H. Anatomy of the Platysma Muscle. J Craniofac Surg. 2016. [Epub ahead of print]. doi: 10.1097/SCS.0000000000003318

58. INCA. Estimativa 2016: Incidência de câncer no Brasil. Instituto Nacional de Câncer José Alencar Gomes da Silva. Rio de Janeiro: 2015.

59. IUNES, D.H. Análise da confiabilidade inter e intra-examinador na avaliação postural pela fotogrametria computadorizada. 2004. 108f. Dissertação (Mestrado em Ciências Médicas) - Faculdade de Medicina de Ribeirão Preto, Universidade de São Paulo, Ribeirão Preto, 2004.

60. IUNES, D.H.; CASTRO, F.A.; SALGADO, H.S.; MOURA, I.C.; OLIVEIRA, A.S.; BEVILAQUA-GROSSI, D. Confiabilidade intra e inter examinadores e repetibilidade da avaliação postural pela fotogrametria. Revista Brasileira de Fisioterapia, v. 9, n. 3, p. 327-334. 2005.

61. IUNES, D.H.; BEVILAQUA-GROSSI, D.; OLIVEIRA， A.S.; CASTRO, F.A.; SALGADO, H.S. Comparative analysis between visual and computerized photogrammetry postural assessment. Revista Brasileira de Fisioterapia, v. 13, n. 4, p. 308-315. 2009.

62. JUHL, A.A. et al. Unilateral breast reconstruction after mastectomy - patient satisfaction, aesthetic outcome and quality of life. Acta Oncol. 2017. [Epub ahead of print]. doi: 10.1080/0284186X.2016.1266087

63. JULIEN, K.C.; BUSCHANG, P.H.; THROCKMORTON, G.S.; DECHOW, P.C. Normal masticatory performance in young adults and children. Archs Oral Biol, v. 41, n. 1, p. 6975. 1996. 
64. KILIARIDIS, S.; KALEBO, P. Masseter muscle thickness measured by ultrasonography and its relation to facial morphology. Journal of Dental Research, v. 70, n. 9, p. 12621265. 1991.

65. KLASSEN, O.; SCHMIDT, M.E.; ULRICH, C.M.; SCHNEEWEISS, A.; POTTHOFF, K.; STEINDORF, K.; WISKEMANN, J. Muscle strength in breast cancer patients receiving different treatment regimes. J Cachexia Sarcopenia Muscle. 2016. [Epub ahead of print]. doi: $10.1002 / j \operatorname{csm} .12165$

66. KOGAWA, E.M.; CALDERON, P.S.; LAURIS, J.R.; ARAUJO, C.R.; CONTI, P.C. Evaluation of maximal bite force in temporomandibular disorders patients. Journal of oral rehabilitation, v.33, n.8, p.559-565, 2006.

67. KOLOKYTHAS, A. Long-term surgical complications in the oral cancer patient: a comprehensive review. Part II. J Oral Maxillofac Res, July-Sep;1(3):e2. 2010.

68. LAYEEQUE, R. et al. Botulinum toxin infiltration for pain control after mastectomy and expander reconstruction. Ann Surg, v. 240, n. 4, p. 608-613. 2004.

69. LIMA, L.C.O;; BARAÚNA, M.A.; SOLOGUREM, M.J.J.; CANTO, R.S.T.; GASTALDI, A.C. Postural alterations in children with mouth breathing assessed by computerized biophotogrammetry. Journal of Applied Oral Science, v. 12, n.3. 2004.

70. LOH, S. Y.; MUSA, A. N. Methods to improve rehabilitation of patients following breast cancer surgery: a review of systematic reviews. Breast Cancer, v. 7, p. 81-98. 2015.

71. LOSTER, J.; WIECZOREK, A.; MAJEWSKI, S. Co-existence of dysfunction of the stomatognathic system and incidences of depressive conditions based on examination of patients at the University Dental Clinic in Cracow. J Stoma, v. 64, n. 12, p. 1017-1025. 2011.

72. MALICKA， I.; BARCZYK， K.; HANUSZKIEWICZ， J.; SKOLIMOWSKA， B.; WOŹNIEWSKI, M. Body posture of women after breast cancer treatment. Ortop Traumatol Rehabil, v. 12, n. 4, p. 353-361. 2010.

73. MALUF, M.F.M.; MORI, L.J.; BARROS, A.C. O impacto psicológico do câncer de mama. Revista Brasileira de Cancerologia, v.51, n.2., p.149-154. 2005.

74. MAPELLI, A.; TARTAGLIA， G.M.; CONNELLY, S.T.; FERRARIO, V.F.; DE FELICIO, C.M.; SFORZA, C. Normalizing surface electromyographic measures of the masticatory muscles: comparison of two different methods for clinical purpose. J Electromyogr Kinesiol, v. 30, p. 238-242. 2016.

75. MARCELLO-MACHADO, R.M.; BIELEMANN, A.M.; NASCIMENTO, G.G.; PINTO, L.R.; CURY, A.A.D.B.; FAOT, F. Masticatory function parameters in patients with varying degree of mandibular bone resorption. J Prosthodont Res. 2016. In press. 
76. MATSUDO, S. et al. Questionário Internacional de Atividade Física (IPAQ): estudo de validade e reprodutividade no Brasil. Brazilian Journal of Physical Activity and Health, v. 6, n. 2, p. 5-18. 2001.

77. MILANESI, J.M.; BORIN, G.; CORRÊA, E.C.R.; $\quad$ SILVA, A.M.T. da; BORTOLUZZI, D. C.; SOUZA, J. A. Impact of the mouth reathing occurred during childhood in the adult age: Biophotogrammetric postural analysis. International Journal of Pediatric Otorhinolaryngology, v. 75, n. 8, p. 999-1004. 2011.

78. MINGHELlI, B.; MORGADO, M.; CARO, T. Association of temporomandibular disorder symptoms with anxiety and depression in Portuguese college students. Journal of Oral Science, v. 56, n. 2, p. 127-133. 2014.

79. MITCHELL, H. L.; NEWTON, I. Medical Photogrammetric Measurement: overview and prospects. Journal of Photogrammetry and Remote Sensing, v. 56, n. 5, p. 286- 294, 2002.

80. MOCHIZUKI, H.; TASHIRO, M.; KANO, M.; SAKURADA, Y.; ITOH, M.; YANAI, K. Imaging of central itch modulation in the human brain using positron emission tomography. Pain, v. 105, n. 1-2, p. 339-346. 2003.

81. MONTEZUMA, T.; GUIRRO, E.C.O.; VAZ, M.M.O.L.L; VERNAL, S. Changes in postural control in mastectomized women. Journal of Cancer Therapy, v. 5, p.493-499. 2014.

82. MUÑOZ-GARCÍA, D.; LOPEZ-URALDE-VILLANUEVA, I.; BELTRÁN ALACREU, H.; LA TOUCHE, R.; FERNÁNDEZ-CARNERO, J. Patients with concomitant chronic neck pain and myofascial pain in masticatory muscles have more widespread pain and distal hyperalgesia than patients with only chronic neck pain. Pain Med. 2016. $10.1093 / \mathrm{pm} / \mathrm{pnw} 274$.

83. ORCHADSON, R.; CADDEN, S.W. Mastication, in scientific basis of eating. Front Oral Biol, v. 9, p. 79-121. 1998.

84. OLIVEIRA, R.H.; HALLAK, J.E.; SIÉSSERE, S.; SOUSA, L.G.; SEMPRINI, M.; DE SENA, M.F.; OSORIO, F. L.; NUNES, E.A.; PINTO, J.P.; REGALO, S.C. Electromyographic analysis of masseter and temporal muscles, bite force, masticatory efficiency in medicated individuals with schizophrenia and mood disorders compared with healthy controls. J Oral Rehabil, v. 41, n. 6, p. 399-408. 2014.

85. OKIYAMA, S.; IKEBE, K.; NOKUBI, T. Association between masticatory performance and maximal oclusal force in young men. J Oral Rehabil, v. 30, n. 3, p. 278-282. 2003.

86. OMOLEHINWA, T.T; AKINTOYE, S.O. Chemical and radiation associated jaw lesions. Dent Clin North Am, v. 60, n. 1, p. 265-277. 2016.

87. PALINKAS, M.; NASSAR, M.S.P.; CECILIO, F.A.; SIÉSSERE, S.; SEMPRINI, M.; SOUSA, J.P.M.; HALLAK; J.E.C.; REGALO, S.C.H. Age and gender influence on maximal bite force and masticatory muscles thickness. Archives of Oral Biology, v.55, n.10, p.797-802, 2010. 
88. PALINKAS, M.; CECILIO, F.A.; SIÉSSERE, S.; BORGES, T.F.; CARVALHO, C.A.M.; SEMPRINI, M.; SOUSA, L.G.; REGALO, S.C.H. Aging on masticatory efficiency in healthy subjects: electromyographic analysis - Part 2. Acta Odontol Latinoam, v. 26, n.3, p. 161-166, 2013.

89. PALINKAS, M.; BATAGLION, C.; CANTO, G.L.; CAMOLEZI, N.M.; THEODORO, G.T.; SIÉSSERE, S.; SEMPRINI, M.; REGALO, S.C. Impact of sleep bruxism on masseter and temporalis muscles and bite force. Cranio, v. 34, n. 5, p. 309-315. 2016.

90. PALMA, M.R.; VANDERLEI, L.C.; RIBEIRO, F.E.; MANTOVANI, A.M.; CHRISTOFARO, D.G.; FREGONESI, C.E. The relationship between post-operative time and cardiac autonomic modulation in breast cancer survivors. Int J Cardiol, v. 224, p. 360-365. 2016.

91. PEPATO, A.O.; PALINKAS, M.; REGALO, S.C.; DE MEDEIROS, E.H.; DE VASCONCELOS, P.B.; SVERZUT, C.E.; SIÉSSERE, S.; TRIVELLATO, A.E. Effect of surgical treatment of mandibular fracture: electromyographic analysis, bite force, and mandibular mobility. J Craniofac Surg, v. 25, n. 5, p. 1714-1720. 2014.

92. PERES, A.C.A.M.; LATORRE, M.R.D.O.; MAESAKA, Y.; FILASSI, J. R.; BARACAT, E.C.; FERREIRA, E.A.G. Body posture after mastectomy: comparison between immediate breast reconstruction versus mastectomy alone. Physiother Res Int, v. 22, n.1. 2017.

93. PIANCINO, M.G. Electromyographic evaluation of neuromuscular co-ordination during chewing in a subject with organic occlusion. Minerva Stomatol, v. 54, n. 6, p. 379-387. 2005.

94. PITA, M.S.; RIBEIRO, A.B.; GARCIA, A.R.; PEDRAZZI, V.; ZUIM, P.R. Effect of occlusal splint thickness on electrical masticatory muscle activity during rest and clenching. Brazilian Oral Research, v.25, n.6, p.506-511, 2011.

95. PIZOLATO, R.A; FREITAS-FERNANDES, F.S.; GAVIAO, M.B.D. Anxiety/depression and orofacial myofacial disorders as factors associated with TMD in children. Braz Oral Res, v. 27, n. 2, p. 155-162. 2013.

96. POLITTI, F.; CASELlATO, C.; KALYTCZAK, M.M.; GARCIA, M.B.; BIASOTTOGONZALEZ, D.A. Characteristics of EMG frequency bands in temporomandibullar disorders patients. J Electromyogr Kinesiol, v. 31, p. 119-125. 2016.

97. PORTO, M.AT.; TEIXEIRA, L.A.; SILVA, R.C.F. Aspectos históricos do controle do câncer de mama no Brasil. Revista Brasileira de Cancerologia, v.59, n.9, p.331-339. 2013.

98. PRABHU, N.T.; MUNSHI, A.K. Measurement of masseter muscle thickness using ultrasonographic technique. The journal of clinical pediatric dentistry, v.19, n.1, p.4144, 1994. 
99. RAADSHEER, M.C.; KILIARIDS, S.; VAN EIJDEN, T.M.; VAN EIJDEN, F.C.; PRAHL-ANDERSEN, B. Masseter muscle thickness in growing individuals and its relation to facial morphology. Archives of Oral Biology, v.41, n.4, p.323-332, 1996.

100. RANCAN, S.V.; BATAGLION, C.; BATAGLION, S.A.; BECHARA, O.M.; SEMPRINI, M.; SIÉSSERE, S.; et al. Acupuncture and temporomandibular disorders: a 3-month follow-up EMG study. J Altern Complement Med, v. 15, n. 12, p. 1307-1310. 2009.

101. REGALO, S.C.; SANTOS, C.M.; VITTI, M.; REGALO, C.A.; VASCONCELOS, P.B.; MESTRINER, W. Jr.; SEMPRINI, M.; DIAS, F.J.; HALLAK, J.E.; SIÉSSERE, S.; Evaluation of molar and incisor bite force in indigenous compared with white population in Brazil. Archives of Oral Biology, v.53, n.3, p.282-286, 2008.

102. RESZKA E, PRZYBEK M, MUURLINK O, PEPLONSKA B. Circadian gene variants and breast cancer. Cancer Letters, v. 390, p. 137-145. 2017.

103. RETT, M.T.; MESQUITA, P.J.; MENDONÇA, A.R.C.; MOURA, D.P.; DESANTANA, J.M. A cinesioterapia reduz a dor no membro superior de mulheres submetidas à mastectomia ou quadrantectomia. Rev. Dor, v. 13, n.3, p. 201-207. 2012.

104. REZENDE, L.M.; MARSON, F.A.; LIMA, C.S.; BERTUZZO, C.S. Variants of estrogen receptor alpha and beta genes modify the severity of sporadic breast cancer. Gene, v. 608, p. 73-78. 2017.

105. ROBERTSON, J.F.R.; HERROD, P.J.J.; MATTHEW, J.; KILBURN, L.S.; COLES, C.E. BRADBURY, I. Treatment of the axilla in patients with primary breast cancer and low burden axillary disease: limitations of the evidence from randomised controlled trials. Critical Reviews in Oncology/Hematolog, v. 110, p. 74-80. 2017.

106. ROCHA-BRISCHILIARI, S.C. et al. The rise in mortality from breast cancer in young women: trend analysis in Brazil. PLoS One, v. 12, n. 1. 2017.

107. ROGGIA, B.; SANTOS, V.A.F.; CORREA, B.; ROSSI, Â.G. Posture and body balance of schoolchildren aged 8 to 12 years with and without oral breathing. Codas, v. 28, n. 4, p. 395-402. 2016.

108. ROSTKOWSKA, E.; BQK, M.; SAMBORSKI, W. Body posture in women after mastectomy and its changes as a result of rehabilitation. Advances in Medical Sciences, v.51, p. 281-297. 2006.

109. SACCHINI, V. et al. Quantitative and qualitative cosmetic evaluation after conservative treatment for breast cancer. Eur. J Cancer, v. 27, n. 11, p. 1395-1400. 1991.

110. SANDER, A.P.; HAJER, N.M.; HEMENWAY, K.; MILLER, A.C. Upper-Extremity volume measurements in women with lymphedema: a comparison of measurements obtained via water displacement with geometrically determined volume. Physical Therapy, v. 82, n. 12, p. 1201-1212. 2002. 
111. SANTOS, C.B.; CARIA, P.H.F.; TOSELLO, D.O.; BÉRZI, F. Behavior of cervical muscles in individuals with esophageal speech and artificial larynx. Rev. CEFAC, v. 12, n 1, p 82-90. 2010.

112. SEREL, S.; TUZLALI, Z.Y.; AKKAYA, Z.; UZUN, Ç.; KAYA, B.; BAYAR, S. Physical effects of unilateral mastectomy on spine deformity. Clin Breast Cancer. 2016. doi: 10.1016/j.clbc.2016.10.004. In press.

113. SERRA, M.D.; DUARTE-GAVIÃO, M.B.; DOS-SANTOS-UCHÔA, M.N. The use of ultrasound in the investigation of the muscles of mastication. Ultrasound in Medicine \& Biology, v. 34, n. 12, p. 1875-1884, 2008.

114. SHAMLEY, D.; LASCURAIN-AGUIRREBEÑA, I.; OSKROCHI, R.; SRINAGANATHAN, R. Shoulder morbidity after treatment for breast cancer is bilateral and greater after mastectomy. Acta Oncol, v. 51, n. 8, p. 1045-1053. 2012.

115. SHAMLEY, D.; LASCURAIN-AGUIRREBEÑA, I.; OSKROCHI, R. Clinical anatomy of the shoulder after treatment for breast cancer. Clin Anat, v. 27, n. 3, p. 467477. 2014.

116. SHIAU, Y.Y.; WANG, J.S. The effects of dental condition on hand strength and maximum bite force. The journal of craniomandibular practice, v.11, n.1, p.48-54, 1993.

117. SIEGEL, R.L.; MILLER, K.D.; JEMAL, A. Cancer statistics, 2016. CA Cancer J Clin 2016, v. 66, n. 1, p. 7-30. 2016

118. SIERPINSKA, T.; GOLEBIEWSKA, M.; DLUGOSZ, J.W. The relationship between masticatory efficiency and the state of dentition at patients with non rehabilitated partial lost of teeth. Advances in Medical Sciences, v. 51, p. 196-199. 2006.

119. SIÉSSERE, S. et al. Masticatory process in individuals with maxillary and mandibular osteoporosis: electromyographic analysis. Osteoporos Int, v. 20, p. 1847-1851. 2009.

120. SIÉSSERE, S.; SOUSA, L.G.; LIMA, N.A.; SEMPRINI, M.; VASCONCELOS, P.B.; WATANABE, P.C.A; RANCAN, S.V.; REGALO, S.C. Electromyographic activity of masticatory muscles in women with osteoporosis. Braz Dent J, v. 20, n. 3, p. 237-242. 2009.

121. SILVA, A.P.; SASSI, F.C.; ANDRADE, C.R. Oral-motor and electromyographic characterization of patients submitted to open and closed reductions of mandibular condyle fracture. Codas, v. 28, n. 5, p. 558-566. 2016.

122. SILVA, J. M.; PIRES, C.P.A.B.; RODRIGUES, L. A. M.; PALINKAS, M.; CANTO, G. L.; VASCONCELOS, P. B.; RANCAN, S. V.; SEMPRINI, M.; SIÉSSERE, S.; REGALO, S.C. Influence of mandibular tori on stomatognathic system function. Cranio, v. 35, n. 1, p. 30-37. 2017.

123. SPAGNOL, G.; PALINKAS, M.; REGALO, S.C.; DE VASCONCELOS, P.B.; SVERZUT, C.E.; TRIVELLATO, A.E. Impact of midface and upper face fracture on bite 
force, mandibular mobility, and electromyographic activity. Int J Oral Maxillofac Surg, v. 45 , n. 11, p. 1424-1429. 2016.

124. FERNANDES SEN, L.; BAKKE, M.; SOLOW, B. Bite force in pre-orthodontic children with unilateral crossbite. European journal of orthodontics, v.23, n.6, p.741$749,2001$.

125. SOUZA, J.A.; PASINATO, F.; BASSO, D.; CORRÊA, E.C.R.; SILVA, A.M.T. Biofotogrametria confiabilidade das medidas do protocolo do software para avaliação postural. Revista Brasileira de Cineantropometria \& Desempenho Humano, v.13, n.4, p.299-305. 2011.

126. STEVEN, S. C.; EKWUEME, D. U. Breast cancer as a global health concern. Cancer Epidemiology, v.33, p. 315-318. 2009.

127. STRINI, P.J.S.A.; MACHADO, N.A.G.; GORRERI, M.C.; FERREIRA, A.F.; SOUSA, G.C., FERNANDES NETO, A.J. J. Postural evaluation of patients with temporomandibular disorders under use of occlusal splints. Appl Oral Sci, v.17, n.5, p.539-543. 2009.

128. SUGDEN, E.M.; REZVANI, M.; HARRISON, J.M.; HUGHES, L.K. Shoulder movement after the treatment of early stage breast cancer. Clinical Oncology, v. 10, p. 173-181. 1998.

129. SUVINEN, T.I.; KEMPPAINEN, P. Review of clinical EMG studies related to muscle and occlusal factors in healthy and TMD subjects. Journal of Oral Rehabilitation, v. 34, p. 631-644. 2007.

130. TAYLOR, R.; JAYASINGHE, U.W.; KOELMEYER, L.; UNG, O.; BOYAGES, J. Reliability and validity of arm volume measurements for assessment of lymphedema. Physical Therapy, v.86, n. 2, p. 205-214. 2006.

131. TESTA, M. et al. A validation study of a new instrument for low cost bite force measurement. Journal of Electromyography and Kinesiology, v. 30, p. 243-248. 2016.

132. TIEZI, D.G. Cirurgia conservadora no câncer de mama. Rev Bras Ginecol Obstet, v. 29, n.8. p. 428-434. 2007.

133. TIRCOVELURI, S.; SINGH, JR.; RAYAPUDI, N.; KARRA, A.; BEGUM, M.; CHALLA, P. Correlation of masseter muscle thickness and intermolar width - an ultrasonography study. J Int Oral Health, v.5, n.2, p.28-34. 2013.

134. TSUGA, K.; CARLSON, G.E.; OSTERBERG, T.; KARLSSON, S. Self-assessed masticatory ability in relation to maximal bite force and dental state in 80-year-old subjects. Journal of Oral Rehabilitation, v.25, p.117-124, 1998.

135. VAN MAAREN, M.C.; POORTMANS, P.; SIESLING S. Breast-conserving therapy versus mastectomy. Oncoscience, v. 3, p. 11-12. 2016. 
136. VASCONCELOS, P.B.; DE SOUSA, L.G.; REGALO, S.C.; SANTOS, C.M.; DE ROSSI, M.; SEMPRINI, M.; SCALIZE, P.H.; SIÉSSERE, S. The influence of maxillary and mandibular osteoporosis on maximal bite force and thickness of masticatory muscles. Acta Odontol Latinoam. v. 28, n. 1, p. 22-27. 2015.

137. VEIGA, D.F. et al. Mastectomy versus conservative surgical treatment: the impact on the quality of life of women with breast cancer. Rev Bras Saúde Matern Infant, v.10, n. 1. P.51-57. 2010.

138. VERONESI, U. et al. Comparision of Halsted mastectomy with quadrantectomy, axillary dissection, and radiotherapy in early breast cancer: long-term results. Eur $\mathbf{J}$ Cawrr C/in Ond, v.22, n.9. p.1085-1089. 1986.

139. VILLAFUERTE, K.R.V. Avaliação das condições periodontais em mulheres portadoras de câncer de mama sob tratamento quimioterápico. 2014. 95p. Dissertação (Mestrado em Periodontia) - Faculdade de Odontologia de Ribeirão Preto, Universidade de São Paulo, Ribeirão Preto, 2014.

140. WIJAYASINGHE, N. et al. Ultrasound guided intercostobrachial nerve blockade in patients with persistent pain after breast cancer surgery: a pilot study. Pain Physician, v.19, n.2. p. 309-317. 2016.

141. WONG, H.M. Oral complications and management strategies for patients undergoing cancer therapy. The Scientific World Journal, v. 2014. 2014.

142. WOZNIAK, K.; PIATKOWSKA, D.; LIPSKI, M.; MEHR, K. Surface electromyography in orthodontics - a literature review. Medical Science Monitor, v. 19, p. 416-423. 2013.

143. WU, S. et al. Low rate of positive margins and re-excision after partial mastectomy in highly selected breast cancer patients: A Chinese single-institution experience. Oncotarget. 2017. [Epub ahead of print]. doi: 10.18632/oncotarget.14686.

144. ZHANG, P.; LI, C.-Z.; WU, C.-T.; JIAO, G.-M.; YAN. F.; ZHU, H.-C.; ZHANG, X.$\mathrm{P}$. Comparison of immediate breast reconstruction after mastectomy and mastectomy alone for breast cancer: a meta-analysis. European Journal of Surgical Oncology, v. 43, v. 2, p. 285-293. 2017.

145. ZHAO, L.; MONAHAN, R. Functional assessment of the stomatognathic system. Clinics in Plastic Surgery, v. 34, n. 3, p. e1-e9. 2007.

146. YANG, S; PARK, D.H.; AHN, S.H.; KIM, J.; LEE, J.W.; HAN, J.Y.; KIM, D.K.; JEON, J.Y.; CHOI, K.H.; KIM, W. Prevalence and risk factors of adhesive capsulitis of the shoulder after breast cancer treatment. Support Care Cancer. 2016. [Epub ahead of print]. doi: 10.1007/s00520-016-3532-4. 



\section{APÊNDICES}

\section{APÊNDICE A - TERMO DE CONSENTIMENTO LIVRE E ESCLARECIDO}

\section{Título do Projeto: Avaliação do sistema estomatognático em mulheres submetidas à mastectomia.}

\section{Pesquisador Responsável: Danilo Stefani Esposto}

Você está sendo convidada a participar deste estudo que tem por objetivo avaliar o funcionamento dos músculos que realizam sua mastigação, o tamanho dos músculos do seu rosto e a sua força de mordida e verificar se a cirurgia feita para o câncer de mama pode ter influenciado em algum destes aspectos. Ao participar desta pesquisa, você terá como benefício uma avaliação completa de sua capacidade e eficiência mastigatória e poderá tomar conhecimento sobre como estão as condições musculares de sua boca e pescoço e, com isso, podemos indicar melhores tratamentos odontológicos e fisioterapêuticos para todo o seu corpo.

Para tanto, será necessário realizar os seguintes procedimentos:

1. Avaliação da atividade dos músculos de seu rosto e pescoço por meio de um aparelho chamado eletromiógrafo, que consiste em fixar algumas pequenas placas em seu rosto por meio de fita adesiva (esparadrapo), após uma limpeza superficial de sua pele. Nesta avaliação, você poderá ter algum desconforto por causa da fita adesiva (esparadrapo) sobre a pele, onde estão os músculos que serão avaliados. Os riscos na execução deste procedimento podem estar relacionados caso você tenha alergia do esparadrapo e da limpeza da pele feita previamente, mas serão tomados todos os cuidados necessários com o uso de esparadrapo antialérgico e na esfoliação da pele realizada de forma leve. O benefício esperado aqui é saber como está o trabalho de seus músculos. Este aparelho não aquece, não provoca dor e não causa risco à sua saúde.

2. Avaliação de sua força de mordida, que consiste em colocar um aparelho com duas pontas pequenas em sua boca protegido por uma borracha descartável, na região dos seus dentes do fundo e morder por três vezes, para ver os maiores valores da força de mordida. Este método pode ser um pouco incômodo ao colocar o aparelho na boca, mas não provoca dor e não causa risco à sua saúde.

3. Em seguida, será feito o exame de ultrassom, que consiste em passar o aparelho de ultrassom pelo rosto com um gel, de forma suave e sem pressão. Este método não aquece, não provoca dor e não causa risco à sua saúde. $\mathrm{O}$ objetivo é medir na tela do aparelho (computador) o tamanho dos músculos do seu rosto. O gel utilizado é antialérgico e seu incômodo encontra-se apenas por ser levemente frio, porém tolerável.

Durante qualquer etapa desta pesquisa, você tem total direito de receber resposta às perguntas e esclarecimentos sobre os procedimentos, riscos, benefícios ou quaisquer outras dúvidas relacionadas à pesquisa.

Você é livre para retirar seu consentimento e deixar de participar da pesquisa a qualquer momento, sem nenhum prejuízo. 
Sua identidade e as informações relacionadas à sua privacidade serão mantidas em segredo, em absoluto caráter confidencial. Ao consentir com este termo, você autoriza o uso, a divulgação e publicação em revistas científicas apenas dos dados obtidos nesta pesquisa, e não será identificada em hipótese alguma. Você tem, por parte dos pesquisadores, a garantia do sigilo (segredo) que garante a sua privacidade

Este Termo de Consentimento Livre e Esclarecido é somente para autorizar a utilização dos seus dados na pesquisa. Se for descoberto algum problema, você será informada e obterá ajuda e encaminhamento para tratamento.

Em caso de dúvidas ou notificação de acontecimentos não previstos, procure a professora Simone Cecilio Hallak Regalo por meio do telefone (16) 3602-0281 ou o pesquisador responsável pelo telefone (16) 99137-8044.

Desta forma, confirmo que recebi de maneira clara todas as informações necessárias ao meu consentimento e desejo participar desta pesquisa por livre e espontânea vontade.

de de

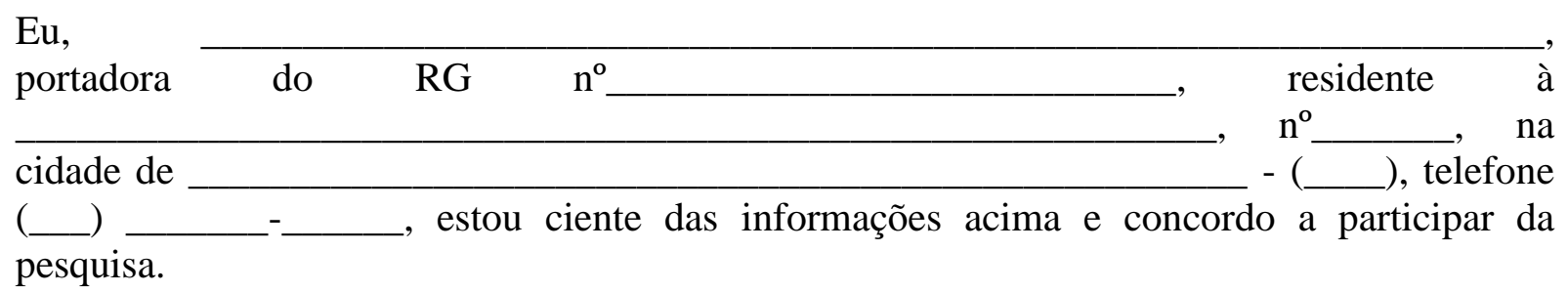

Assinatura do Participante ou Responsável

$\mathrm{Eu}$, Danilo Stefani Esposto, declaro que forneci todas as informações referentes ao projeto ao participante e/ou responsável.

Danilo Stefani Esposto (CPF: 379.109.848-98)

Telefone para contato: (16) 99137-8044 

ANEXOS

\section{ANEXO A - APROVAÇÃO PELO COMITÊ DE ÉTICA EM PESQUISA}

\section{CENTRO UNIVERSITÁRIO \\ CLARETIANO - CEUCLAR \\ Platoformo}

\section{PARECER CONSUBSTANCIADO DO CEP}

DADOS DO PROJETO DE PESQUISA

Título da Pesquisa: Avaliação do sistema estomatognático em mulheres submetidas à mastectomia

Pesquisador: Danilo Stefani Esposto

Área Temática:

Versão: 2

CAAE: 38290714.8 .0000 .5381

Instituição Proponente: ACAO EDUCACIONAL CLARETIANA

Patrocinador Principal: Financiamento Próprio

\section{DADOS DO PARECER}

Número do Parecer: 866.645

Data da Relatoria: $16 / 11 / 2014$

Apresentação do Projeto:

O projeto é apresentado de maneira clara e objetiva

Objetivo da Pesquisa:

A pesquisa apresenta objetivos coerentes ao tema

Avaliação dos Riscos e Beneficios:

A descrição de riscos e beneficios atendem as solicitações exigidas

Comentários e Consideraçōes sobre a Pesquisa:

A pesquisa é sem duvida de grande relevância, é de muito importância ter informações que estão diretamente ligadas as condiçőes de saúde deste publico, que passo por esta questăo do câncer de mama

Consideraçōes sobre os Termos de apresentação obrigatória:

Os documentos e os termos estão de acordo com as exigências

Recomendações:

Que siga todas os aspectos éticos no decorrer da pesquisa

Conclusões ou Pendências e Lista de Inadequaçōes:

Após a avaliação deste projeto por este comitê de ética e Pesquisa, declara-se que o mesmo se encontra dentro normas e exigências, e esta aprovado para sua realização

Endereço: Rua Dom Bosco, n⿳0 466

Bairro: Castelo

UF: SP

Municipio: BATATAIS

Telefone: (16)3660-1777 Fax: (16)3761-5030

CEP: $14.300-000$

E-mail: cepclaretiano@claretiano.edu.br 


\section{CENTRO UNIVERSITÁRIO Plotoformo CLARETIANO - CEUCLAR}

Continuaçăo do Parecer: 866.645

Situação do Parecer:

Aprovado

Necessita Apreciação da CONEP:

Não

Consideraçōes Finais a critério do CEP:

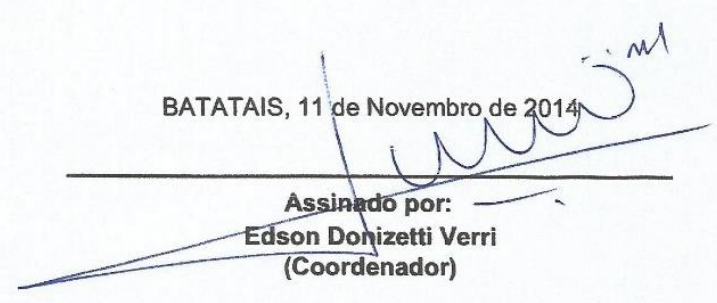

Endereço: Rua Dom Bosco, no 466 


\section{ANEXO B - QUESTIONÁRIO IPAQ VERSÃO CURTA}

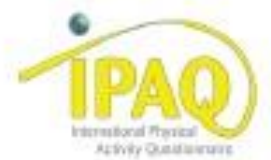

\section{QUESTIONÁRIO INTERNACIONAL DE ATIVIDADE FÍSICA - VERSÄO CURTA -}

Nome:

Data:

l_ Id Iade :

Sexo: F ( ) M ( )

Nós estamos interessados em saber que tipos de atividade física as pessoas fazem como parte do seu dia a dia. Este projeto faz parte de um grande estudo que está sendo feito em diferentes países ao redor do mundo. Suas respostas nos ajudarão a entender que tão ativos nós somos em relação à pessoas de outros paises. As perguntas estão relacionadas ao tempo que você gasta fazendo atividade física na ULTIMA semana. As perguntas incluem as atividades que você faz no trabalho, para ir de um lugar a outro, por lazer, por esporte, por exercício ou como parte das suas atividades em casa ou no jardim. Suas respostas são MUITO importantes. Por favor responda cada questão mesmo que considere que não seja ativo. Obrigado pela sua participação !

Para responder as questões lembre que:

> atividades físicas VIGOROSAS são aquelas que precisam de um grande esforço físico e que fazem respirar MUITO mais forte que o normal

> atividades físicas MODERADAS são aquelas que precisam de algum esforço físico e que fazem respirar UM POUCO mais forte que o normal

Para responder as perguntas pense somente nas atividades que você realiza por pelo menos 10 minutos contínuos de cada vez.

1a Em quantos dias da última semana você CAMINHOU por pelo menos 10 minutos contínuos em casa ou no trabalho, como forma de transporte para ir de um lugar para outro, por lazer, por prazer ou como forma de exercicio?

dias por SEMANA

( ) Nenhum

1b Nos dias em que você caminhou por pelo menos 10 minutos contínuos quanto tempo no total você gastou caminhando por dia?

horas: Minutos:

2a. Em quantos dias da última semana, você realizou atividades MODERADAS por pelo menos 10 minutos contínuos, como por exemplo pedalar leve na bicicleta, nadar, dançar, fazer ginástica aeróbica leve, jogar vôlei recreativo, carregar pesos leves, fazer serviços domésticos na casa, no quintal ou no jardim como varrer, aspirar, cuidar do jardim, ou qualquer atividade que fez aumentar CENTRO COORDENADOR DO IPAQ NO BRASIL-CELAFISCS INFORMAÇOES ANALISE, CLASSIFICAÇAO E COMPARAÇAO DE RESULTADOS NO BRASIL Tel-Fax: - 011-42296980 ou 42299643. E-mall: c9lanics @icelaflscs.com.br Home Page: Www.celanscs.com.br IPAQ Internaclonal: wWW.Ipaq.k1.as 
moderadamente sua respiração ou batimentos do coração (POR FAVOR NÄO INCLUA CAMINHADA)

dias__ por SEMANA ( ) Nenhum

2b. Nos dias em que você fez essas atividades moderadas por pelo menos 10 minutos contínuos, quanto tempo no total você gastou fazendo essas atividades por dia?

horas: Minutos:

3a Em quantos dias da última semana, você realizou atividades VIGOROSAS por pelo menos 10 minutos contínuos, como por exemplo correr, fazer ginástica aeróbica, jogar futebol, pedalar rápido na bicicleta, jogar basquete, fazer serviços domésticos pesados em casa, no quintal ou cavoucar no jardim, carregar pesos elevados ou qualquer atividade que fez aumentar MUITo sua respiração ou batimentos do coração.

dias___ por SEMANA ( ) Nenhum

3b Nos dias em que você fez essas atividades vigorosas por pelo menos 10 minutos contínuos quanto tempo no total você gastou fazendo essas atividades por dia?

horas: Minutos:

Estas últimas questões são sobre o tempo que você permanece sentado todo dia, no trabalho, na escola ou faculdade, em casa e durante seu tempo livre. Isto inclui o tempo sentado estudando, sentado enquanto descansa, fazendo lição de casa visitando um amigo, lendo, sentado ou deitado assistindo TV. Não inclua o tempo gasto sentando durante o transporte em ônibus, trem, metrô ou carro.

4a. Quanto tempo no total você gasta sentado durante um dia de semana? horas minutos

4b. Quanto tempo no total você gasta sentado durante em um dia de final de semana? horas___minutos

\section{PERGUNTA SOMENTE PARA O ESTADO DE SÃO PAULO}

5. Você já ouviu falar do Programa Agita São Paulo? ( ) Sim( ) Não

6.. Você sabe o objetivo do Programa? ( ) Sim ( ) Não

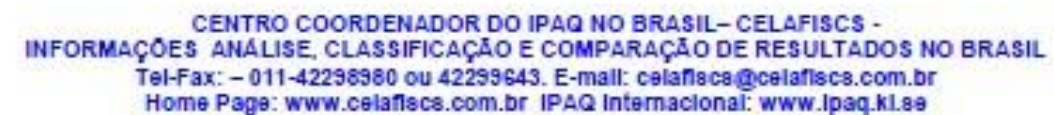




\section{Apresentação da Pesquisa em Eventos Científicos}

\section{IV Congresso Brasileiro de Eletromiografia e Cinesiologia (COBEC)}

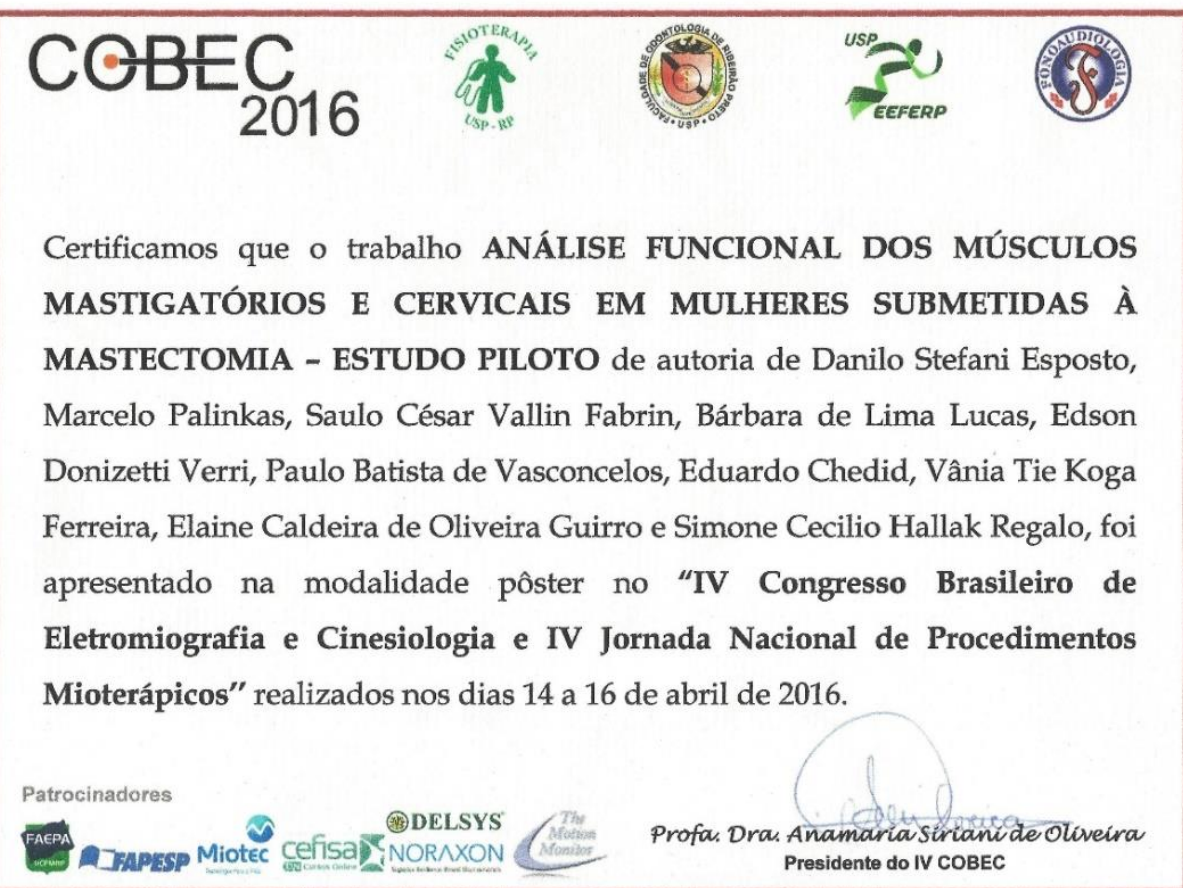

\section{II Simpósio de Câncer de Mama, VI Jornada de Câncer de Mama (EERP-USP)}

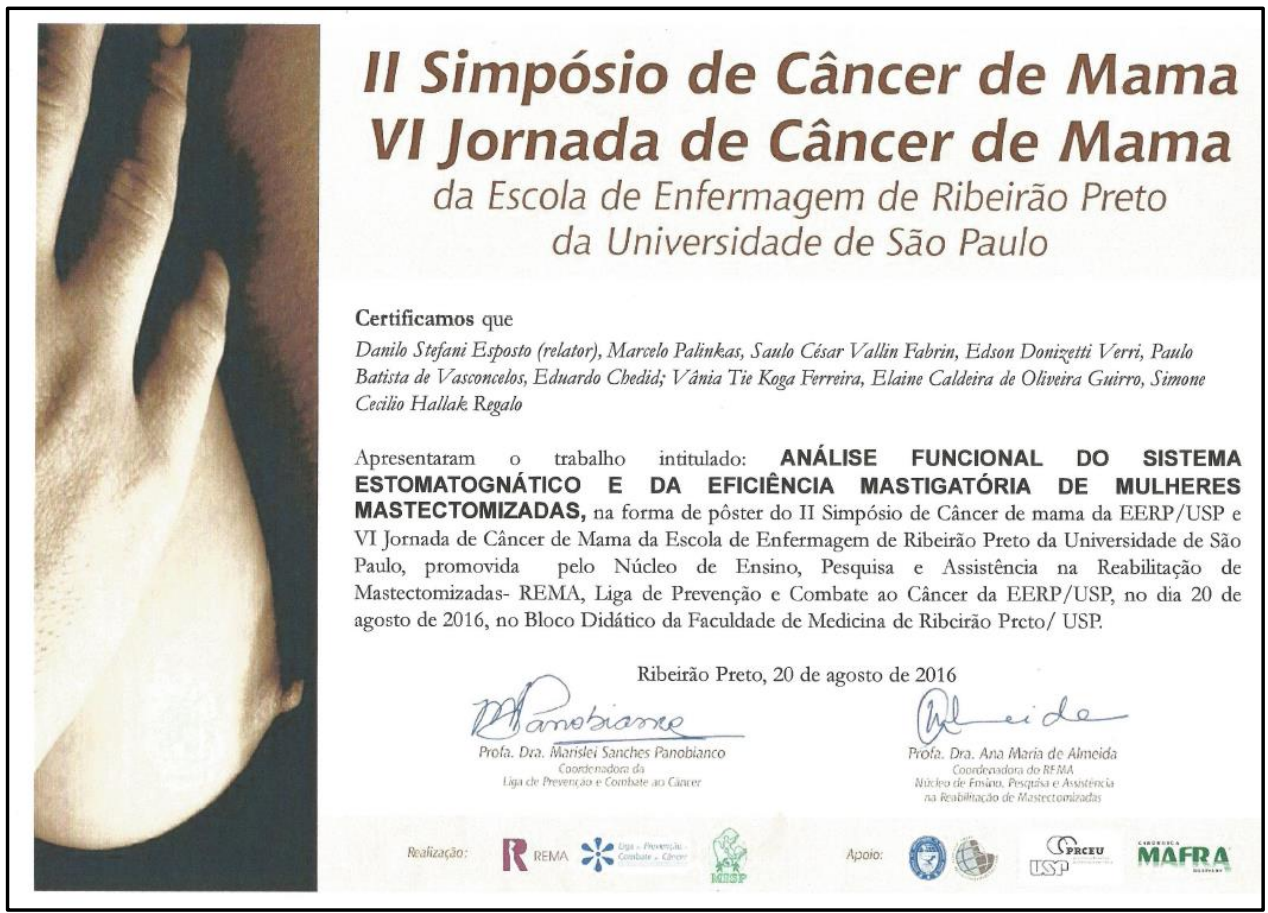

